\title{
An Integrated Approach for Downhole Leak Detection
}

BY

\section{Ali Musa Al-Hussain}

A Thesis Presented to the

DEANSHIP OF GRADUATE STUDIES

KING FAHD UNIVERSITY OF PETROLEUM \& MINERALS

DHAHRAN, SAUDI ARABIA

In Partial Fulfillment of the

Requirements for the Degree of

\section{MASTER OF SCIENCE}

In

PETROLEUM ENGINEERING

December 2014 


\section{KING FAHD UNIVERSITY OF PRTROLEUM AND MINERALS \\ DHAHRAN 31261, SAUDI ARABIA DEANSHIP OF GRADUATE STUDIES}

This thesis, written by ALI MUSA AL-HUSSAIN under the direction of this thesis advisor and approval by this thesis committee, has been presented to and accepted by the Dean of Graduate Studies, in partial fulfillment of the requirements for the degree of MASTER OF SCIENCE IN PETROLEUM ENGINEERING.

\section{Thesis Committee}

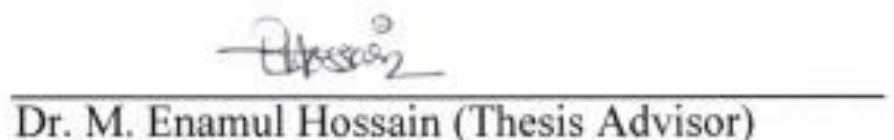

Dr. M. Enamul Hossain (Thesis Advisor)

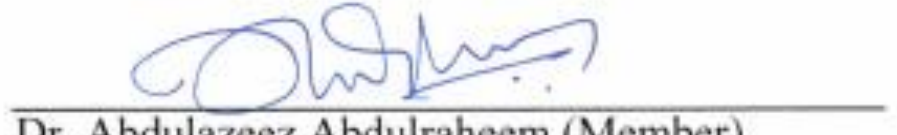

Dr. Abdulazeez Abdulraheem (Member)

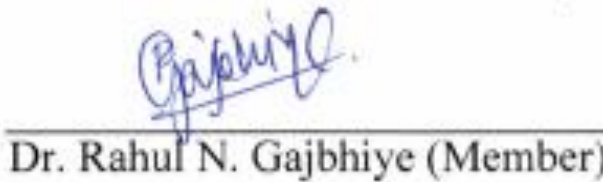

Dr. Abdullah S. Sultan

(Department Chairman)

Dr. Salam A. Zummo

(Dean of Graduate Studies)

Date

21) $121 / 4$

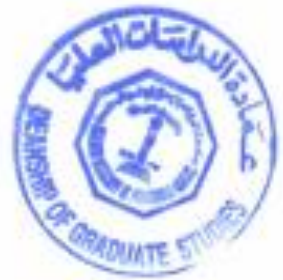


(c) ALI MUSA AL-HUSSAIN

2014 


\section{DEDICATION}

I would like to dedicate this work to my family specially my father who supported and encouraged me to get this degree and he was following my progress with great enthusiasm until he returned back to God. I also feel grateful to my family: mother, sisters and brothers for showing their unconditional support, kindness, encouragement, and pure love. 


\section{ACKNOWLEDGMENTS}

Most respectfully, I express my thanks to ALLAH for the endless help and support to complete the thesis. Then, I would like to express my appreciation and recognition to my family specially my father who supported and encouraged me to get this degree and he was following my progress with great enthusiasm until he returned back to God without seeing me that I have completed my master degree. I also feel grateful to my family mother, sisters and brothers for showing their unconditional support, kindness, encouragement, and pure love.

I would like to express my sincere appreciation and gratitude to Dr. M. Enamul Hossain for serving as the Chairperson of the Thesis Committee. His tremendous and generous guidance accelerated the progress of this research.

I would like to thank Dr. Abdulazeez Abdulraheem and Dr. Rahul Gajbhiye for serving as members of my thesis committee. Working with all of you was indeed a wonderful learning experience, which I thoroughly enjoyed.

The author is grateful to the Department of Petroleum Engineering at King Fahd University of Petroleum \& Mineral for accepting me into its graduate program to pursue my education and to carry out this research work.

Finally, special thanks to the reader of this report for taking time to read this report. 


\section{MASTER OF SCIENCE DEGREE \\ KING FAHD UNIVERSITY OF PETROLEUM \& MINERALS \\ DHAHRAN, KINGDOM OF SAUDI ARABIA}

\section{Preface:}

The purpose of this research is to enhance the current practice by introducing an integrated approach and model for identifying a depth where minor downhole leak appears. In this integrated approached, a specific field study was applied through evaluating different types of logs under different flowing and shut-in conditions scenarios. Also, a comparison of log results with conventional rig results was completed to evaluate the obtained results. Finally, artificial intelligence was implemented and a model for the purposed of identifying any future downhole leakage was developed. The developed model will be used to simplify the process of identifying downhole leakage source during the life cycle of any well in future. This work will add a value to the current well integrity standard which is highly recommended by all oil companies. 


\section{TABLE OF CONTENTS}

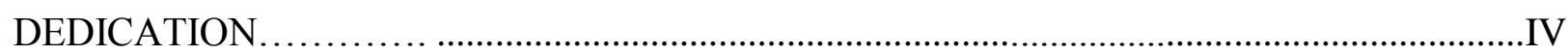

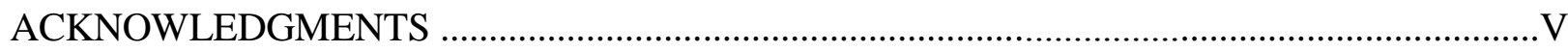

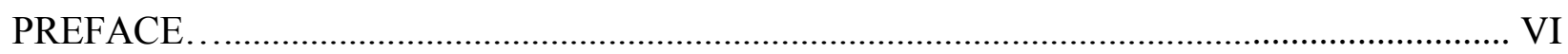

TABLE OF CONTENTS...................................................................................................

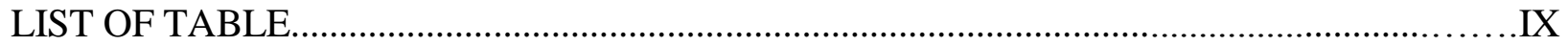

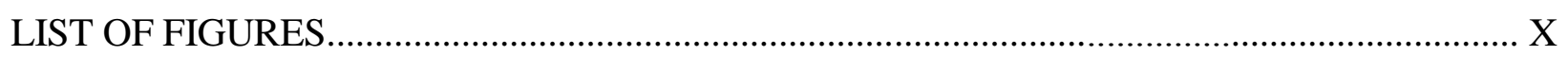

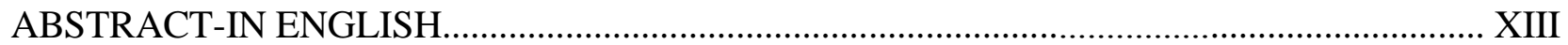

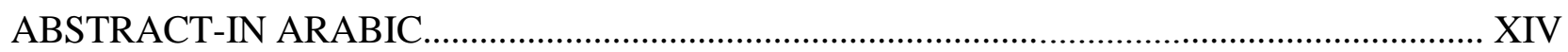

\section{CHAPTER 1}

Introduction and Significance of This Study.................................................................................................. 1

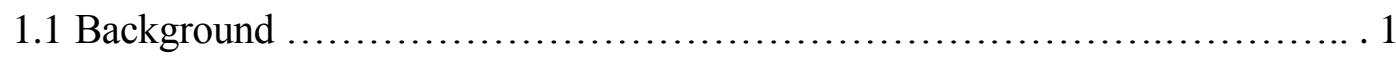

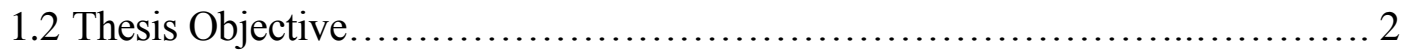

1.3 Thesis Approach..................................................... 3

1.4 Knowledge Gap ....................................................... 3

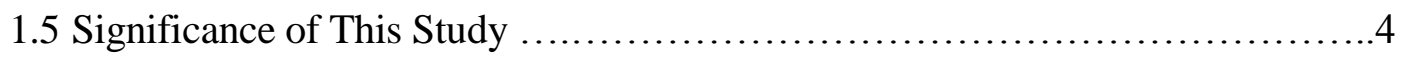

\section{CHAPTER 2}

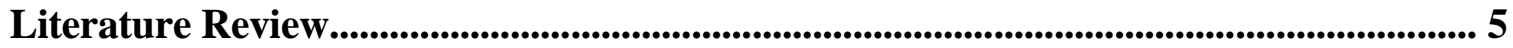

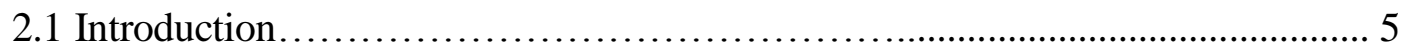

2.2 Method of locating downhole Anomalies........................................... 7

2.2.1 Temperature Logging Survey.................................. 7

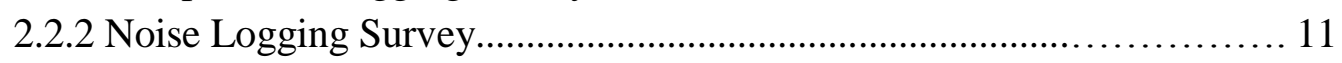

2.2.3 Corrosion Logging Survey ........................................ 13

2.3 Summary............................................................. 15 


\section{CHAPTER 3}

Methodology and Approaches ......................................................... 16

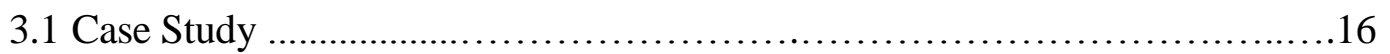

3.2 An Integrated Rigless Approach for Downhole Leak Detection................ 19

3.2.1 Quality Check ............................................19

3.2.2 Job Performance and Operation Sequence.....................20

3.2.3 Model Development for Rigless Leak Identification ...........21

3.3 Rig Approach for Detecting and fixing Downhole Leak .................... 23

3.3.1 Introduction to Rig ................................... 23

3.3.2 Health, Safety and Environment ........................27

3.4 Artificial Intelligence Approach for Leak Detection ......................... 29

3.4.1 Introduction to Artificial Intelligence.......................29

3.4.2 Decision Tree Structures ................................31

3.4.3 Model Development of Decision Tree ......................36

\section{CHAPTER 4}

Results and Discussion........................................................ 38

4.1 Rigless Approach for Downhole Leak detection ....................... 38

4.1.1 Integrated Interpretation Results ............................. 38

4.1.2 Rigless Model Development Results......................51

4.2 Rig Approach for Detection and fixing Downhole Leak ................... 53

4.3 Artificial Intelligence Results for Leak Detection...................... 57

\section{CHAPTER 5}

Conclusion and Recommendation.................................................... 83

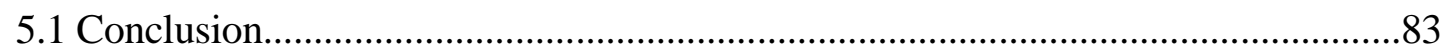

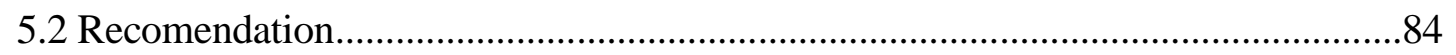

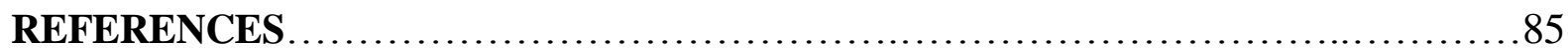

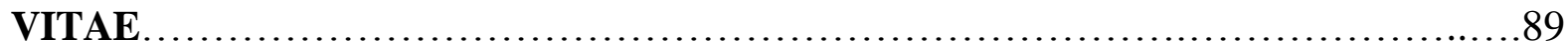




\section{LIST OF TABLES}

Table 4.1 Example of Mechanical Integrity Test Table ............................ 56

Table 4.2 Regression Result for Well No.1 ...................................57

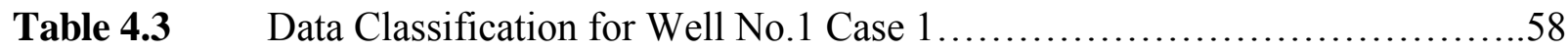

Table 4.4 Data Classification for Well No.1 Case 2.................................59

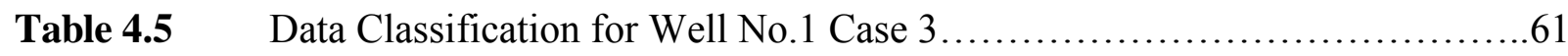

Table 4.6 Regression Result for Well No.2 ….................................63

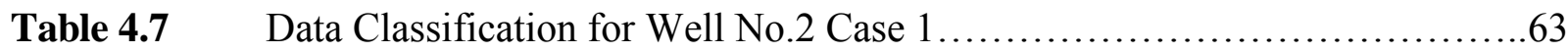

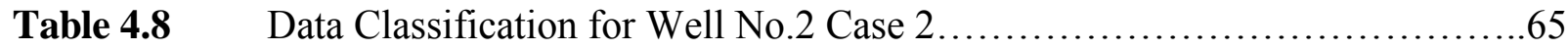

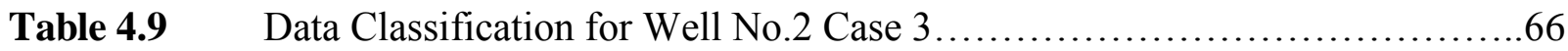

Table 4.10 Regression Result for Well No.3 …...................................68

Table 4.11 Data Classification for Well No.3 Case 1 ...................................68

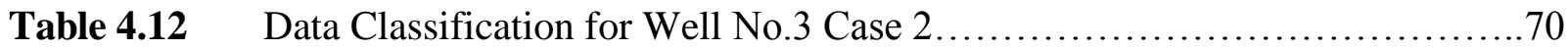

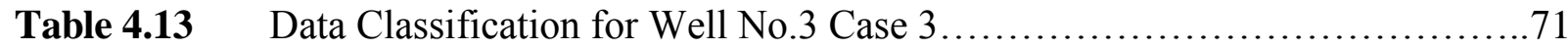

Table 4.14 Regression Result for Well No.4 f....................................73

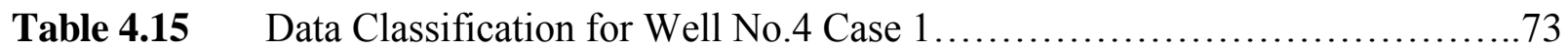

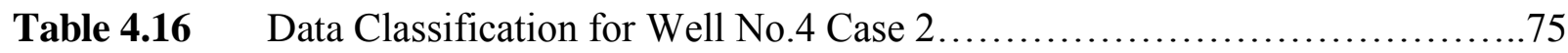

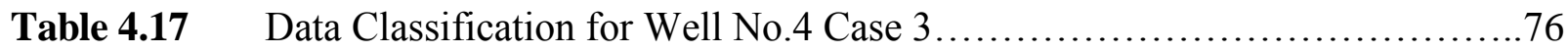

Table 4.18 Summary of Decision Tree Model within A well .......................... 79

Table 4.19 Summary of Decision Tree Model Across Wells. .......................... 81 


\section{LIST OF FIGURES}

Figure 2.1 Downhole Well Integrity.............................................................5

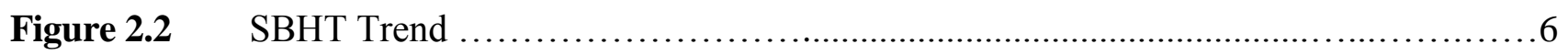

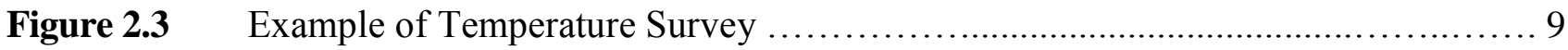

Figure 2.4 Temperature trend for detecting zone isolation .................................. 10

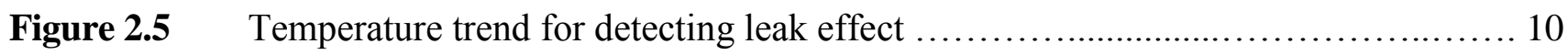

Figure 2.6 Temperature trend for gas entry effect ........................................ 11

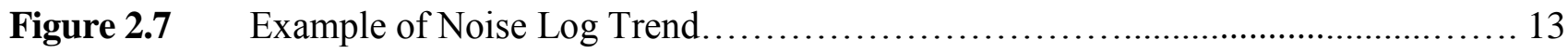

Figure 2.8 Example of Corrosion Log Survey .......................................... 14

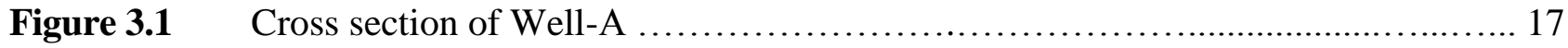

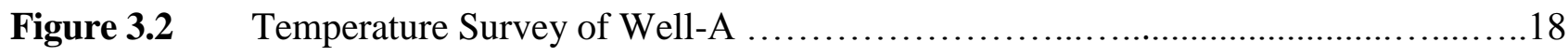

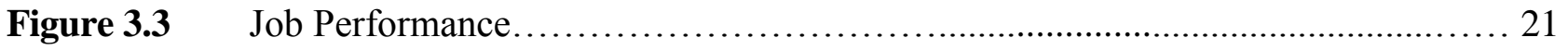

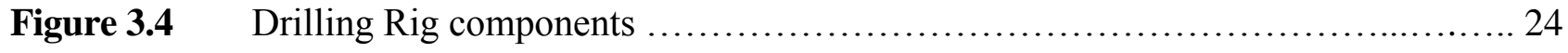

Figure 3.5 Top-drive Connected to Hook and Travelling Block ..........................25

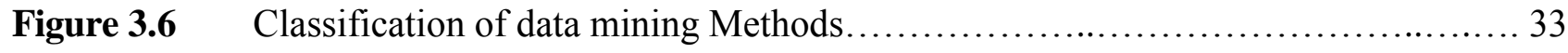

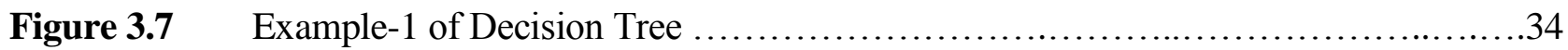

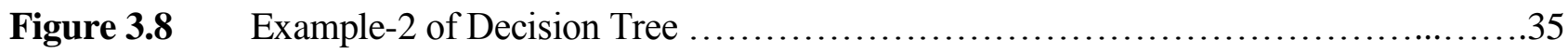

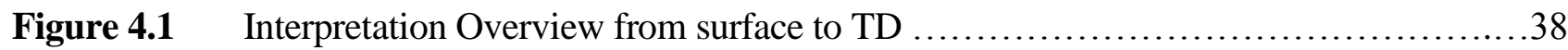

Figure 4.2 Shut-in Noise Log Interpretation before and after bleed off CCA ...................39

Figure 4.3 Shut-in Noise Log Interpretation before and after bleed off TCA ................. 40

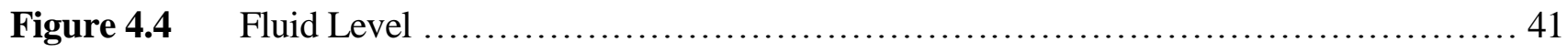

Figure 4.5 Zoom of Noise Log Interpretation at Shut-in, and after bleed off both CCA and TCA.. 42 
Figure 4.6 Integrated Interpretation of Casing, Tubing Corrosion and Shut-in Temperature, and the bleed TCA Temperature

Figure 4.7 Integrated Interpretation of Casing, Tubing Corrosion, Shut-in Temperature, and the bleed TCA Temperature with noise $\log$.....

Figure 4.8 Integrated Interpretation of Casing, Tubing Corrosion, Shut-in Temperature, and the bleed off TCA and CCA Temperature

Figure 4.9 Integrated Interpretation of Tubing, Casing Corrosion, Shut-in Temperature, and the

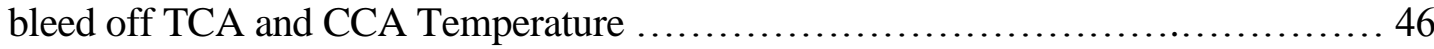

Figure 4.10 Integrated Interpretation of Casing Corrosion and Tubing ....................... 47

Figure 4.11 Integrated Interpretations of Casing Corrosion and Tubing ..................... 48

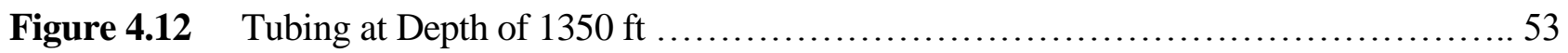

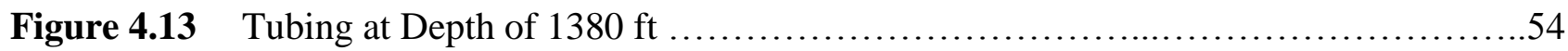

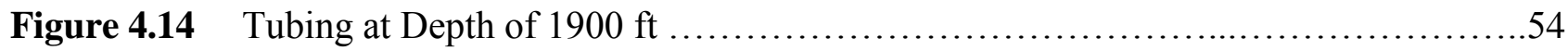

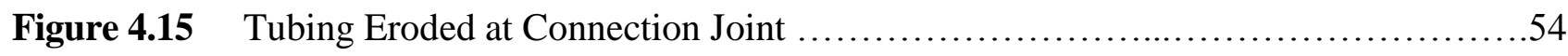

Figure 4.16 Area under Curve for Group $0 \& 1$ of case-1 for Well No.1 ..................... 59

Figure 4.17 Decision Tree Model of case-1 for Well No.1 ............................ 59

Figure 4.18 Area under Curve for Group $0 \& 1$ of case-2 for Well No.1 ....................... 60

Figure 4.19 Decision Tree Model of case-2 for Well No.1..............................61

Figure 4.20 Area under Curve for Group $0 \& 1$ of case-3 for Well No.1 .................... 62

Figure 4.21 Decision Tree Model of case-3 for Well No.1 ................................62

Figure 4.22 Area under Curve for Group $0 \& 1$ of case-1 of Well No.2 ....................64

Figure 4.23 Decision Tree Model of case-1 for Well No.2 ..............................64

Figure 4.24 Area under Curve for Group $0 \& 1$ of case-2 for Well No.2 ......................65

Figure 4.25 Decision Tree Model of case-2 for Well No.2 …...........................66

Figure 4.26 Area under Curve for Group $0 \& 1$ of case-3 of Well No.2 .....................67

Figure 4.27 Decision Tree Model of case-3 of Well No.2 ...............................67

Figure 4.28 Area under Curve for Group $0 \& 1$ of case- 1 for Well No.3 .....................69 
Figure 4.29 Decision Tree Model of case-1 for Well No.3 .................................70

Figure 4.30 Area under Curve for Group $0 \& 1$ of case-2 for Well No.3.....................70

Figure 4.31 Decision Tree Model of case-2 for Well No.3 .............................71

Figure 4.32 Area under Curve for Group $0 \& 1$ of case-3 for Well No.3 .....................72

Figure 4.33 Decision Tree Model of case-3 for Well No.3 ..............................72

Figure 4.34 Area under Curve for Group $0 \& 1$ of case-1 for Well No.4 ......................74

Figure 4.35 Decision Tree Model of case-1 for Well No.4 ................................ 74

Figure 4.36 Area under Curve for Group $0 \& 1$ of case-2 for Well No.4 .......................75

Figure 4.37 Decision Tree Model of case-2 for Well No.4 ................................76

Figure 4.38 Area under Curve for Group $0 \& 1$ of case-3 for Well No.4 .....................77

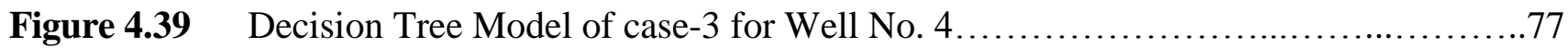




\title{
Thesis Abstract
}

\author{
Student Name: Al-Hussain, Ali Musa T. \\ Title of Study: An Integrated Approach for Downhole Leak Detection \\ Major Field: Petroleum Engineering \\ Date of Degree: December 2014
}

Checking the downhole integrity regularly of any well is important for well integrity purpose and it is part of safety system to ensure all resources that are available maintaining safe hydrocarbon production. In this research, full interpretation and evaluation was achieved after conducting and evaluating different logs in the field: temperature, pressure, noise, and corrosion log in different scenarios. Moreover, after combining and analyzing the rigless data, rig approached was completed by surface inspection for tubing and hydrostatic pressure test for casing. Finally, a model for leak detection was developed through utilizing artificial intelligence. The developed model can detect any downhole leak for any well.

The results of this work would led to enhance the current practice of identifying any minor downhole leak since the developed model is able to identify many of downhole integrity issues. This work added a value to the current well integrity standard which is highly appreciated by oil companies.

\author{
MASTER OF SCIENCE DEGREE \\ KING FAHD UNIVERSITY OF PETROLEUM \& MINERAL \\ Dhahran, Kingdom of Saudi Arabia \\ December 2014
}




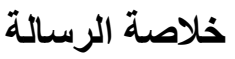

\section{اسم الطالب : علي موسى طاهر الحسين عنوان الار اسة :طريقة متكاملة للتبؤ بحالة التكامل السفلي للآبار التخصص : هندسة البترول تاريخ الارجة العلمية : ديسمبر 2014}

التحقق من سلامة قاع البئر بشكل منتظم مهم لغرض التكامل و هو كذلك جزء من نظام الأمان لضمان سلامة جميع المو ارد الهنوفرة للحفاظ على إنتاج النفطو الغاز بشكل آمن ومستقر. في هذا البحث ، تم التوصل لتفسير كامل وشامل وذلك بعد اجر اء التقييم في سجلات مختلفة من هذا الججال على سبيل المثال : كدرجة الحر ارة و الضغط ، و الضوضاء، و التآكل في سيناريو هات مختلفة ومتعددة. بالإضافة على ذلك ، وبعد الجمع وتحليل البيانات فلقد تمت معاينة سطح الأنابيب و اختبار الضغط الهيدروليكي للغلاف الداخلي للأنابيب للتأكد من سلامة البيانات المحللة. أخير ، فلقد تم تطوير وحدة للكثف عن التنرب من خلال استخدام الذكاء الاصطناعي. حاليا ، يمكن للبرنامج المطور من خلال الذكاء الاصطناعي الكثف عن التنرب في قاع البئر لاي بئر.

إن نتائج هذا العمل لسوف تؤدي إلى تعزيز الممارسة الحالية الدتمثلة في تحديد أي تسرب أسفل البئر ولسوف تساعد بثكل كبير في حل كثير من المشاكل المتجذرة في هذا المجال. بالإضافة لذلك، فإن هذا العمل لسوف يضيف قيمة لمعيار التكامل و السلامة الحالي الذي هو محل تقدير واهتمام كبير من قبل شركات النفط العالمية.

\author{
درجة الماجستير في العلوم \\ جامعة الملك فهد للبترول و المعادن \\ الظهر ان، المملكة العربية السعودية \\ ديسمبر 2014
}




\section{CHAPTER 1}

\section{INTRODUCTION AND SIGNIFICANCE OF THIS STUDY}

\subsection{Background:}

Well Integrity ${ }^{(1)}$ is defined as an application of protecting the environment and health of people by avoiding the risk of uncontrolled release of formation fluids throughout the life cycle of a well, so petroleum engineers are always required to ensure well integrity. Part of well integrity is to make sure downhole equipment and barriers are in excellent condition. Identifying the downhole leak source of pressure communication between tubing-casing and casing-casing annulus in any well is a huge challenge for petroleum engineers. Detecting any leak in early stage is a key of that strength. Therefore, managing well integrity has become as important as managing oil or gas.

Before placing any well on production or injection, a base temperature profiles is recorded and set as a typical temperature gradient of this well, which can be compared with subsequent profiles. If a base temperature profile is not available for a particular well which is being surveyed, a base temperature profile of nearby wells could be used. This type of log works as the first subsurface safety measures which is to identify any casing leaks after placing the well on stream for the purposed of production or injection. For example, in case of another survey is conducted and showed a sudden abnormal decrease in the temperature which is a typical signature of a dumping casing leak or another type of leak known as up flow casing leak which happen when we have an abnormal increase in the temperature. For decades temperature surveying has been a good methodology for identifying casing leaks. However, in many cases this technique gives a very late warning due to small unclear leak profile. 
Following safety systems are one of many corporate elements to ensure all resources are made and available to maintain safe hydrocarbon production. So, in the planning stage of drilling a new well setting the casing across competent formations is a key of integrity success. Moreover, using appropriate casings and wellhead materials and grades based on field characterization which is related to pressure and presence of corrosive fluids is another success. Also, ensuring good cementing behind casing to avoid future problems such as channeling or flowing behind pipe is playing a main role of delaying or preventing downhole leakages. Finally, utilizing downhole packers and proper annular fluid like diesel to ensure the safe running of wells would reduce work activities on that type of wells.

\subsection{Thesis Objective:}

The objectives of this research are:

- To evaluate different types of logs under different flowing and shut-in conditions scenarios in order to find a new integrated approach for downhole leak identification.

- To develop a method and program that can detect downhole leak depth by utilizing only rigless data.

- To compare rigless approach results with conventional rig approach for downhole leak detection.

- To develop an artificial intelligence model for identifying any future downhole leakage that may occur in any well through utilizing both rigless and rig data. 


\subsection{Thesis Approach:}

This research will be achieved throughout the following points:

- Conducting full interpretation and evaluation of different $\operatorname{logs}$ in the field: temperature, noise, and corrosion log in different scenarios. The first scenario is shut-in condition. The second scenario is flowing condition. The flowing condition will be either after bleeding off Casing Tubing Annulus or Casing-Casing Annulus. This approach was implemented in a specific operation order to ensure job success. Also, corrosion log was run to evaluate the condition of tubing and casing separately.

- Analyzing corrosion, temperature, and noise surveys statistically. Moreover, guidelines were set in each step of these surveys to confirm leak occurrence.

- Analyzing the rigless data for the proposed approached with the current condition of tubing and casing. The rig approach will be accomplished by surface inspection for tubing and hydrostatic pressure test for casing.

- Collecting set of data to build an artificial intelligence model for leak detection through utilizing decision tree. The developed model can detect any downhole leak for any well.

\subsection{Knowledge Gap:}

In general, there is misconception between service companies and an operator for detecting leak due to lacking of clear information about the provided service. Sometime service companies run different logs in order to identify the sources of leak. However, they cannot properly detect because of uncertainty. Therefore, the conducted work in this report will fill the existing gap in the area of downhole leak detection. 


\subsection{Significance of this Study:}

This work would lead to enhancing the current practice of identifying any minor downhole leak. Moreover, this approach of data gathering, interpretation, analysis, sequence of logs and operation could be extended to be implemented in all type of wells especial in mature field where many casing leaks could occur. Also, the developed model simplifies the process of identifying downhole leakage in any well in future. In addition, this approach will allow petroleum engineers to be active in doing a good surveillance program for the purposed of monitoring the downhole completion condition to avoid any unknown leak in early stage. Finally, this approach would add a value to the current well integrity standard which is high value to oil companies in term of security and safety to the environment. 


\section{CHAPTER 2}

\section{LITERATURE REVIEW}

\subsection{Introduction}

Confirming the subsurface well integrity is important for any type of wells to avoid the risk of uncontrolled release of formation fluids throughout the life cycle of that well which is needed for both protecting the environment and health of people. Discovering any downhole leak source of pressure communication between tubing-casing and casing-casing annulus of any well during the life cycle of that well is a huge challenge for oil industry. Noticing the leak in early stage is a key of that strength. Therefore, well integrity has become as important as managing hydrocarbon production.

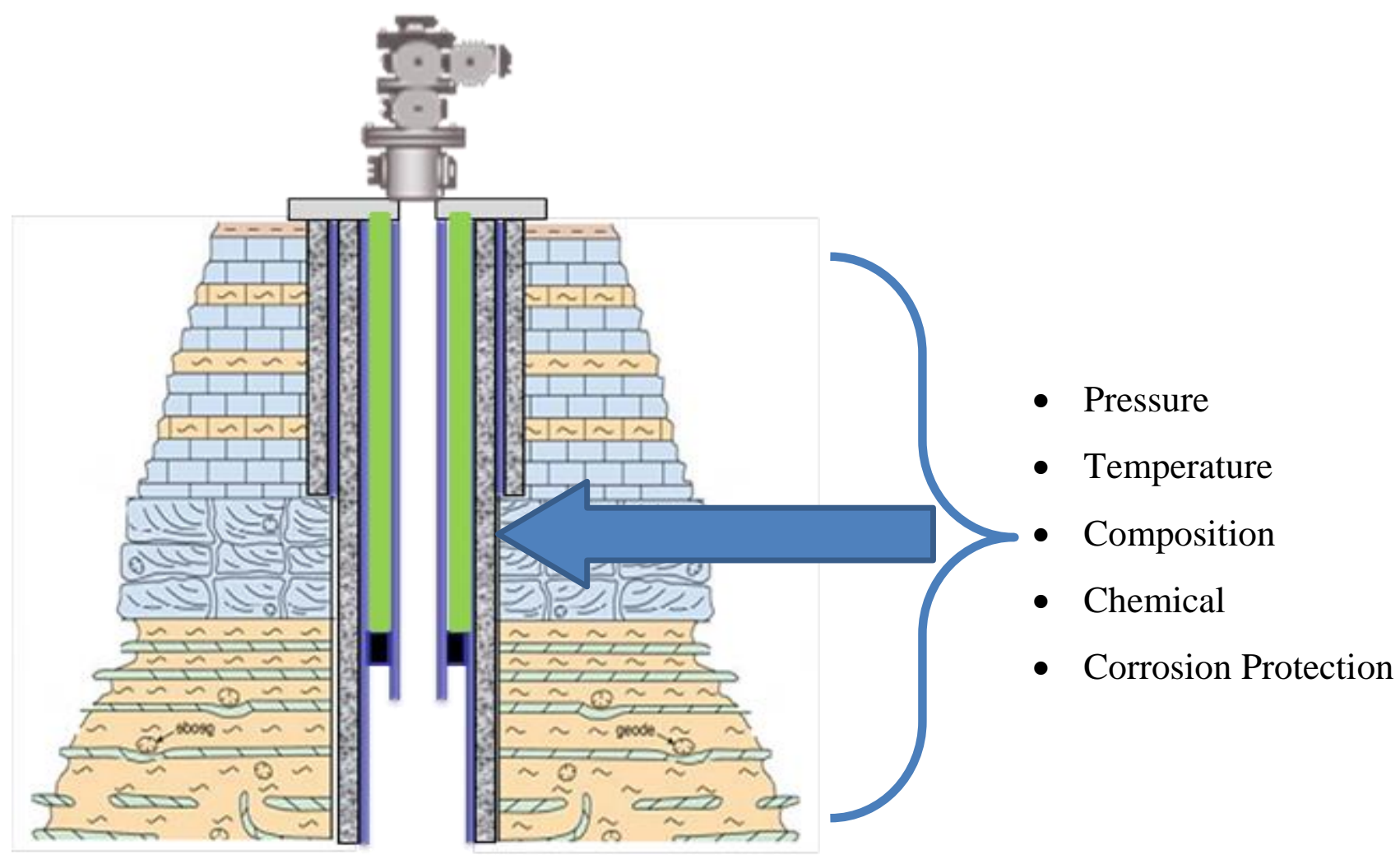

Figure 2.1: Downhole Well Integrity 
Before placing any well on production or injection ${ }^{(2)}$, a base temperature profiles should be recorded and set as a typical temperature gradient of this well, which can be compared with the later subsequent profiles. If a base temperature profile is not available for a particular well which is being surveyed, a base temperature profile of nearby wells could be used. This type of $\log { }^{(3)}$ work as the first subsurface safety measures which is to identify any casing leaks after placing the well in stream for the purpose of production or injection. For example, in case another survey is conducted that show a sudden abnormal decrease in the temperature profile which is a typical signature of a dumping casing leak or another type of leak known as up flow casing leak which happen when we have an abnormal increase in the temperature. Below are different static bottom hole temperature trends that show the normal and abnormal temperature phenomena.

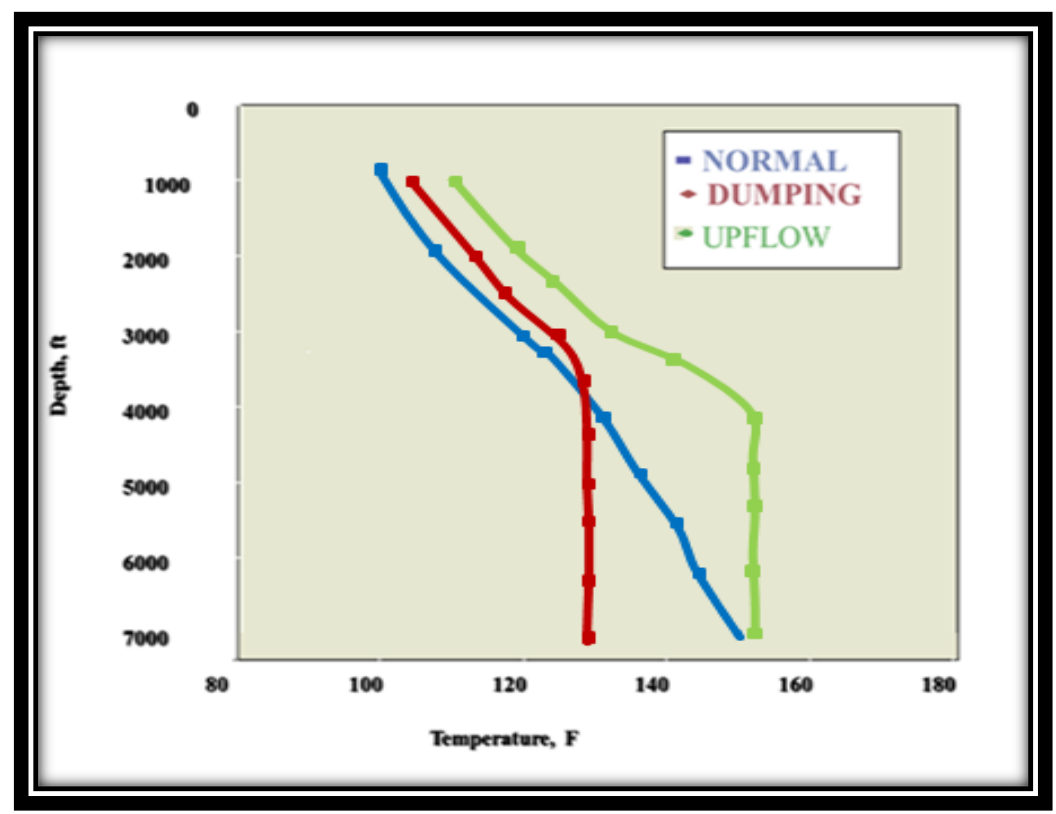

Figure 2.2: SBHT Trend

For decades temperature surveying has been a good methodology for identifying casing leaks. However, in many cases this technique gave a very late warning due to small unclear leak profile. 
There are many methods available to detect the source of downhole leak. However, many of those techniques are not effective enough especially for small leak detection ${ }^{(4)}$. In this case study, running integrated logging such as production spanner, Temperature, Pressure, Noise, and corrosion log in different flowing and shut-in conditions has been proven to be significantly more effectual in locating anomalies. Identifying the source of downhole pressure communication in tubing casing annulus and casing casing annulus is a huge challenge.

\subsection{Method of locating downhole Anomalies:}

The current technique which is used in oil industry to allocate anomalies is not strong enough, so integrated interpretation analyzes and evaluation should be planned to identify any small source of downhole leak by conducting the following logs in both flowing and shutting condition; temperature, pressure, production spanner, corrosion and noise logs. The purpose of temperature log is to identify any cross flow and abnormal geothermal phenomena. Pressure log is to identify pressure gradient and type of fluid from its gradient. Noise $\log$ is used to detect any fluid movement even gas flow which is measure fluid frequency movement. In addition, corrosion log was run to evaluate both the condition of tubing and casing.

\subsubsection{Temperature Logging Survey}

Temperature $\log { }^{(5)}$ is the oldest logging techniques. The original purpose of this survey is to allocate hydrocarbon zones from non-productive interval. However, this purpose fails due to the small difference of thermal, lithological and formation properties. 
Later, temperature profiles have been used extensively for problem diagnostics related to downhole fatigues and cross-flows behind the casing. Nowadays, this type of log is one of the reliable logs for leak detection. The classical procedure is to obtain a true geothermal temperature profile and correlate future temperature changes to the geothermal to obtain an estimate of the location, magnitude and direction of the cross-flow anomalies. It indicates the presence of flow from its static or geothermal value. Under static conditions, temperature increases gradually with depth. The nature of well completion also influences the method in which temperature returns to its geothermal value. A good knowledge of the geothermal gradient is necessary for having representative interpretation. Interpretation of temperature logging was observed for flow measurements and studied by Nowak ${ }^{(6)}$ in 1953. In 1969 and 1979, Cocanwer and Romero-Juarez ${ }^{(6)}$ respectively have provided similar approaches. As a result of that, several works consider rate calculations from either temperature profile alone or fixed point measurements. Recently, the introduction of the distributed temperature survey (DTS) helped to provide large amount of data for flow allocation techniques. Flow profiling is one of the most important field applications of distributed temperature sensors. However, distributed temperature sensors are still not widely used and a lot of issues still exist regarding the complexity of the data analysis which is acting as a barrier to distributed temperature sensors usage. Currently, DTS ${ }^{(7-17)}$ are used for evaluating the effectiveness of a stimulation job. Figure 2.3 shows a based temperature profile which increase with depth. In other hand, a recent temperature trends shows the temperature trend of same well is decrease with depth. That trend is due to shallow leak. In most cases, this trend of leak will not be discovered early if the leak is small. 


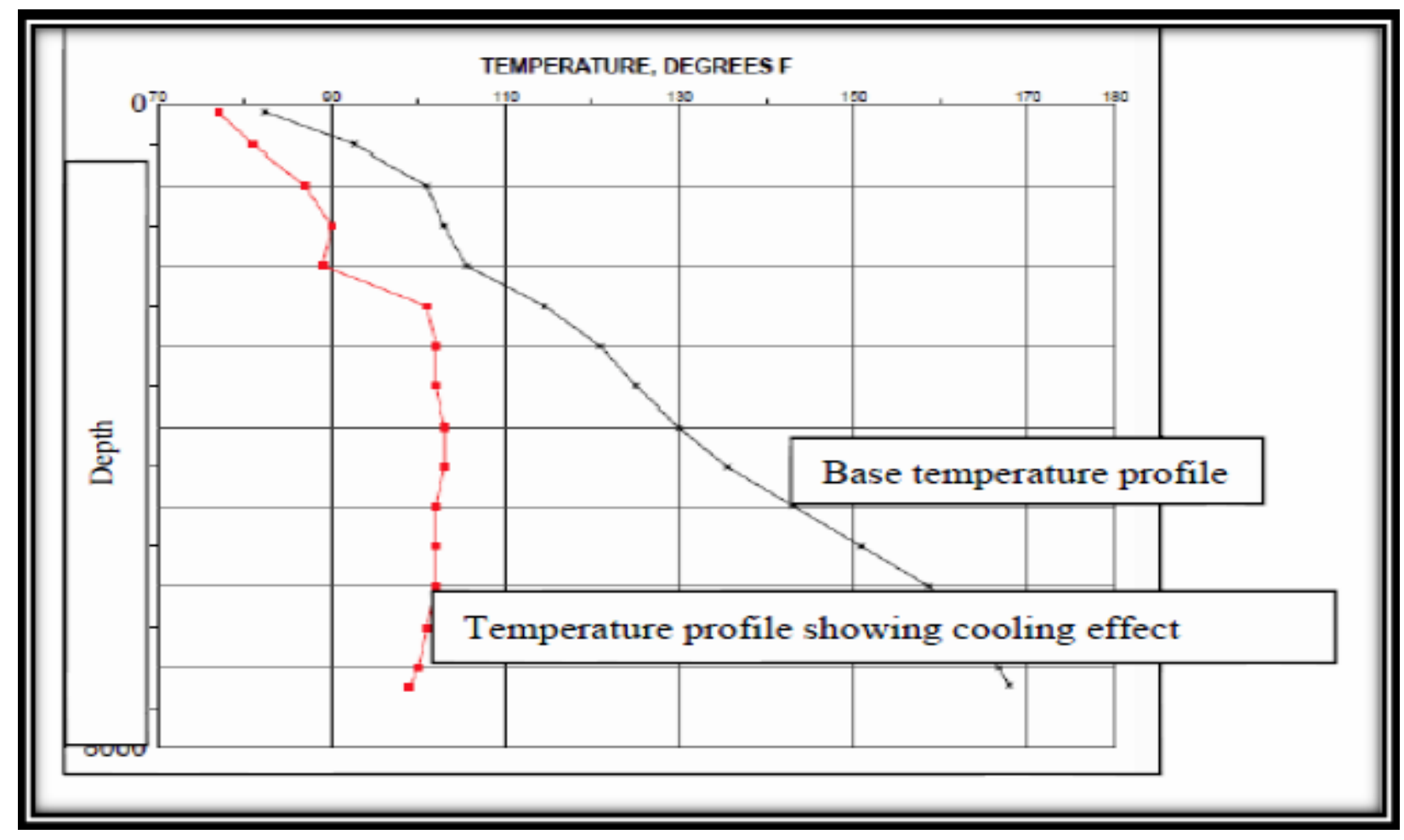

Figure 2.3: Example of Temperature Survey

The applications of temperature for problem diagnostics ${ }^{(8)}$ have been in practice for a long time in the oil industry. The following items are typical applications of temperature survey purposed:

- Fluid cross-flow after well is shut down and stabilized over a long period of time to achieved geothermal equilibrium: upward or downward, behind the casing or between casings in multiple casing configurations.

- Fluid cross-flow behind the casing under flowing conditions: this technique could yield inconclusive results if the magnitude of the anomaly under investigation is small. This also needs to be conducted after conducting the shut-in survey for a comprising purpose (Figure 2.4). 


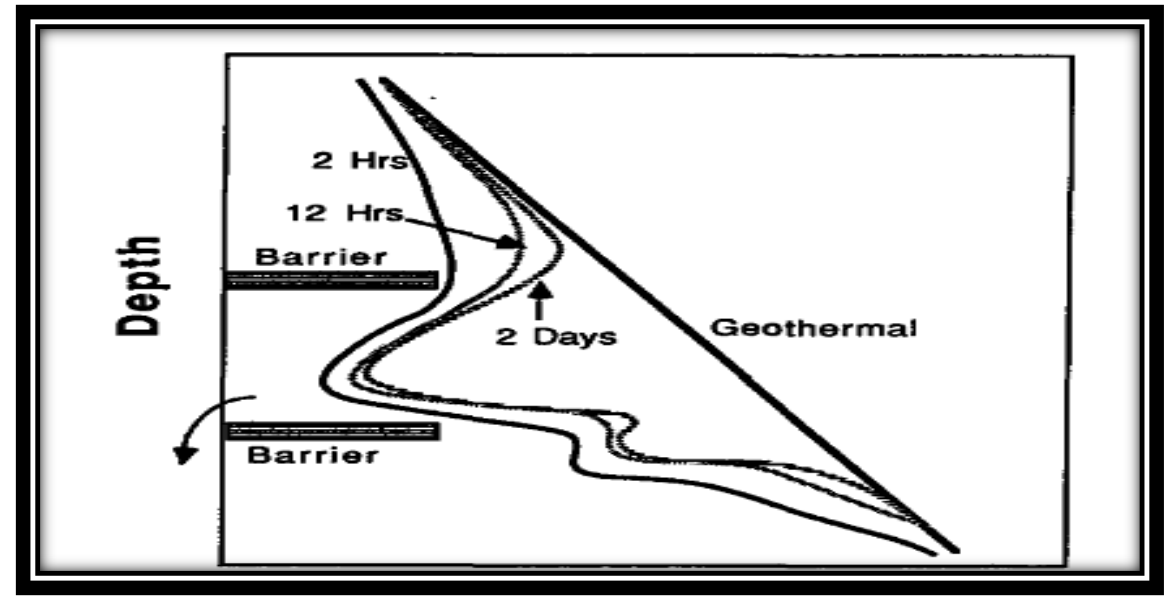

Figure 2.4: Temperature trend for detecting zone isolation

- Leaks identification where flow into or from the production string: the trend of temperature profile will be changed because of the change in fluid temperature which is a result of fluid and is entering the mainstream and the volume of fluid flowing with deferent gradient (Figure 2.5).

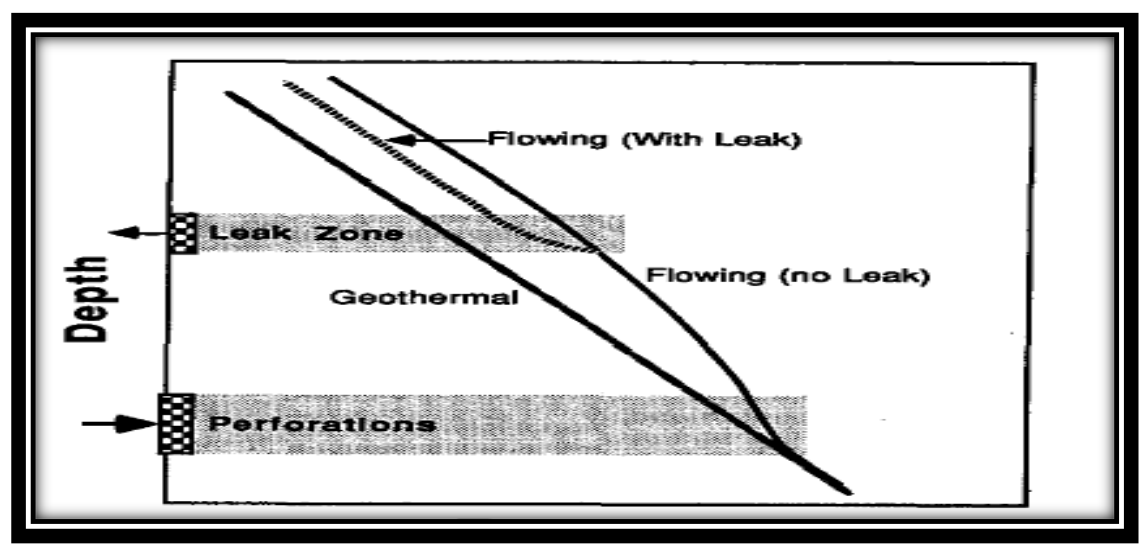

Figure 2.5: Temperature trend for detecting leak effect

- Gas entering into wellbore: the production of gas, and the change in pressure, normally results in a cooling effect (Figure 2.6). The magnitude of the change in temperature is a function of the pressure change, volume of gas entering the flow string, and the initial temperature conditions of both the gas and borehole fluids. Under normal conditions, this feature is relatively easier to detect. 


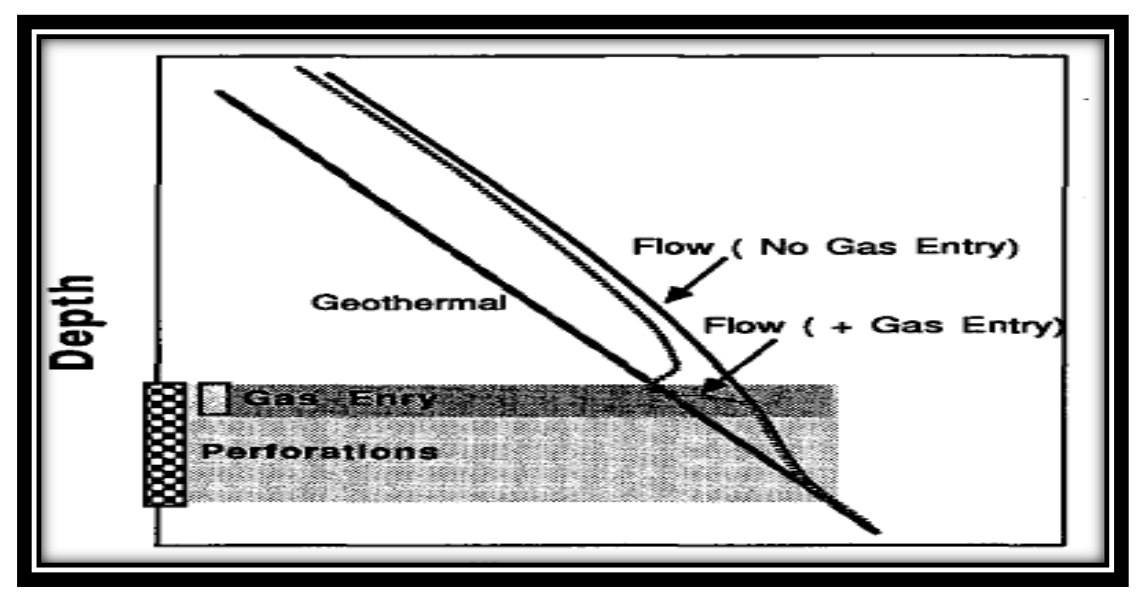

Figure 2.6: Temperature trend for gas entry effect

Having good logging techniques are necessary to obtain representative temperature profiles.

This is because the anomalies are of the order of a fraction of one degree Fahrenheit. Fluid mixing and the associated temperature convection resulting from that caused by the tool movement in the borehole, and the dynamic response of the temperature changes, could be a major limiting factor.

\subsubsection{Noise Logging Survey}

A noise $\log { }^{(18-20)}$ is simply a record of a passive measure of the noticeable sound detected by sensitive hydrophones at a number of locations in the wellbore. It is designed to record sounds in specific frequency range based on the design tool. The tool can be effectively used to survey production and injection wells under both shut-in and flowing conditions. Liquid movement generates noise through the vibration of various features of the geological environment and wellbore components. Noise amount increases with linear flow rate. Because sound is generated by fluid turbulence, high noise amplitude indicates locations where the flow path causes additional turbulence to develop. Fluid moving through restricted channels, leaks, and flow from perforations can produce characteristic sounds in the wellbore and that may be detected with a noise log. Analyzing the recorded 
noise in various frequency ranges allows identifying whether it is a wellbore flow, casing and tubing leaks, perforations, cement channeling and flows through the rock matrix and fractures. Usually the records are done by highly sensitivity hydrophones placed in an oil chamber. Then, hydrophone data pass through a high-quality ultra-silent gain stage and are converted into a digital bit stream for further digital processing.

In 1955 Enright $^{(21)}$ introduced noise log as a qualitative indicator of channeling behind pipe. This concept describes the procedure of locating tubing and casing leaks with acoustic recorder which detect the highest noise level at leaks. In 1970 Korotaev $^{(22)}$ used a noise detector to identify gas bearing zones in uncased well. In 1994 McKinley $^{(22)}$ introduced a noise logging technology based on the recording of acoustic noise into several frequency channels and presented the results of his own experimental research. Later on with noise technology development, noise log started to be used quantitatively to estimate flow rates in some instances, and its application has been extended beyond channel detection.

Figure-2.7 is an example of noise log. This log shows noise power distribution between 117 $\mathrm{Hz}$ on the left side of the panel and $30 \mathrm{kHz}$ on its right side. The red color is for the highest power noise: yellow, green, blue until lower power noise; and white for noise at and below the tool threshold. The scale clearly indicates flow through the rock matrix as a noise peak at $18 \mathrm{kHz}$. Such peaks are often associated with one or two other peaks at $2-6 \mathrm{kHz}$ produced by fracture flow. 


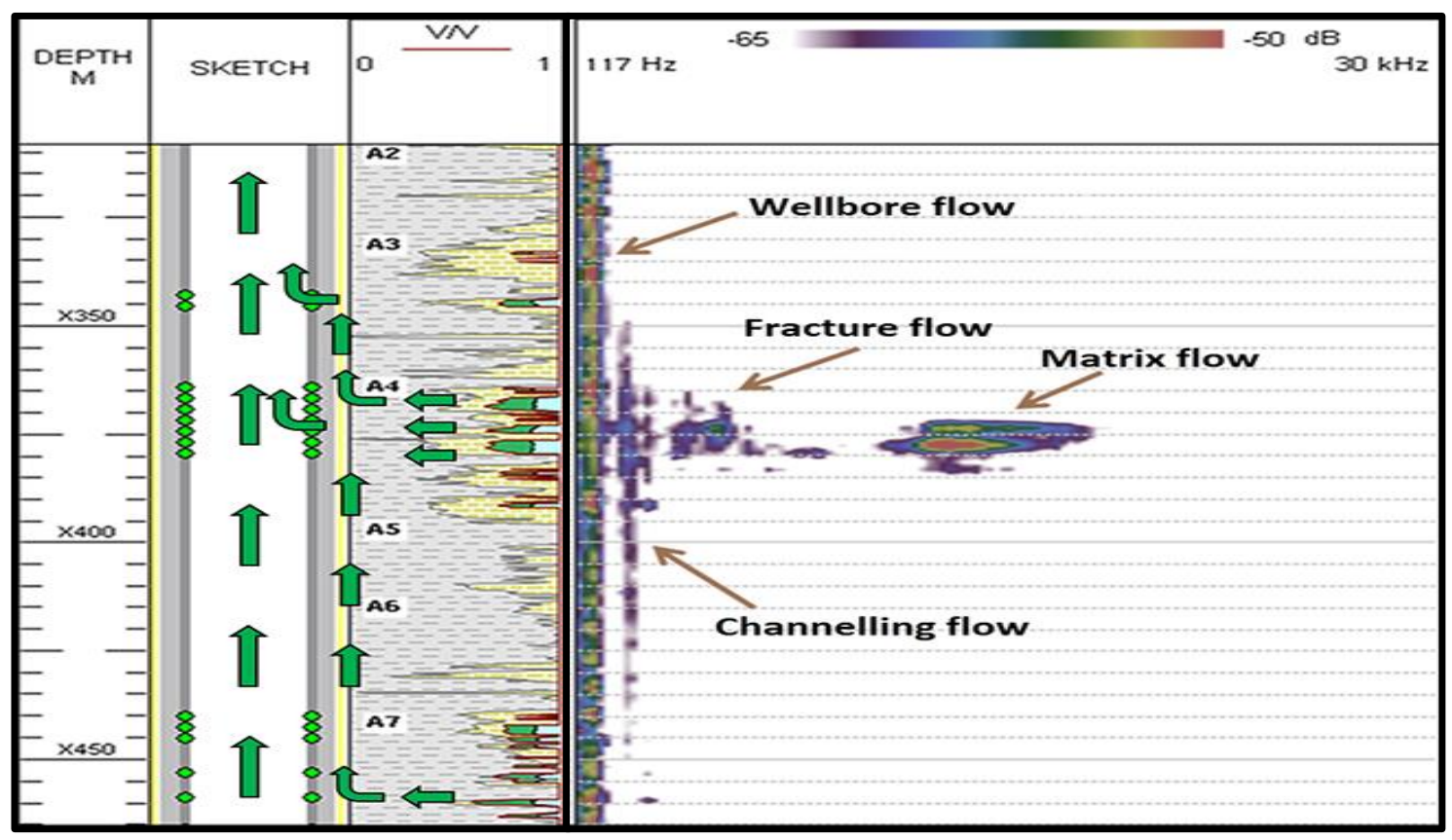

Figure 2.7: Example of Noise Log Trend

\subsubsection{Corrosion Logging Survey}

Corrosion ${ }^{(23)}$ is defined by electrochemical degradation of a material by its environment. Corrosion is caused by a flow of electrons from one material to another or to a recipient of some kind; or from one part of the surface of a material to another part of the same material where conditions permit the flow of electrons. Corrosion logging offers valuable visions to ensure the effective application of safety and environmental regulations.

Corrosion $\operatorname{logs}$ have three different $\log$ approaches ${ }^{(24-27)}$. The objective of each type is to evaluate the condition of the pipe with a specific limitation and approach: The first $\log$ is mechanical caliper tool which is used to detect the internal condition of pipe. Its log results are affected by scale build up on the internal wall. The second type is electromagnetic tool 
which is used to detect the overall inside and outside condition or thickness of pipe. It consists of transmitters and receivers to generate casing condition profiles. The third type is ultrasonic acoustic tool which is used to detect the signal casing string thickness. Its result depends on how deep the signal can go to detect the condition of pipe. The tool generates high frequency ultrasonic pulses through the casing wall. The recorded information, amplitude of echoes, and transit timings are used to generate casing profile. The example below in fig- 2.8 shows typical reading of corrosion log in tubing. Tubing collars are seen in the tubing and the read thickness is 0.4 in. Moreover, corrosion was noticed in tubing in the bottom as the current thickness of tubing decrease to 0.23 in compared to the original tubing thickness which is 0.26 in.

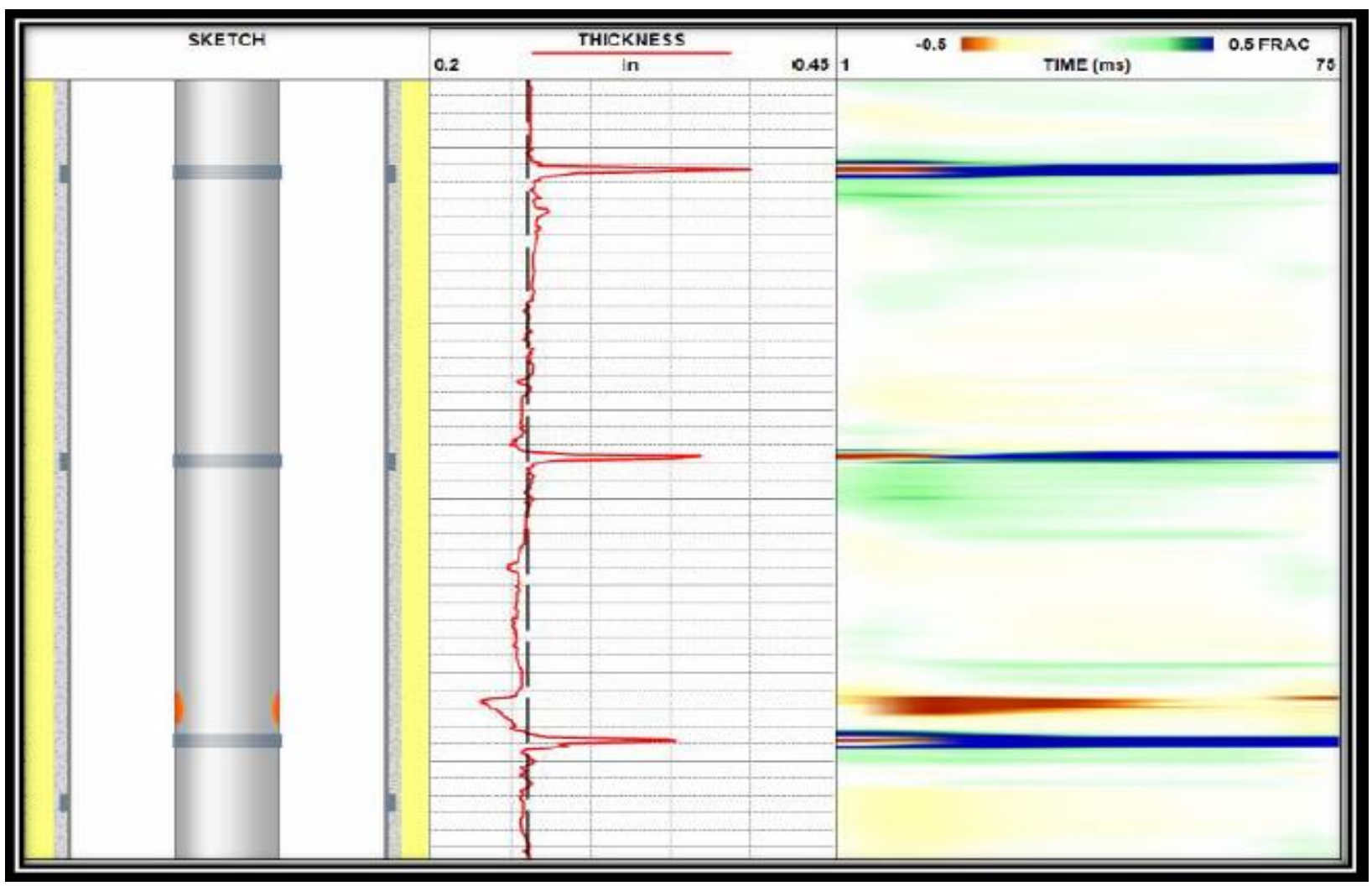

Figure 2.8: Example of Corrosion Log Survey 


\subsection{Summary}

Checking the downhole integrity routinely of any well is important for well integrity purpose and it is part of safety measurements to ensure all resources that are available maintaining safe hydrocarbon production. For all types of wells, downhole inspection is required by conducting the following logs in different conditional scenarios such as temperature, pressure, and noise logs. The purpose of temperature log is to identify any cross flow and abnormal geothermal phenomena. Pressure log is to identify pressure gradient and type of fluid from its gradient. Noise logs can detect any fluid movement which measures fluid frequency movement. In addition, corrosion log is used to evaluate the condition of tubing and casing separately. These are some of the used technique for evaluating the downhole condition. Each of those techniques is used based on the needed requirement and limitation of each technique.

This thesis is divided into five chapters. After the introduction and literature review chapters, Chapter 3 discusses methodology and approaches for detecting minor downhole leakage. Chapter 4 discusses the obtained results for the three approaches which are rigless, rig, and artificial intelligence approached. Finally, chapter 5 shows the conclusions and recommendations. 


\section{CHAPTER 3}

\section{METHODOLOGY AND APPROACHES}

In this case study, running integrated logging in different conditions has been proven to be significantly more efficient in locating anomalies whereas many of the existing tools are not effective for locating a small leak if it has not been run in the required sequence and technique. Because of the small leak in this case study a spanner in production log tool could not work properly in both flowing and shut in conditions and this let the challenge of identifying the leak is high. So, production log was cancelled after conducting the first run.

\subsection{Case Study}

Well-A is an example where leak detections were done by three approaches: rigless, rig and Artificial intelligence approach. This well was drilled in sandstone reservoir as water injector and completed as a vertical 7 inch cased hole and 4-1/2 inch tubing in mature field. During drilling time, the integrity of cement behind 7" casing was good and confirmed by the Run CBL-VDL log. The well was perforated at the target reservoir with 8 Shot per feet with 4" Hyper jet casing gun and six set of perforation as follows:

5540'-5605', 5611'-5626', 5629'-5649', 5654'-5694', 5705'-5810', and 5816'-5826'. Later on, Stimulation job was conducted to improve the injectivity of this well. However, during the stimulation job, hydrogen sulfide gas was noticed in the area which was an indication of downhole leak since the field is sweet. The annuli survey showed: 400 psi in wellhead pressure (WHP), 400 psi in tubing-casing annulus (TCA), and 40 psi in first casing- casing annulus (CCA) which meant there was a downhole communication between tubing and first casing. The below figure is the cross section plot of Well-A that shows the details of downhole completion. 


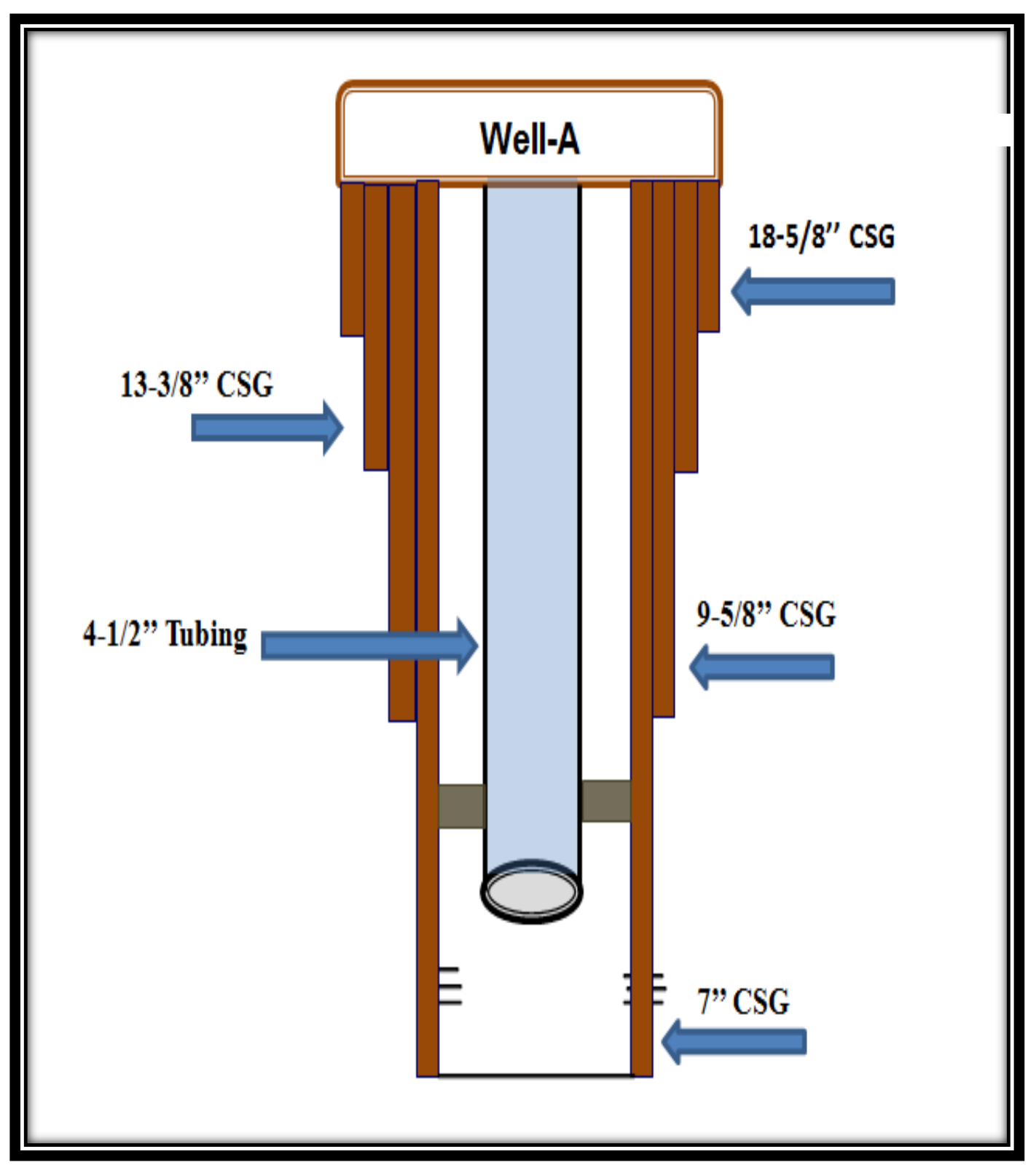

Figure 3.1: Cross section of Well-A

The first step of diagnostic this problem was to conduct special temperature survey.

The result of that survey confirmed the doubt but new integrated approach was required to confirm the leak depths and details of that leak. The primary analysis of temperature survey shows possible leaks in the following areas of well-A: two leaks in the tubing, and one leak in the packer. 


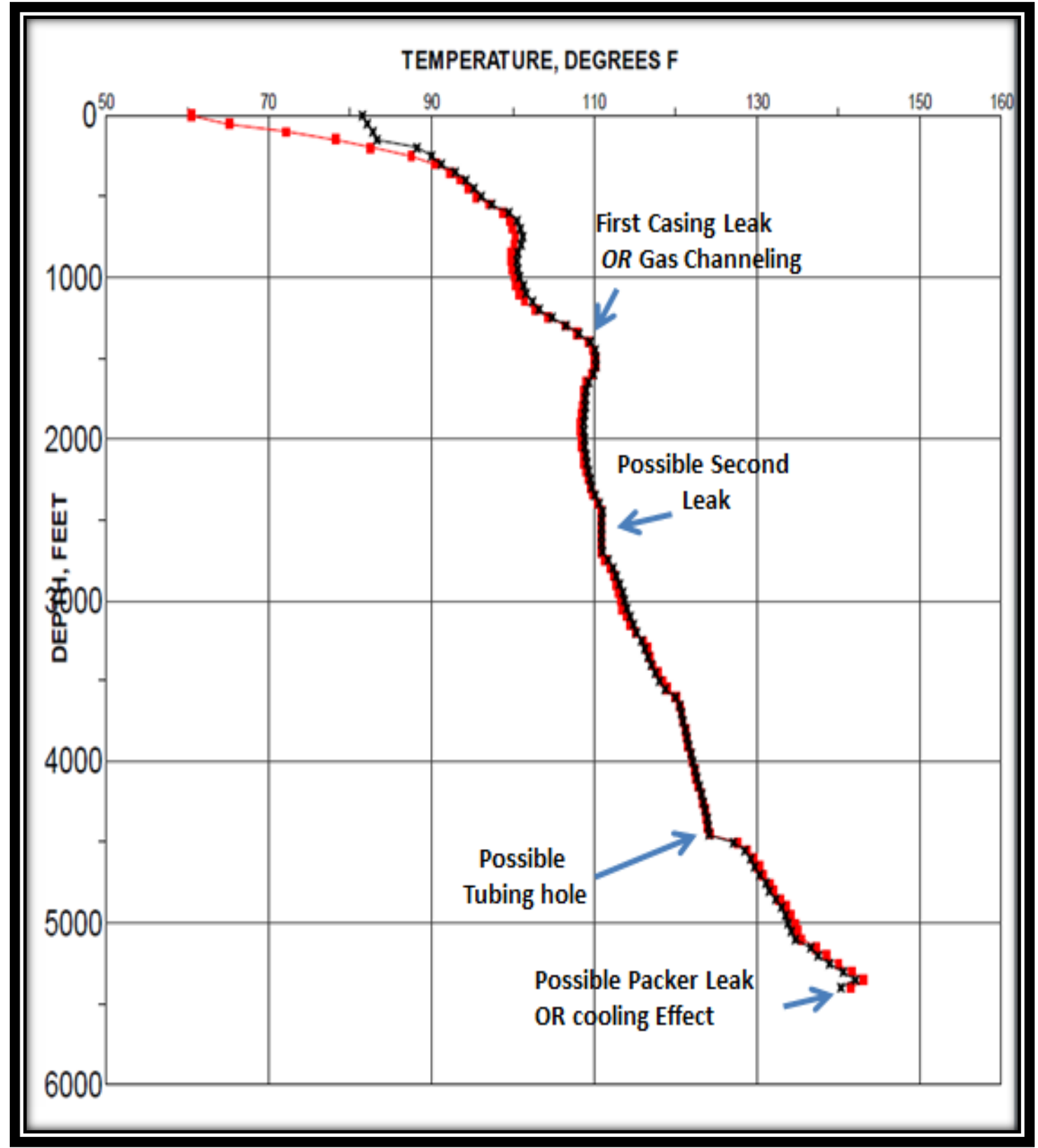

Figure 3.2: Temperature Survey of Well-A

Since this is a primary analysis and this survey was taken every $50 \mathrm{ft}$, another continues surveys with high accuracy, with a new integrated approach, was planned to confirm the details of that leak. 


\subsection{An Integrated Rigless Approach for Downhole Leak Detection}

Full and deep analysis with new ideas and approaches were needed to confirm the suspected leak areas since there is no well-known idea or technology available in oil industry to grantee leak depth. Set of data for the problematic well were collected to identify the downhole problems in this well. The reported data includes: well history with drilling and workover activities, well capacity, completion configuration and condition, historical downhle pressure, temperature and annuli survey. Finally, the effect of the injected water and chemical treatment in downhole well condition were study as per of the evaluation of this problem. These data were collected from different sources for the plan objective formerly.

\subsubsection{Quality Check}

After filtration, evaluation and doing a quality check, a new approach was identify to come up with a new methodology to do downhole wave movement which is needed for creating a sound. That sound will be the key to identify the leaking depth while conducting pressure, temperature, and noise logging at different scenarios. Moreover, corrosion log was run to help in determining the condition of 4-1/2"' tubing and 7"' casing with metal loss associated.

Quality check was done to ensure that all the used data are valid and from that step a new approached of conducting these logs will be managed very well to meet the objective. Moreover, full interpretation was done many times to guarantee the excellence. First, independent variables were determined by studying their relationships with the dependent variables. Then, different comparisons of same log were conducted to get an idea how the log result will look like at the different implemented scenarios. Next, tool inspection with data quality check was done at each step of logging prior and after pull out of hole the logging tool. After that, full integrated interpretations of those logs were done to confirm the 
downhole leak depths. Finally, surface inspection for the 4-1/2', tubing was done after pulling the tubing to surface and hydro-pressure test was done both by a rig prior of fixing any leakages in the 7', casing. In the end, a model for leak detection was developed through utilizing artificial intelligence. Currently, the developed model can detect any future downhole leak for any well.

\subsubsection{Job Performance and Operation Sequence}

The first step of developing the integrated logging approached was to gather all the influencing data. From that step, the performed job was set to be in the following sequence:

- Run in hole from surface to total depth (TD) with a precision temperature tool to record the downhole temperature and while pulling the tool up only noise log will be recorded both at static condition to be based for other next steps.

- Bleed off casing-casing annulus for 5 min while recording any changes in WHP, TCA, and CCA pressure. Then, wait another 5 min after bleeding off the pressure and conduct a precision temperature survey while pulling the tool out of hole.

- Bleed off tubing-casing annulus for 5 min while recording any changes in WHP, TCA, and CCA pressure. Then, wait another 5 min after bleeding off the pressure and conduct another precision temperature survey while pulling the tool out of hole.

- Run in hole with a noise tool and when the tool at TD start bleed off casing-casing annulus for 5 min while recording any changes in WHP, TCA, and CCA pressure. Then, conduct downhole noise survey while pulling the tool out of hole.

- Again run in hole with the noise tool and when the tool at TD start bleed off tubingcasing annulus for $5 \mathrm{~min}$ while recording any changes in WHP, TCA, and CCA pressure. Then, conduct downhole noise survey from TD to surface. 
- Finally, conduct corrosion survey from surface to TD to get an idea about the condition of both tubing and casing.

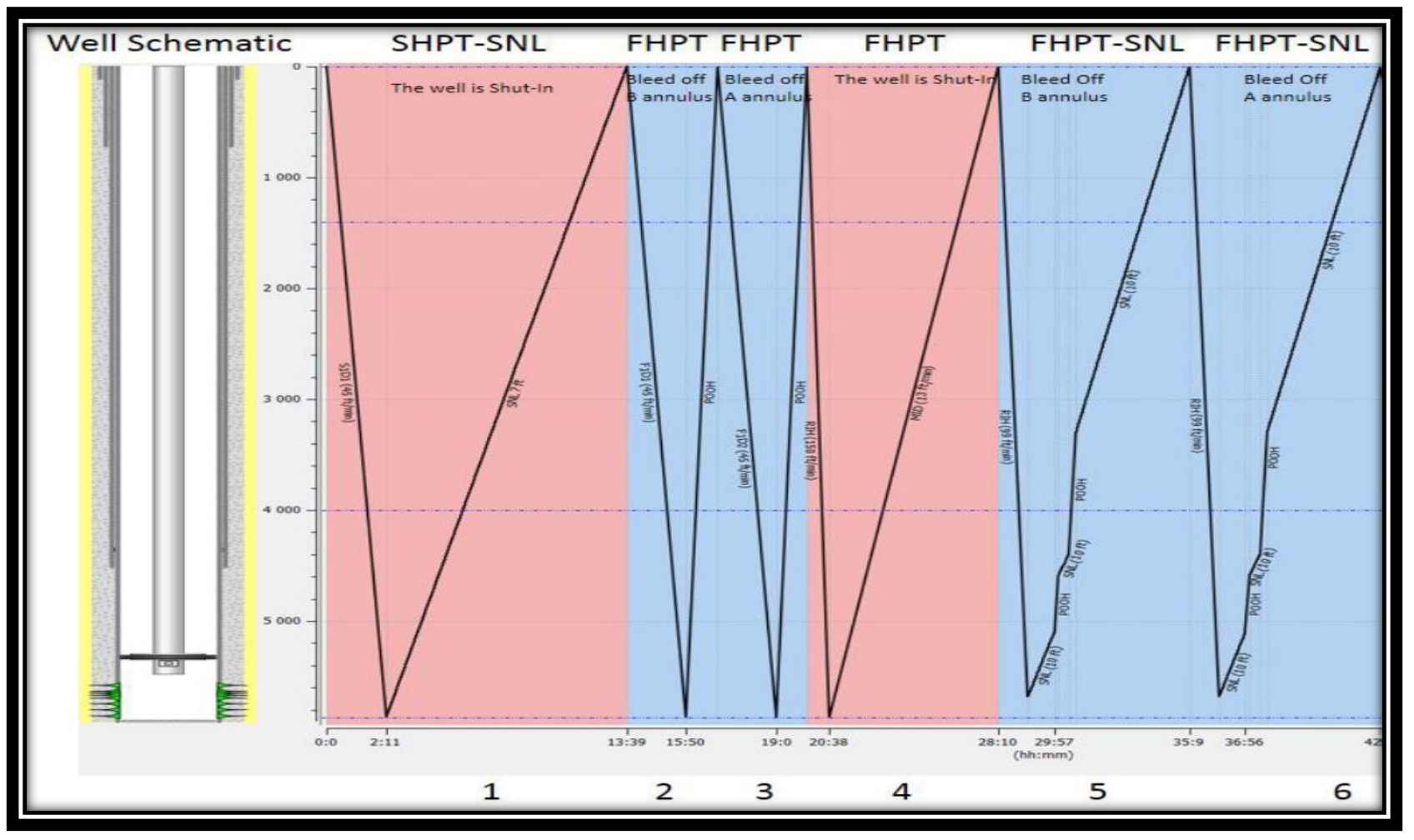

Figure 3.3: Job Performance

\subsubsection{Model Development for Rigless Leak Identification}

The developed model is used to detect the downhole leak through analyzing only the numerical log data of corrosion, temperature and noise surveys. Based on the developed program, some instructions were implemented to allow the program decided that: the completion in a specific depth is either leaked or only corroded or in a good condition. These rules were put based on these following surveys and in a specific order:

A-For corrosion survey, a corrosion factor was put as follow:

1. $53 \%$ corrosion factor for $4-1 / 2$ " tubing was implemented to the original tubing thickness which will indicate the presence of either corrosion or leak. If corrosion sigma in a specific depth is less than $53 \%$ of the original tubing thickness. Then, the developed program will highlight this depth for more evaluation by next step-B. 
2. $39 \%$ corrosion factor for $7 "$ casing from the original thickness was implemented to the original casing thickness which will indicate the presence of either corrosion or leak. If corrosion sigma in a specific depth is less than $39 \%$ of the original casing thickness. Then, the developed program will highlight this depth for more evaluation by next step-B.

B- If the detected metal loss in step-A is less than the original thickness multiply by the given corrosion factor for that metal, Temperature survey will confirm the previous result as follow:

1. If temperature profile is constant or decreasing with depth, this will be indication of leak in that selected area.

2. If temperature profile is increasing with depth, this will be indication of corrosion only in that selected area which will not require further evaluation.

C- If irregularity was noticed by both temperature and corrosion survey as above in step-A and B-1. Then, the predictable depth will be tested by this final step thought the conducted noise survey as follow:

1. If noise survey, at the noticed depth as per step B-1, is greater than or equal to the maximum readable frequency from surface to bottom divided by two, then this will support both temperature and corrosion surveys which will indicate the presence of leak.

2. If noise survey, at the noticed depth as per step B-1, is less than the maximum readable frequency from surface to bottom divided by two, then this will not support leak occurrence but it will support the presence of corrosion only. 


\subsection{Rig Approach for Detecting and Fixing Downhole Leak}

Rig approach is needed to confirm the suspected leak areas which were identified in the rigless approached. This step is required since it is part of the evaluation for the previous step which mentions that there is no strong well-known idea in oil industry to identify leak depth. So, this conventional approach is divided into two visible inspection areas which are surface inspection for tubing and pressure test for casing. The purpose is to do mechanical inspection for the integrity of downhole completion.

\subsubsection{Introduction to Rig}

A drilling rig ${ }^{(28)}$ is mainly performed the following three operations as in fig-3.4:

Hoisting: One of the basic functions of a drilling rig is its ability to lower and elevate the drill string into and out of the wellbore.

Rotation: Another basic function that is required during drilling is the ability to make the drill string rotate in the wellbore.

Circulation: During drilling, a drilling rig needs to have functionality to stabilize the pressure in the wellbore, for bit cooling, and to remove cuttings from the wellbore. This functionality is fulfilled by the mud circulation system. 


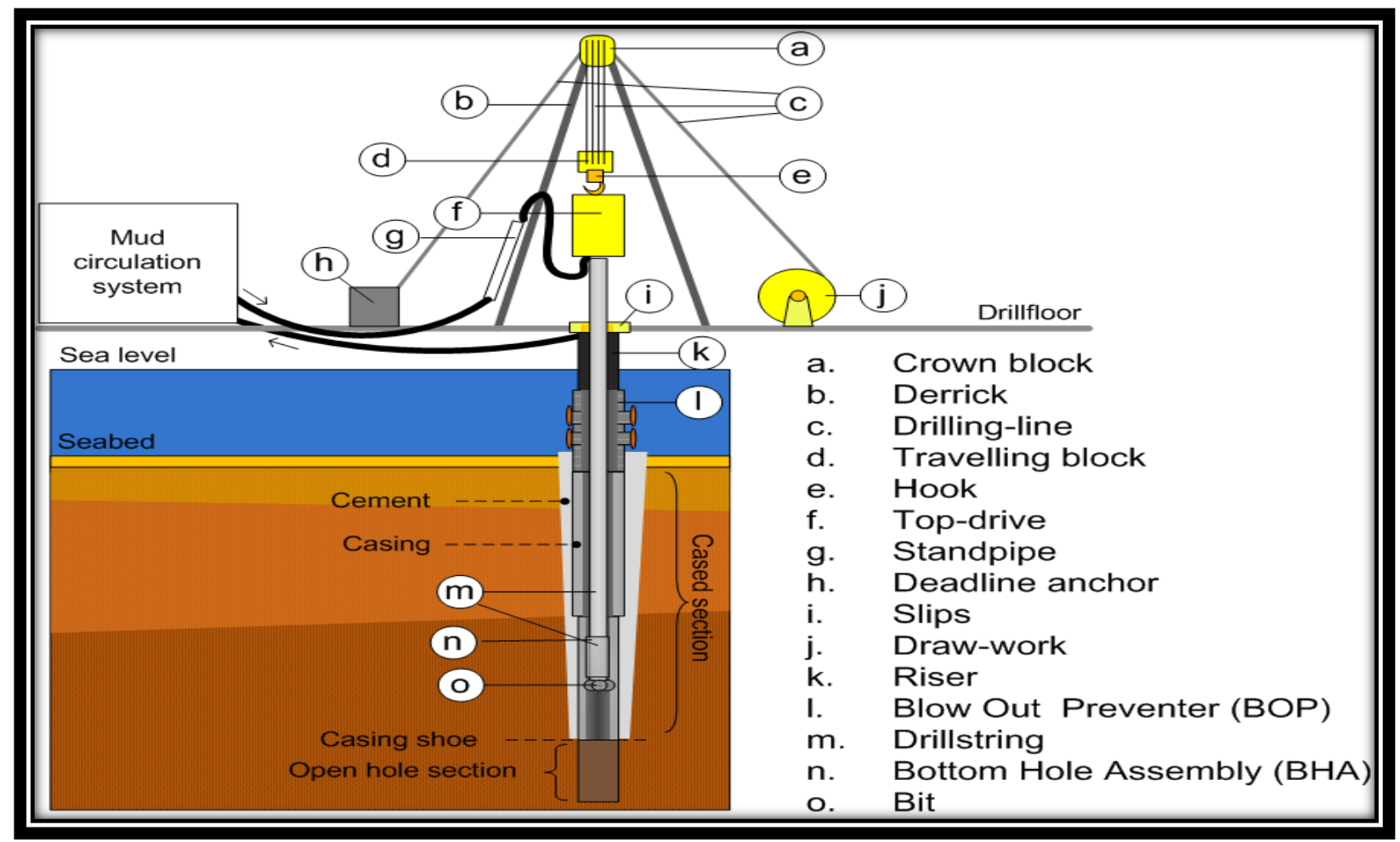

Figure 3.4: Drilling Rig components

There are many techniques and types of equipment that can be used to perform these operations. We will not go into technical details about how they are performed, but instead provide descriptions of the major functional entities. A simplified sketch of drilling rig is shown in Figure 3.4. Descriptions of the components are provided below.

The derrick is a structure which supports the weight of the crown block and the components being hoisted. Actual lifting is performed by a machine called the draw-work consisting of a large-diameter steel spool, brakes, a power source and associated auxiliary devices.

The draw-work reels the drilling line which is a large diameter wire rope in and out in a controlled fashion. The reeling out of the drilling line is powered by gravity and reeling in by engines. The end of the drilling-line, not connected to the draw-work, is connected 
through the crown block at the top of the derrick, threaded into the travelling block and secured to the drill floor with the deadline anchor. The travelling block hangs in the air below the crown block and when the draw-work reels out or in the drilling line, it causes the travelling block and whatever may be hanging underneath it, to be lowered or elevated.

At the drill floor, there is a device called slips, which can grip the drill string in a relatively non-damaging manner. This device consists of three or more steel wedges that are hinged together, forming a near circle around the drill pipe. After the slip is placed around the drill pipe the driller slowly lowers the drill string. This downward force pulls the outer wedges down, providing a compressive force inward on the drill pipe and effectively locking everything together. Then, the upper portion of the drill string can be unscrewed while the lower part is suspended. Attached to the bottom of the travelling block, is hook. The hook provides a way to pick up heavy loads with the travelling block.

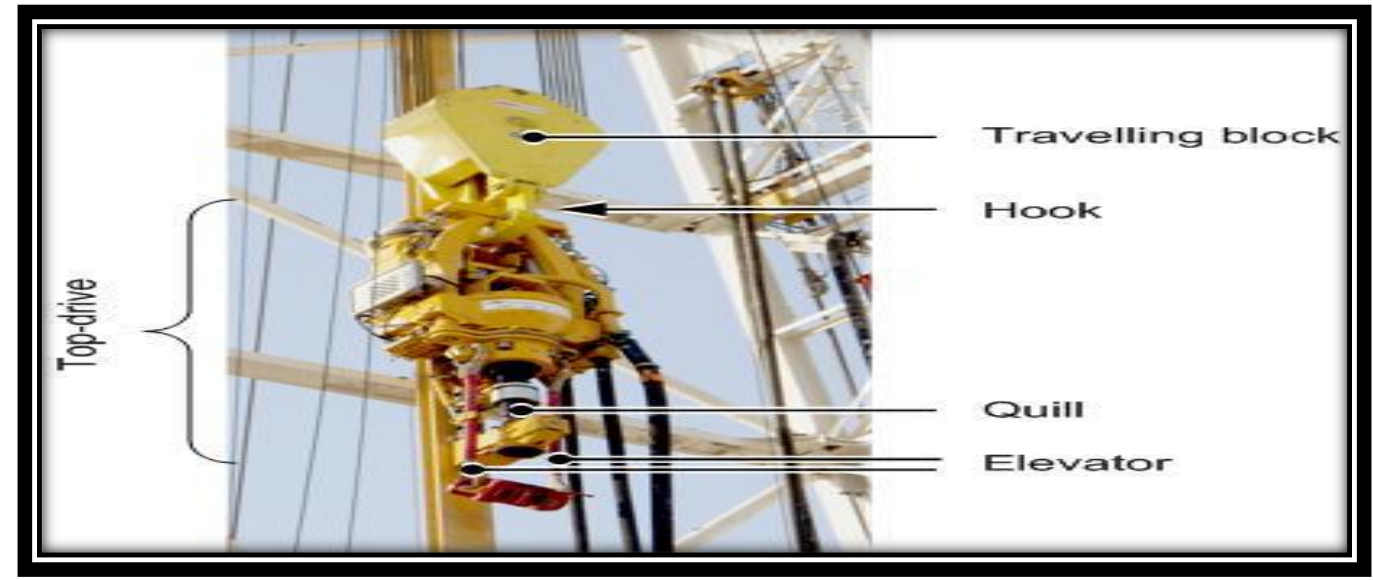

Figure 3.5: Top-drive Connected to Hook and Travelling Block

The hook ${ }^{(29)}$ can be connected to the top-drive of the machine that turns the drill string. The top-drive consists of one or more motors (electric or hydraulic) connected with appropriate gearing to a short section of pipe called a quill, which may be screwed into the drill string 
itself. An alternative to connecting the drill string is to be connected to the elevator. The elevator is a hinged mechanism that may be closed around the drill string. This approach is a quick way to connect the drill string to the hoisting components, whilst disabling the rotation functionality of the top-drive.

The mud circulation system mainly consists of a set of mud pits, mud pumps, and a cleaning system for mud returns. A drilling rig ${ }^{(30-34)}$ can have up to 40 mud pits and a maximum of 4 mud pumps and this also depend in rig size and capability. During circulation a valve is opened, enabling mud to flow into the mud pump. The mud pump pumps the mud through the flow line, up the standpipe manifold, into the top-drive connecting the mud flow to the drill string. The mud flows down through the drill string, exiting through the bit into the wellbore. The mud travels together with rock cuttings and other elements up outside of the drill string and through an important valve at the top of the well called blowout preventer (BOP). This may be closed if the drilling crew loses control of the formation fluids. By closing the BOP which usually operated remotely via hydraulic actuators, control of the reservoir may be regained and the mud density can be increased until it is possible to open the $\mathrm{BOP}$ and retain pressure control of the formation. However, the $\mathrm{BOP}$ is connected to a large-diameter pipe, called a riser. The riser may be considered as a temporary extension of the wellbore to the surface, which enabling the mud returns to enter the mud circulation system.

Drilling Control Unit perform the drilling operations by using heavy machinery operated directly from the drill floor. On modern drilling rigs, the drilling crew is protected to some degree from the most dangerous situations involved in the handling of this equipment. This is done by simply enabling the draw-work, the top-drive, mud pumps, and pipe handling equipment to be remotely controlled from a relatively safe location at the rig. 
Some of operations can be fully automated, but are left semi-automated due to the great safety value in having the operations manually performed with a complete overview of the drill floor activity. Petroleum industry if it has been compared to other industries, it is relatively slow in the area of exploring new technology which enabling tasks to be delegated to computers.

This approach is needed to confirm the suspected leak areas which were identified in the rigless approached. Mechanical inspection for the integrity of downhole completion was completed through two visible inspection areas which are surface inspection for tubing and pressure test for casing.

\subsubsection{Health, Safety and Environment}

At no time safety aspects should be compromised. Many of incidents have had great potential to seriously injure or destroy valuable equipment. The primary risk of dealing with high pressures can be greatly minimized by following simple safety procedures.

Personal safety equipment; each person on rig location should wear appropriate safety equipment to minimize the risk of personal injury. Hard hats, hard-toed shoes and safety glasses should be the minimum level of safety equipment worn on location. Other equipment such as hearing protection, goggles, fire-retardant fabrics and filter masks should be worn if exposure to the conditions they protect against is a possibility. Wearing and fallowing safety equipment and procedure is the most important step that creates a positive safety atmosphere on location. 
Holding safety meeting ensures that all personnel on location are aware of specific dangers and required procedures relative to the conducted job. Each person on location should clearly understand his or her role during the job as well as individual responsibility during emergency situations. A head count must be taken to account for everyone on location. An escape route and meeting place should be agreed upon where all personnel will gather in the event of an emergency situation. Personnel who are not directly involved in the job should have limited location access during the actual operations. Everyone should be aware of the unique dangers since hydrogen sulfide or possibly the fluids being pumped are highly flammable. Potential safety problems or concerns should be brought to the attention of everyone. The pre-safety meeting is the principal means of communication for giving final instructions to all personnel. Finally, a well-organized safety meeting helps ensure operational success. 


\subsection{Artificial Intelligence Approach for Leak Detection}

Petroleum industry all over the world has experienced a rapid increase in the number of artificial intelligence (AI) applications. This expansion in the number of applications of $\mathrm{AI}$ is due to the greater availability of human experts and publications. AI is the science and engineering of making intelligent machines. AI is dedicated to design ways to make computers perform tasks that were previously thought to require human intelligence. AI studies are divided into two main categories; studies that try to simulate the operations of human brains and studies that understand and apply thinking methodologies. The first is the Artificial Neural Networks (ANNs) and the second is the classical Artificial Intelligence. Since AI techniques became aligned with conventional computer hardware architecture, their applications to petroleum exploration and production have become widely available.

\subsubsection{Introduction to Artificial Intelligence}

AI technologies ${ }^{(35)}$ have a major impact in petroleum industry. Artificial neural network is one example of that technique which is a computation methodology that has the ability to learn by reproducing the learning method used in human brain. It is an interconnected assembly of simple processing elements, units, or neurons, whose functionality is loosely based on the brain neuron. The processing ability of the network is stored in the inter unit connection strengths, or weights, obtained by a process of adaptation to, or learning from, a set of training patterns. Neural networks are well suited to complex problems. It is relatively sensitive to data noise, as they have the ability to determine the underlying relationship between model inputs and outputs, resulting in good generalization ability. A neural network model can be subjected to additional training in order to familiarize itself to new situations at which its input-output performance is insufficient. 
In today's computer, databases contain massive quantities of information. The accessibility and wealth of this information makes data mining a matter of considerable importance and necessity. Most data mining techniques are based on inductive learning where a model is constructed explicitly or implicitly by generalizing from a sufficient number of training examples. The original assumption of the inductive approach is that the trained model is applicable to future. Traditionally, data collection was regarded as one of the most important stages in data analysis. A predictor would use the available domain knowledge to select the variables that were to be collected. The number of variables selected was usually small and the collection of their values could be done manually. In the case of computer analysis, the analyst had to enter the collected data into a statistical computer package or an electronic spreadsheet. Due to the high cost of data collection, people learned to make decisions based on limited information.

Data Mining with Decision Trees: as the amount of machine-readable information increases, the ability to understand and make use of it does not keep pace with its growth. Data mining developed as a means of dealing with this exponential growth of information and data. The term describes the process of selecting through large databases in search of interesting patterns and relationships. In practice, data mining provides a tool by which large quantities of data can be automatically analyzed. 


\subsubsection{Decision Tree Structures}

A decision tree ${ }^{(37)}$ is a decision support tool that uses a tree like graph or model of decisions and their possible consequences. It is used as one way of displaying an algorithm. Decision trees are commonly used specifically in decision analysis to help identify a strategy most likely to reach a goal.

\subsubsection{Classification of Decision Trees}

It is useful to distinguish between two main supervised models: classification models which is known as classifiers and regression models which map the input space into a realvalued domain. For example, a regression can predict the demand for a certain product given its characteristics. On the other hand, classification maps the input space into predefined classes. Among the many alternatives for representing classifiers, there are, for example, support vector machines, decision trees, probabilistic summaries, algebraic function, ext. In data mining, a decision tree is an analytical model which can be used to represent both classifiers and regression models as shown in Figure 3.6. In operations research, on the other hand, decision trees refer to a classified model of decisions and their consequences. The decision maker employs decision trees to identify the strategy most likely to reach its goal. When a decision tree is used for classification tasks, it is more appropriately referred to as a classification tree. When it is used for regression tasks, it is called regression tree.

Classification trees ${ }^{(38-39)}$ are used to classify an object or case to a predefined set of classes such as risky and non-risky based on values features such as age or type. Classification trees are frequently used in applied fields such as marketing, petroleum engineering and other engineering disciplinary. The classification tree is useful as an exploratory technique. However it does not attempt to replace existing traditional statistical 
methods and there are many other techniques that can be used classify or predict the membership of instances to a predefined set of classes, such as artificial neural networks. Figure 3.7 presents a typical decision tree classifier. This decision tree is used to facilitate the underwriting process of mortgage applications of a certain bank. As part of this process the applicant fills in an application form that include the following data: number of dependents (DEPEND), loan-to-value ratio (LTV), marital status (MARST), payment-toincome ratio (PAYINC), interest rate (RATE), years at current address (YRSADD), and years at current job (YRSJOB). Based on the above information, the bankroller will decide if the application should be approved for a loan. More specifically, this decision tree classifies mortgage applications into one of the following two classes:

1) Approved indicated as A in figure where the application should be approved.

2) Denied indicated as D in the figure where the application should be denied.

3) Booklet financing indicated as $M$ where a bankroller should manually examine the application and decide if it should be approved in some cases after requesting additional information from the applicant.

The decision tree is based on the fields that appear in the loan applications forms. The above example illustrates how a decision tree can be used to represent a classification model. In fact it can be seen as an expert system, which partially automates the underwriting process and which was built manually by a knowledge engineer after interviewing an experienced bankroller. This sort of expert interrogation is called knowledge elicitation namely obtaining knowledge from a human expert to be used by an intelligent system. Knowledge elicitation is usually difficult because it is not easy to find an available expert who is able, has the time and is willing to provide the knowledge engineer with the information he needs to create a reliable expert system. In fact, the difficulty essential in the process is one of the main 
reasons why companies avoid intelligent systems. This phenomenon is known as the knowledge elicitation bottleneck.

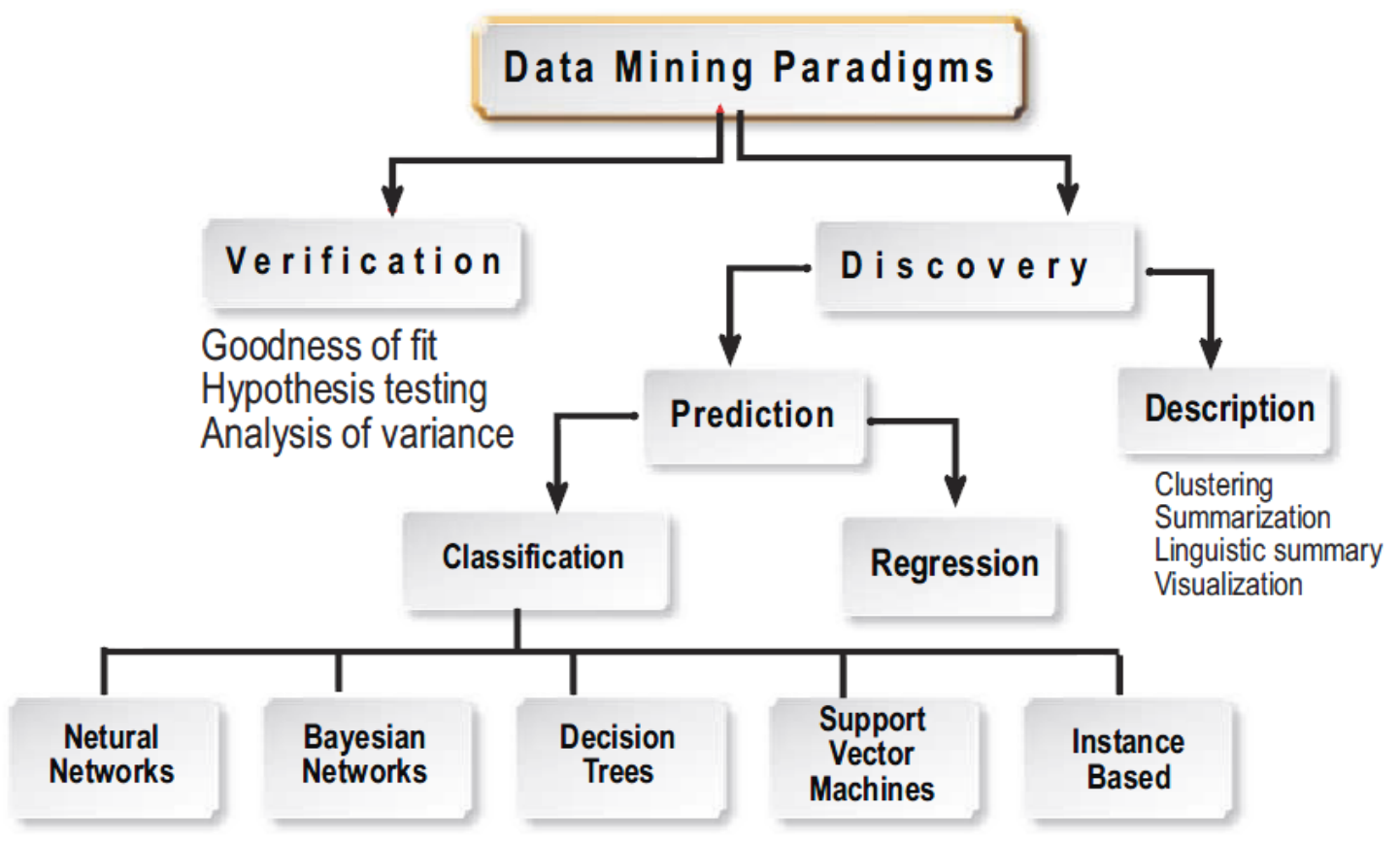

Figure 3.6: Classification of data mining Methods (Ref. 25)

In the opinion of many researchers, decision trees are popular due to their simplicity and transparency. In fact the tree can be grown automatically. Decision trees are selfexplanatory; there is no need to be a data mining expert in order to follow a certain decision tree. Classification trees are usually represented graphically as hierarchical structures, making them easier to interpret than other techniques. 


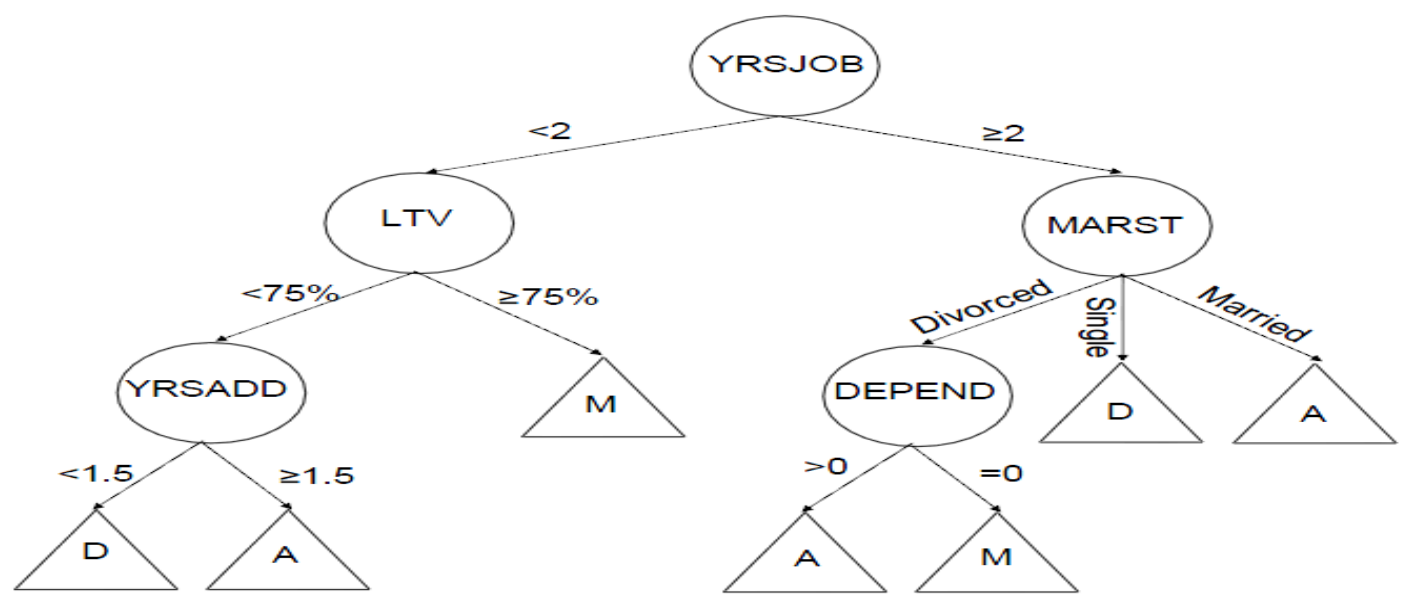

Figure 3.7: Example-1 of Decision Tree (Ref. 22)

\subsubsection{Characteristics of Decision Trees}

A decision tree ${ }^{(40-41)}$ is a classifier that consists of nodes that form a rooted tree, meaning it is a directed tree with a node called a "root" that has no incoming edges. All other nodes have exactly one incoming edge. A node with outgoing edges is referred to as an "internal" or "test" node. All other nodes are called "leaves" also known as "terminal" or "decision" nodes. In the decision tree, each internal node splits the instance space into two or more subspaces according to a certain separate function of the input attribute values. In the simplest and most frequent case, each test considers a single attribute, such that the instance space is partitioned according to the attributes value. In the case of numeric attributes, the condition refers to a range. Each leaf is assigned to one class representing the most appropriate get value. Alternatively, the leaf may hold a probability vector indicating the probability of the target attribute having a certain value. Figure 3.8 describes another example of a decision tree whether or not a prospective customer will respond to a direct mail. Internal nodes are represented as circles, whereas leaves are represented as triangles. Two or more branches may grow from each internal node. Each node corresponds with a certain characteristic and 
the branches correspond with a range of values. These ranges of values must give a partition of the set of values of the given characteristic. Cases are classified by steering them from the root of the tree down to a leaf, according to the outcome of the tests along with the path. Specifically, starting with a root of a tree, which consider the characteristic that corresponds to a root and by defining to which branch the observed value of the given characteristic is corresponds. Then, considering the node in which the given branch appears. Repeat the same operations until reaching a leaf as illustrated below.

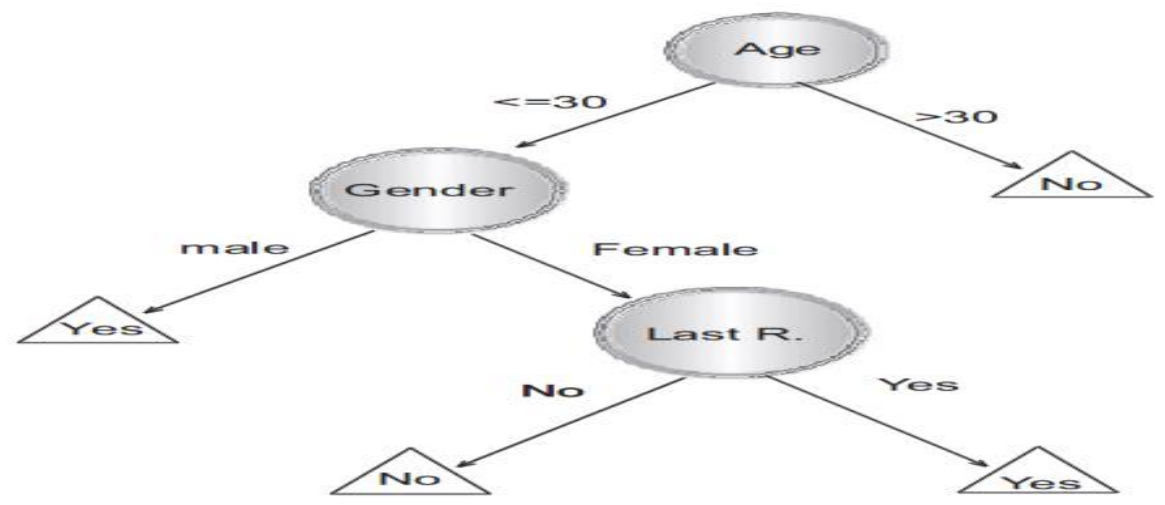

Figure 3.8: Example-2 of Decision Tree (Ref. 22)

Decision tree is suitable to be more logical-able since it is not complex. Usually, the tree complexity is measured by one of the following metrics: the total number of nodes, total number of leaves, tree depth and number of features used. Tree complexity is explicitly controlled by the stopping criteria and the trimming method that are employed. Another characteristic of decision trees is their hierarchical nature. Imagine that you want to develop a system for diagnosing patients according to the results of several medical tests. Based on the result of one test, the physician can perform or order additional laboratory tests based on specific sequence until diagnosing the problem. The objective of this study is to identify downhole leak. After evaluating the data and analyzing the problem, a model was developed to identify future downhole leak. 


\subsubsection{Model Development of Decision Tree}

This part is talking about model development through utilizing algorithm decision tree and the obtained results for identifying downhole leak. Training set can be described in a variety of ways. Most frequently, it is described as a bag instance of a certain bag schema. A bag instance is a collection of tuples which also known as records, rows or instances that may contain duplicates. Each tuple is described by a vector of attribute values. The bag schema provides the description of the attributes and their domains. From that, an induction algorithm is an object that obtains a training set and forms a model that generalizes the relationship between the inputs attributes and the target attribute. For example, an inducer may take as an input specific training tuples with the corresponding class label, and produce a classifier. Decision tree represents a classification tree which was induced by performing decision tree on a training set. Using decision tree is possible to predict the target value of a tuple.

Decision tree inducers are algorithms that automatically construct a decision tree from a given data set. Typically the goal is to find the optimal decision tree by minimizing the generalization error. However, other target functions can be also defined, for example, by minimizing the number of nodes or minimizing the average depth of the tree. The selection of the most appropriate feature is made according to some splitting measures. After the selection of an appropriate split, each node further subdivides the training set into smaller subsets, until a stopping criterion is satisfied. From that point and after several training and testing, a result will be obtained which show the predicted classified result from that model. 
In our case, a model was developed to detect downhole leak through utilizing 5000 set of data for four different oil producer wells. These data are: casing inner diameter (CID), spacing phase (SP), downhole frequency (FREQ), pipe thickness (ETHK), gamma ray (GR), downhole temperature (GTEM), and finally ratio of gamma ray to borehole pressure (RGR). After that, quality check was done by filtering unreadable log data. Then, data was evaluated by regression to find any fitting relationship between input and target. However, since no relation was found, Artificial Intelligence was used to solve the complexity of the model. Decision tree model was the developed model to detect downhole leak. After training 70\% of the data and testing the remaining 30\% several times in three different scenarios for each well random selection, a model was developed to detect any future downhole leak. The testing results from the developed model for the 12 conducted scenarios achieved $93 \%$ and above accuracy. For each well, three scenarios were implemented which are:

Run-A: All data is used in input to be classified as either leak as "1" or no leak as " 0 ".

Run-B: Allow the model to select the most reliable data random selection as per program intelligence and to be classified as either leak or no leak.

Run-C: I only use the most important data as detailed previously which are (Temperature, Frequency, and Pipe Thickness) to be classified as leak or no leak.

Next section shows decision tree classification algorithm results for the four wells with twelve running scenarios. Three scenarios were performed for each well for the purpose of leak detection. Moreover, the obtained results were validated through training and testing these data on other wells to check the accuracy of the obtained results. 


\section{CHAPTER 4}

\section{RESULTS AND DISCUSSION}

\subsection{Rigless Approach for Downhole Leak detection}

This section is divided into two subsections which are: integrated interpretation and model development finding. The results of these subsections will be discussed in detail as follow:

\subsubsection{Integrated Interpretation Results}

At both flowing and static conditions: temperature, noise log and corrosion surveys were conducted using a slick-line unit. The temperature tool recorded: pressure, temperature, gamma ray, casing collar locator, density, water hold-up and noise log. The static temperature survey was also conducted from surface to $\mathrm{TD}=5,680 \mathrm{ft}$. Noise $\log$ at shut-in condition before and after bleed off TCA or CCA was conducted between TD to surface while stationary data was collected at each stopping point. Figure 4.1 shows overview about the conducted logs from surface to TD with the following sequence interpretations from left to right; casing collar locater, logging speed, water hold up, static pressure, static temperature, density, and shut-in noise log.

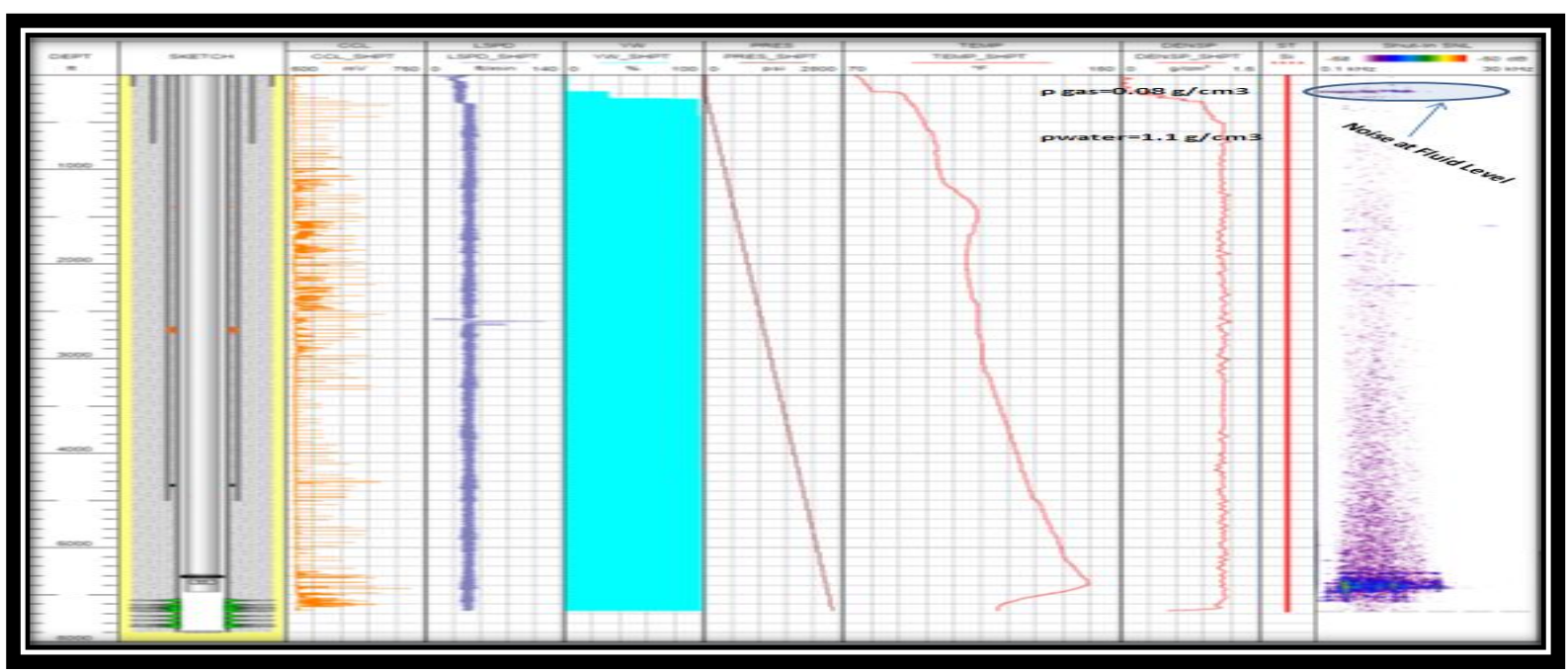

Figure 4.1: Interpretation Overview from surface to TD 
Figure 4.2 shows the full interpretation from surface to total depth of the conducted logs. These $\operatorname{logs}$ are conducted to compare the shut-in condition with the bleed off CCA. The temperature surveys consist of up and down passes. Interpretation was performed for a down pass run at a speed of $\pm 45 \mathrm{ft} / \mathrm{min}$ from the surface to 5,670 $\mathrm{ft}$. Some anomalies were notices and will be discuss in detail in the other enlarge plot.

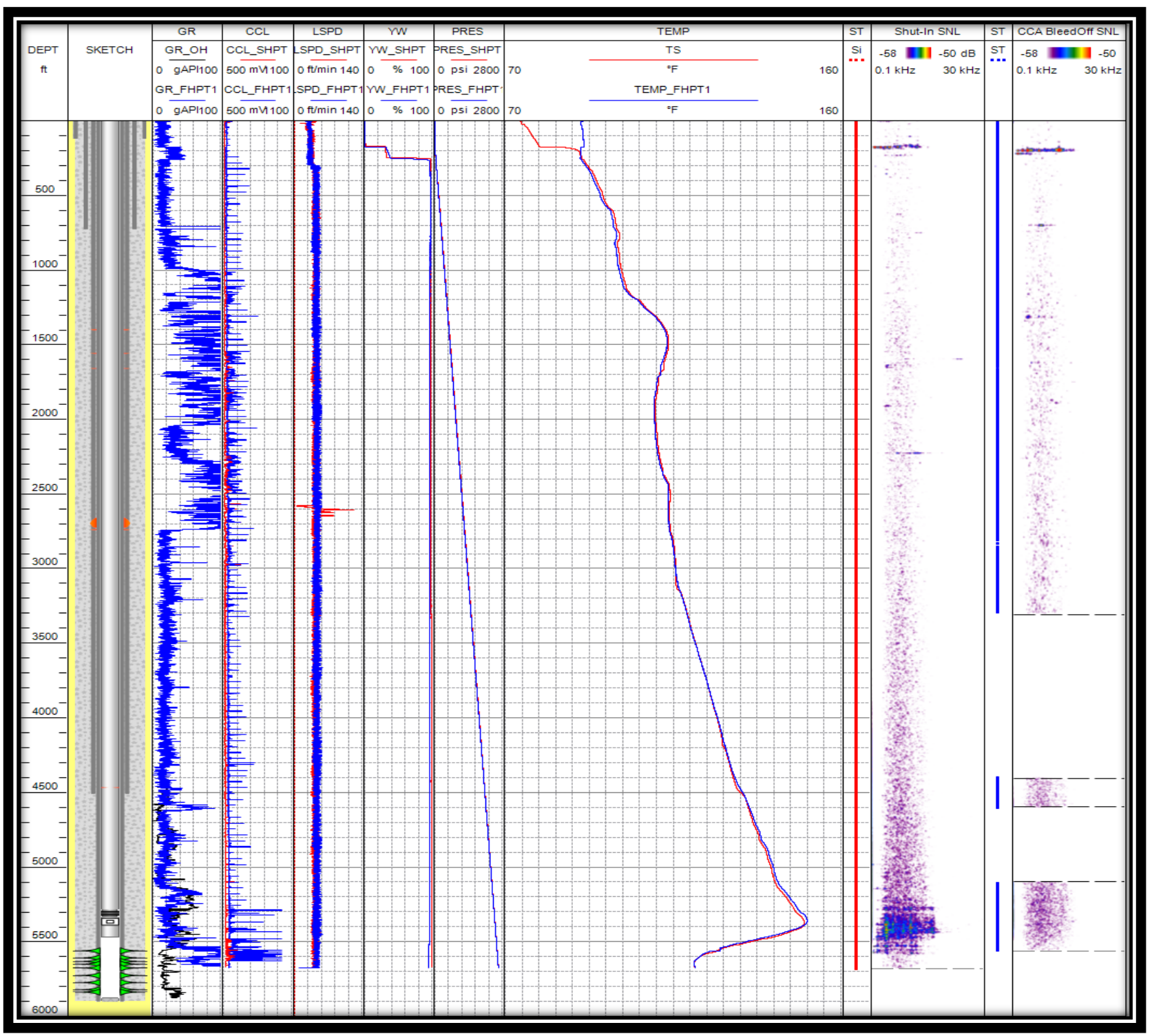

Figure 4.2: Shut-in Noise Log Interpretation before and after bleed off CCA

Figure 4.3 also shows the full interpretation from surface to total depth for the conducted logs. This plot shows some anomalies which are noticed and highlighted in the below plot. 
In these surveys, I am comparing the shut-in condition with the bleed off TCA. During the first measurement, the temperature at top of perforated zone $5,540 \mathrm{ft}$ was $128^{\circ} \mathrm{F}$. During the TCA bleed-off measurement, the flowing pressure at that depth was 2,580 psi. A pressure drop of 10 psi indicates communication between tubing and casing annulus. This will be discussed in detail in the other enlarge figures.

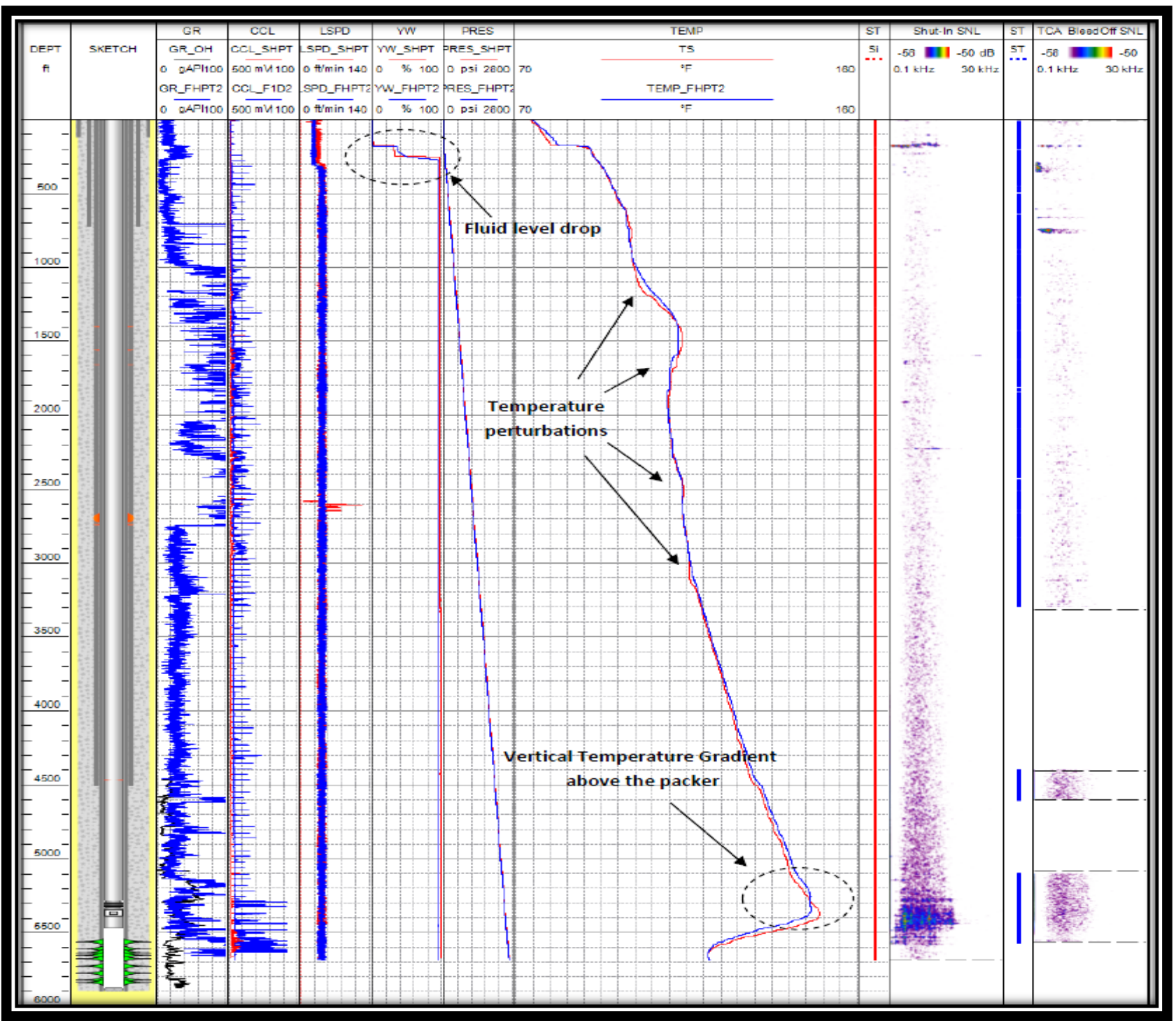

Figure 4.3: Shut-in Noise Log Interpretation before and after bleed off TCA

Fig 4.4 is a zoom of fluid separation which shows that high amplitude of noise in a wide frequency range was detected in the interval of 180-300 ft and could be due to shallow fluid 
inside the tubing. This was detected through the conducted logs. The noticed density and water holdup of these surveys were as follow: Between 0-195ft, the noticed gas density was 0.03 $\mathrm{g} / \mathrm{cm} 3$ with water holdup of $0.65 \%$. Moreover, below $277 \mathrm{ft}$ to down, the noticed water density was $1.1 \mathrm{~g} / \mathrm{cm} 3$ with $100 \%$ water hold up.

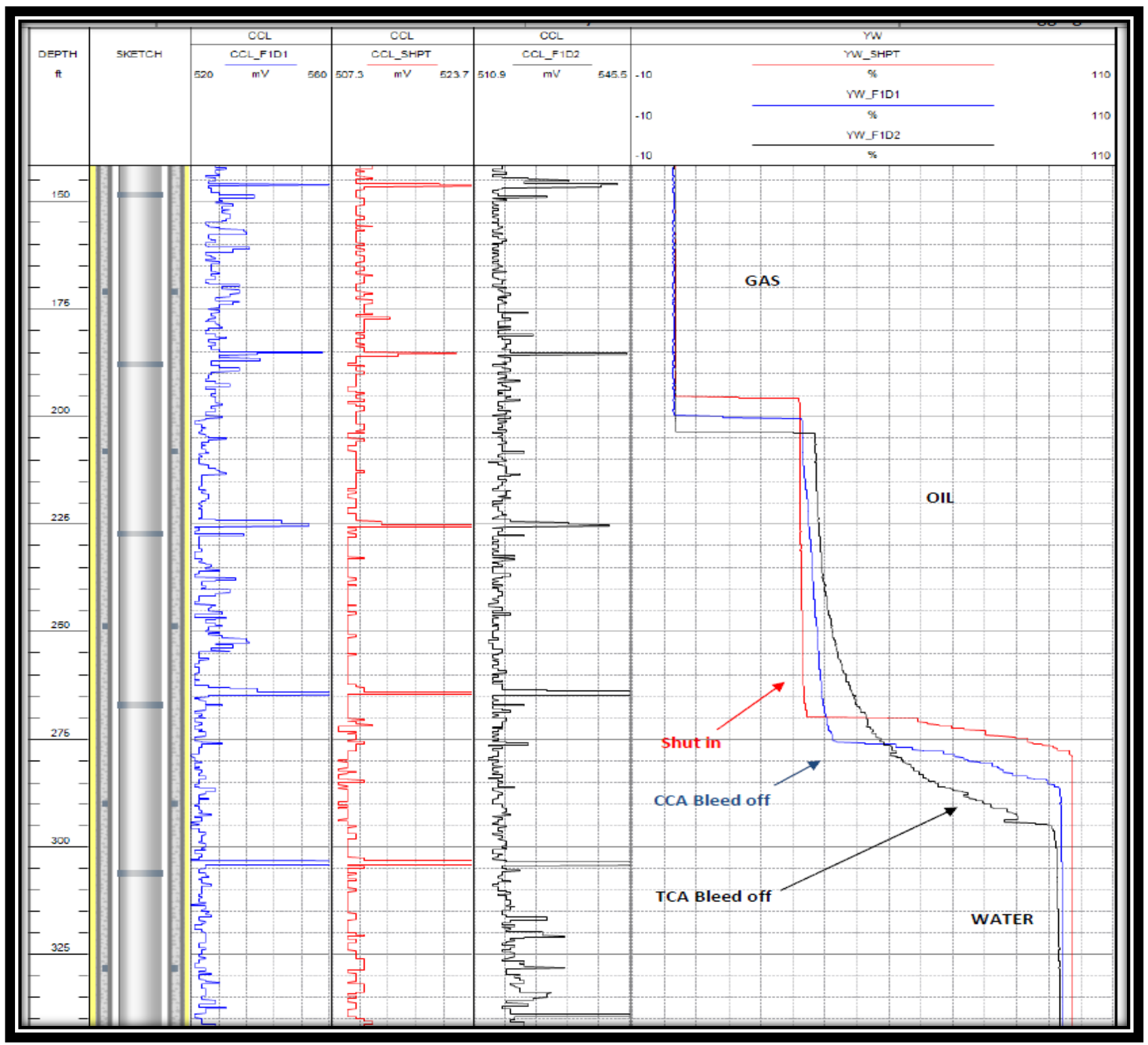

Figure 4.4: Fluid Level

Fig 4.5 is another zoom but for an area slightly above the 7', packer. The measured temperature during the bleed-off survey for CCA is slightly varied from the static survey which is a normal 
survey as of this figure. However, a change in the temperature gradient slightly above the 7', packer zone confirms there is a packer leak which was identified also after bleeding-off TCA. The below noticed temperature trend can be explained as a cooling effect through gas expansion in TCA or injected water for many years.

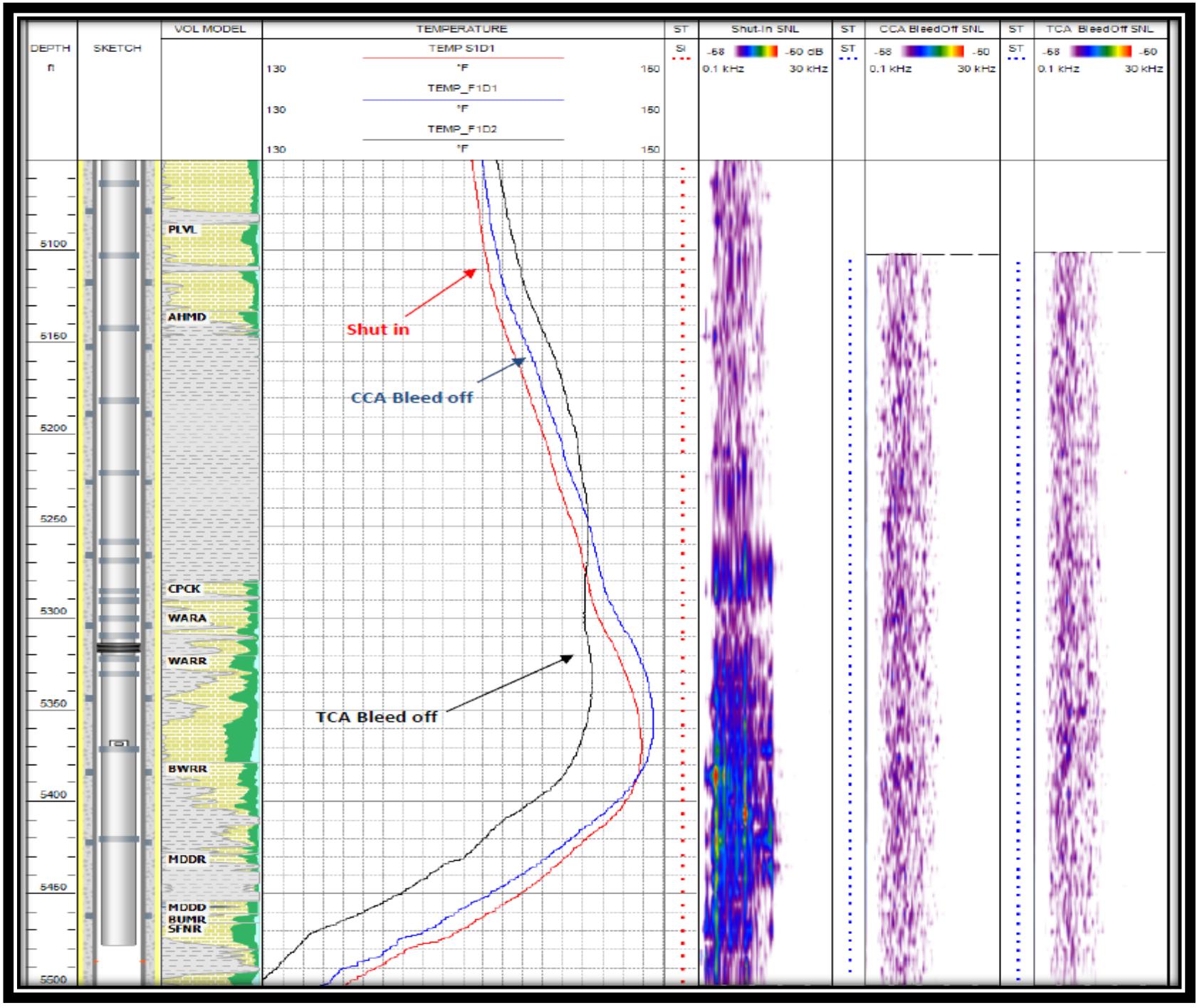

Figure 4.5: Zoom of Noise Log Interpretation at Shut-in, and after bleed off both CCA and TCA 
Fig 4.6 shows shallow minor noise that was detected in the interval of $1350 \mathrm{ft}$ and $1480 \mathrm{ft}$. Moreover, temperature anomaly was detected within the interval of 1,400-1,600 ft. As shown below there is no change in temperature gradient after bleeding-off tubing casing annulus which is indication of leak. These anomalies were detected by both noise and temperature which

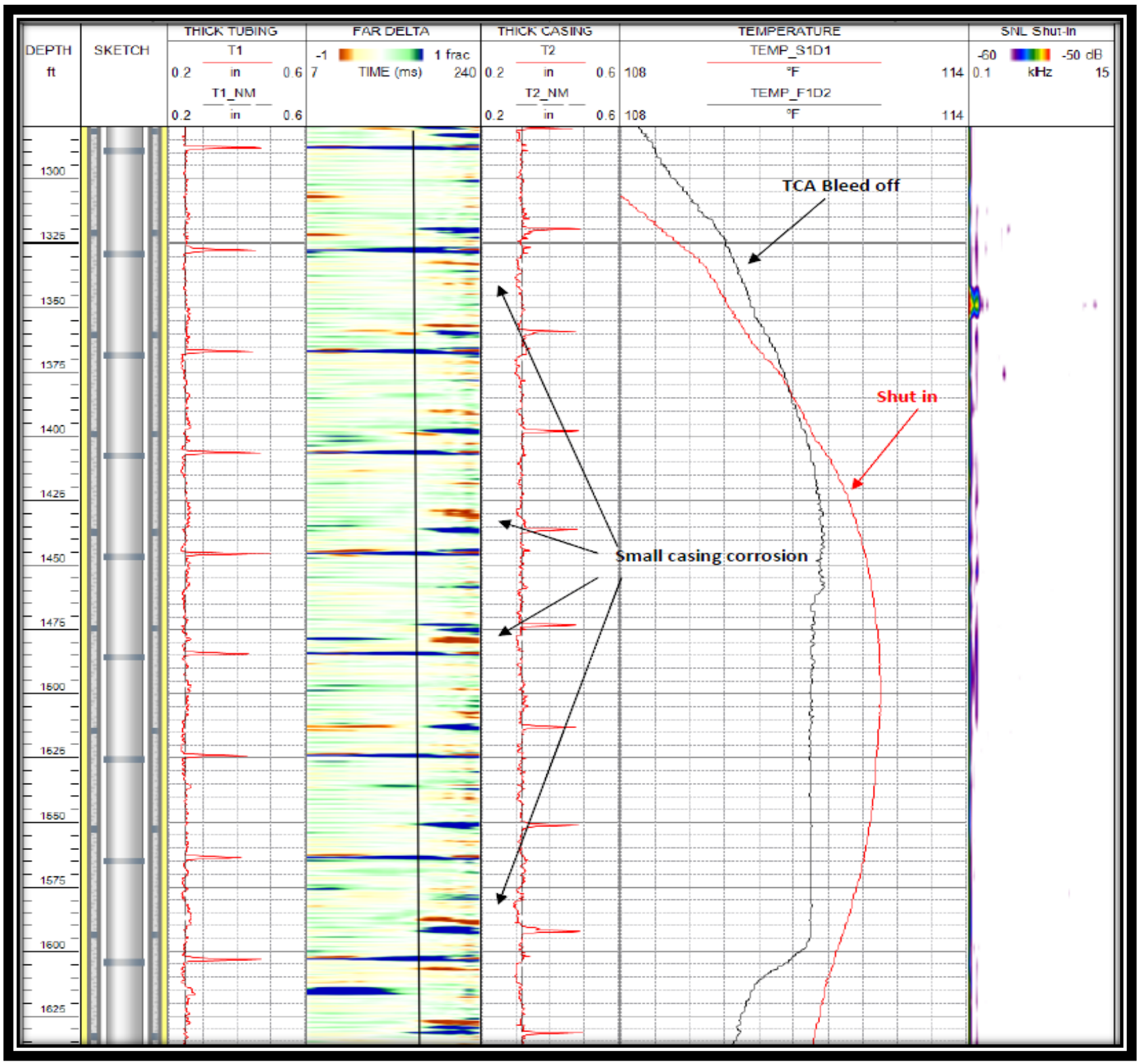

confirms tubing leakage in that area.

Figure 4.6: Integrated Interpretation of Casing, Tubing Corrosion and Shut-in Temperature, and the bleed TCA Temperature 
Moreover, a small noise was detected by the noise log at depth of 1,700' and 1,900' and 2250' ft. So, both Figures 4.6 and 4.7 confirm tubing is leakage in that depth. Also, the temperature curve at shut-in condition between the interval of 1,600 and $1,700 \mathrm{ft}$ is slightly differed from the bleed-off CCA temperature trend. In addition to that a small indication of noise was detected in same interval depth. This noise was also detected during shut-in condition at depths of 1,650 ft, $1,920 \mathrm{ft}$ and 2,230 ft which can be associated with shallow gas leaks.

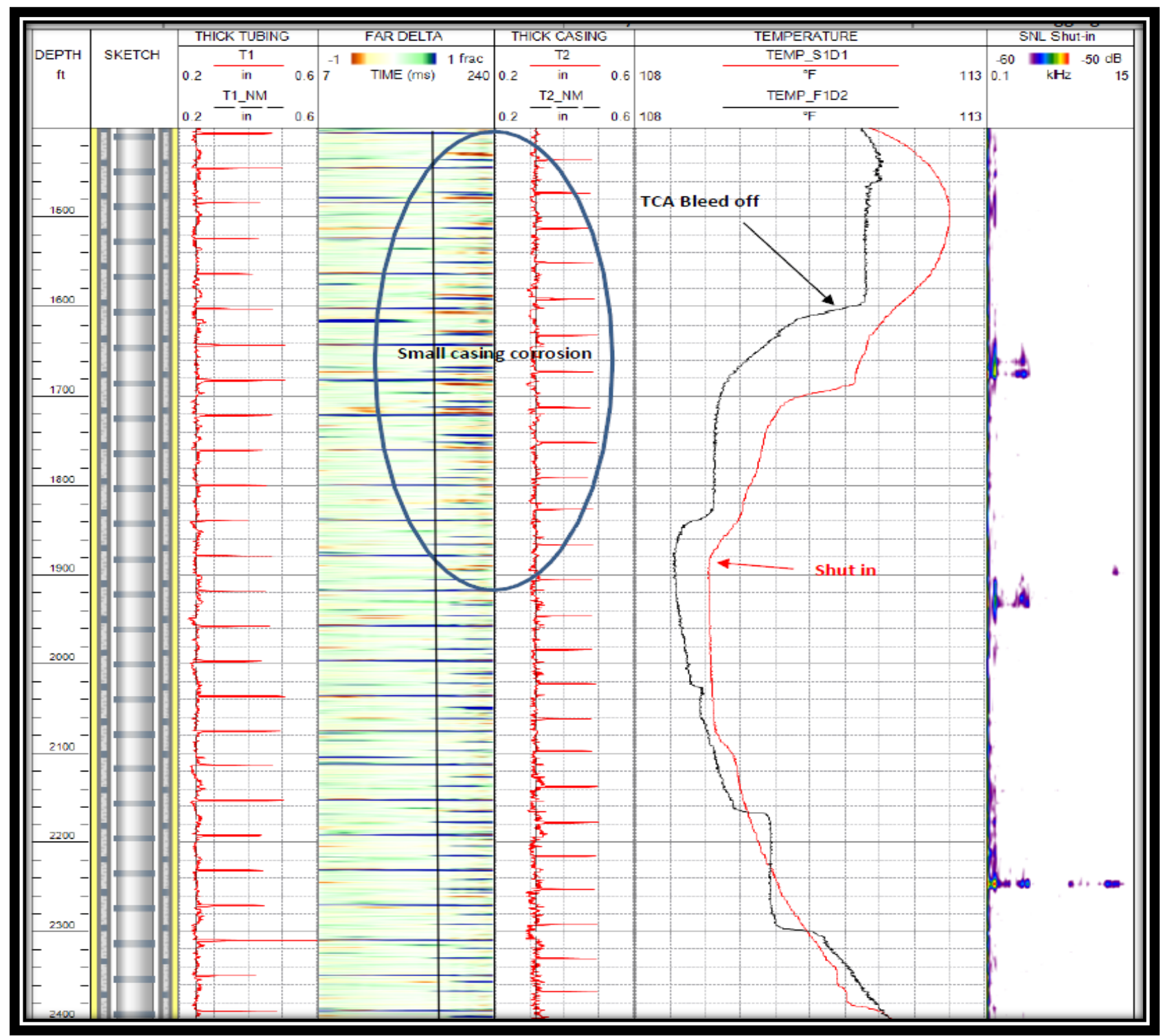

Figure 4.7: Integrated Interpretation of Casing, Tubing Corrosion, Shut-in Temperature, and the bleed TCA Temperature with noise log 
Fig 4.8 shows temperature gradient doesn't change in the interval of 2,450-2,730 during all conditions and characterized by fluid moving in that depth due to leaking zone. In the last three figures $4.6,4.7$, and 4.8 , the interval between 1,380 and $2,400 \mathrm{ft}$ contains many temperature alarms which are indication of many TCA leakages. These leakage zones were supported by both temperature and noise surveys. Moreover, corrosion was detected too in part of these intervals which support leakage occurrence.

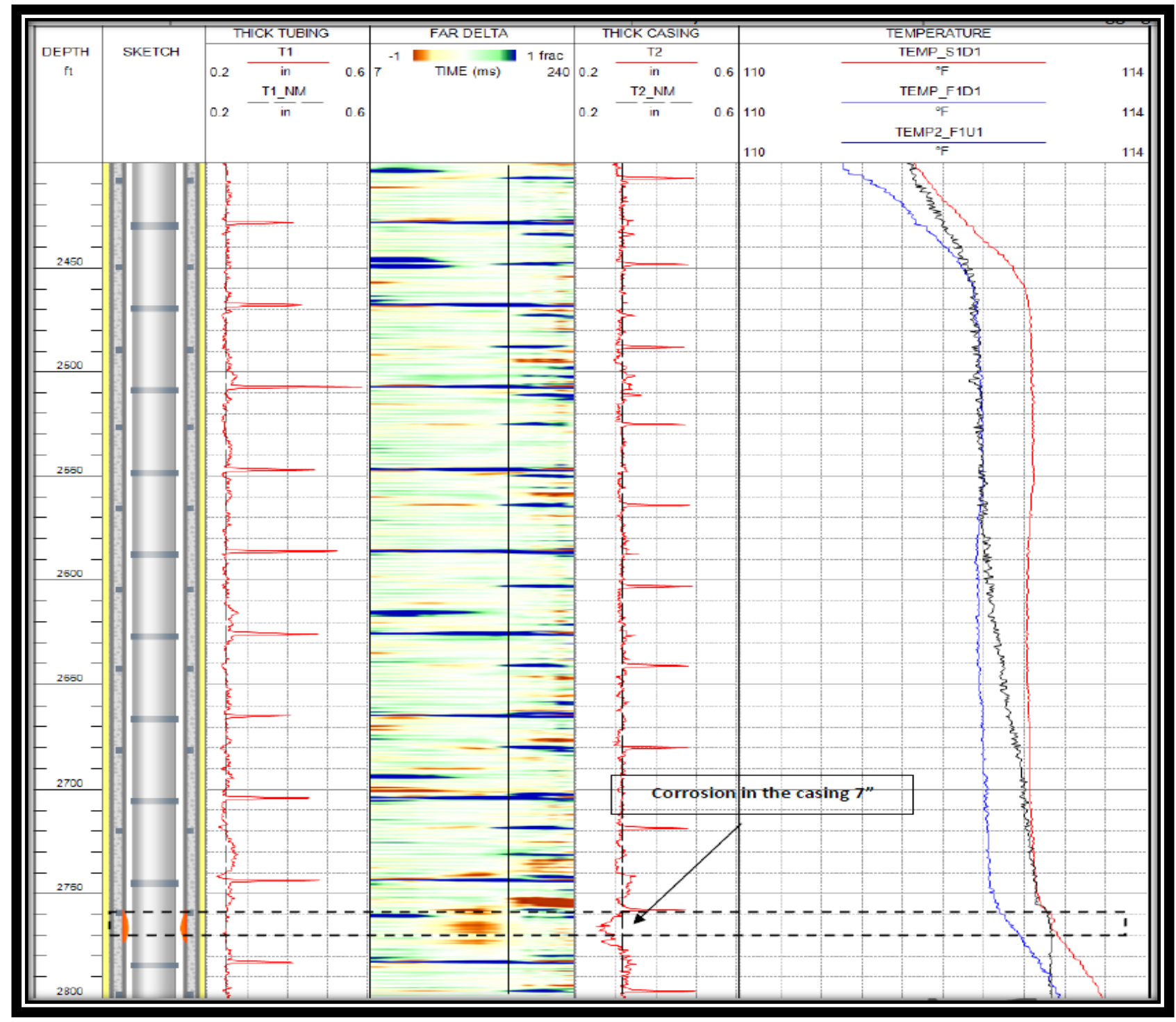

Figure 4.8: Integrated Interpretation of Casing, Tubing Corrosion, Shut-in Temperature, and the bleed off TCA and CCA Temperature 
Fig 4.9 shows corrosion spots which were noticed in 7 inch casing below tubing and above perforation as in the highlighted depths: 5480, 5505, and $5535 \mathrm{ft}$. In the depths, a noticed decreased in the original thickness of the 7 inch casing through corrosion survey. However, there is normal temperate which is indication of corrosion without a leak.

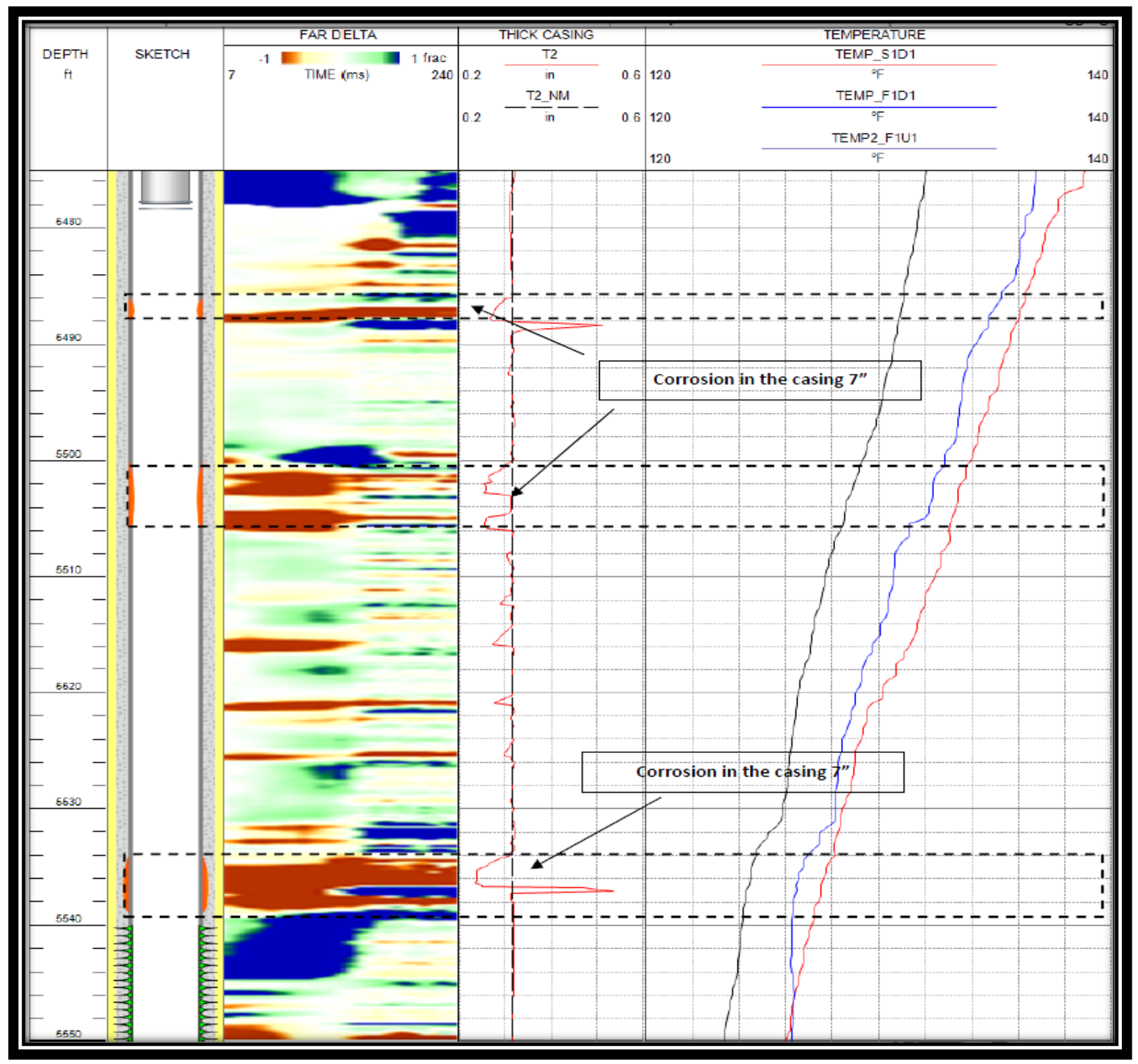

Figure 4.9: Integrated Interpretation of Tubing, Casing Corrosion, Shut-in Temperature, and the bleed off TCA and CCA Temperature

So, from that point, fig-4.10 also shows corrosion spots were noticed in $4-1 / 2$ ' ' tubing in these following depths: at $1950 \mathrm{ft}$, and at casing collar at $2000 \mathrm{ft}$ depth. Moreover, after 
comparing the sigma of corrosion with temperature and noise surveys trend in the same depths, it has been concluded that these areas had a tubing leak due to irregularity in temperature and noise surveys. This also supported by the interpretation of corrosion since there is a drop in the thickness of tubing.

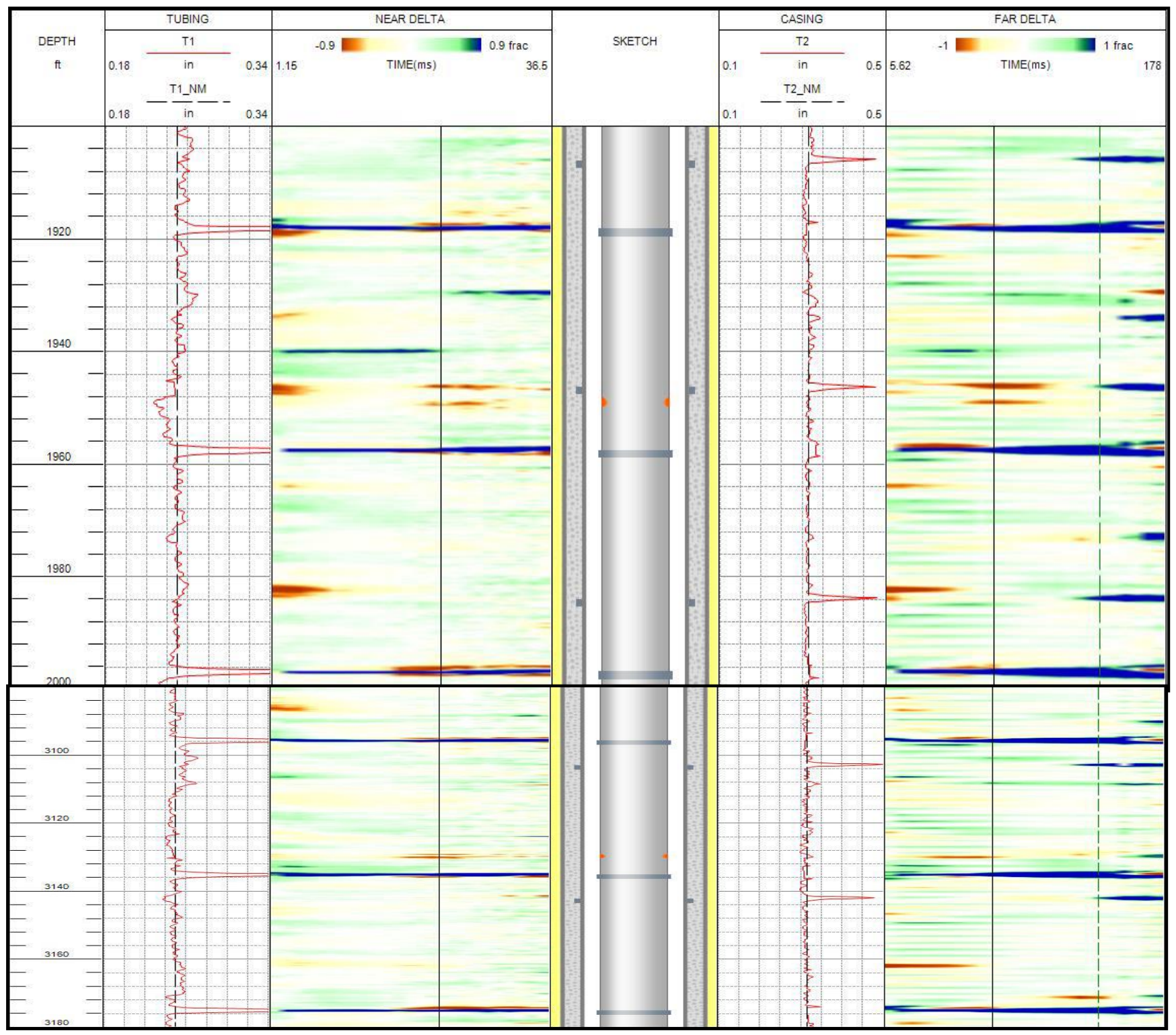

Figure 4.10: Integrated Interpretation of Casing Corrosion and Tubing

Fig 4.11 shows corrosion spots which were noticed in 4-1/2', tubing in the following depths: $3495,3515,4440$ and $4470 \mathrm{ft}$ depth. Usually, corrosion log is needed to know how 
suffer the corrosion in the pipe. The pipe can be corroded internally, externally or from both sides. Having corroded casing or tubing doesn't mean the pipe is leaking but it might mean the pipe is going to leak later in future.

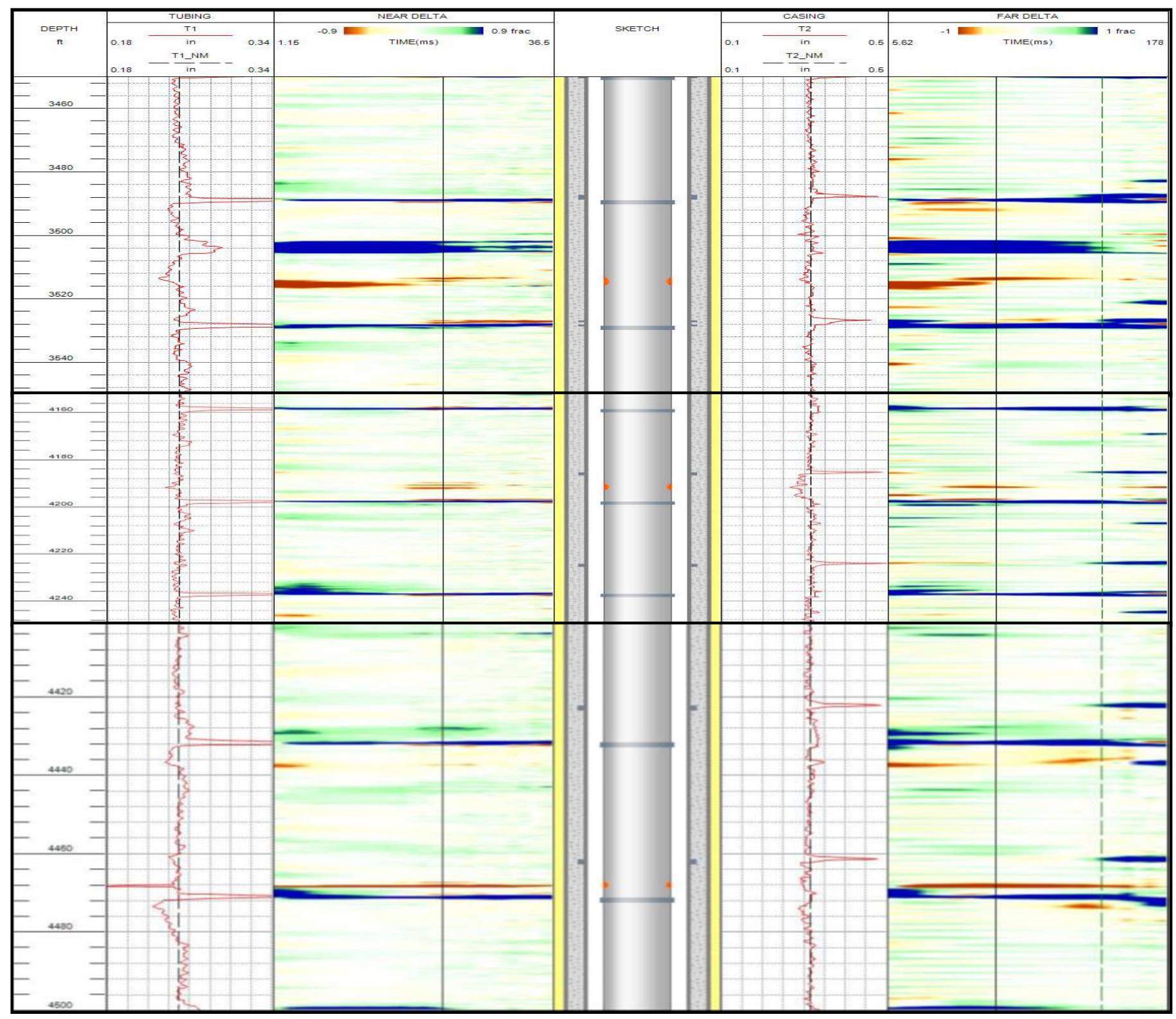

Figure 4.11: Integrated Interpretation of Casing Corrosion and Tubing

By analyzing the previous results of the conducted logs, we concluded that: 


\section{Temperature Surveys}

The recognized temperature in both shut-in and flowing conditions which was in shallow area within 190-280 was due to fluid level inside tubing. Moreover, another shallow zone was recognized in the interval of 1600-2300 ft with an indication of leak in the location depth of 1,350 and 1,380 ft which might be gas source of hydrogen sulfide. Also, the noticed temperature survey at 7', packer proved packer and/or tubing leak in the area of active life reservoir. Moreover, after comparing temperature surveys at shut-in condition and bleed-off TCA as in figure 4.5, this confirmed that there was a tubing leakage in $5250 \mathrm{ft}$ and a small leakage at 7" packer which allow some fluid to segregate.

\section{Noise Surveys}

The recognized noise in both shut-in and flowing conditions in shallow area are due to fluid level inside tubing. Moreover, another shallow noise was identified in the interval of $1300 \mathrm{ft}$ and from 1,650 to 2,300 ft which might be hydrogen sulfide zone. Also, a noise was registered in part of top of perforated zone and at 7' packer which is due packer leak behind life perforated reservoir area. Moreover, after comparing temperature survey at shut-in condition and after bleeding off TCA as in figure 4.5, this confirms the existence of TCA leak at 5,250 ft. In addition, a small leak at 7'' packer was identified which allowed some segregation of fluid in this area. This analysis of noise log is matching with the previous analysis of temperature survey that identified a small packer leak during bleed off TCA.

\section{Corrosion Survey}

After static temperature measurement was taken, the well was shut-in for wellbore temperature and pressure stabilization. Later on, corrosion survey was run from a depth of $5,550 \mathrm{ft}$ to the surface at a slow speed of $15 \mathrm{ft} / \mathrm{min}$. Corrosion data was correlated with CCL 
data that was obtained during temperature survey. Temperature data was also correlated with the original open-hole GR of this well. Metal loss and corrosion proportion is averaged to sensor length which is 5 in for tubing and 13 in for casing for Well-A.

A delta reading is the time responds for corrosion tool to detect and get respond of corrosion proportion which is simplified in this research by either red for amplitudes lower than the pipe standard or in blue for amplitudes higher than that. Identifying corrosion pipe zone consists of; determination of electromagnetic properties of a steel pipe and metal barrier thickness in depth. The recorded response is a function of electrical conductivity, magnetic permeability and the geometry of the surrounding medium. It is assumed that the response is entirely defined by metal completion components and is almost unaffected by the surrounding rocks or fluids, which is in line with the great difference between the electromagnetic properties of metals, rocks and fluids. Therefore, the only variables are electrical conductivity, magnetic permeability and the thicknesses of the first and second barriers. Other parameters are assumed constant.

Corrosion is needed to know how suffer the corrosion in pipe steel. The tubing and first casing can be corroded internally, externally or both. Having corroded casing or tubing doesn't mean the pipe is leaking but it might mean the pipe is going to leak later in future. So, from those points, corrosion spots were noticed in $4-1 / 2$ ' tubing in the following depths; 1150, 1250, 1950, 3495, 3515, 4190, and $4470 \mathrm{ft}$ depth. Moreover, corrosion spots in 7" casing was noticed in some intervals between 1400-1900 ft and in the depth of 2300 'and $2760 \mathrm{ft}$ and directly above perforation and packer.

The corrosion survey with temperature and noise logs in the interval of $2,170-2,290 \mathrm{ft}$ 
clearly shows collars that might have metal losses but not clearly capture. However, there is regularity between the conducted logs at that area which is one of the corded or leaking zones. So, these collars, such as in 2,250-2,255 $\mathrm{ft}$ has metal losses in or near the collar area. Moreover, the log shows corrosion in 7', casing with indication of leak in tubing within the interval of 1400 and $2300 \mathrm{ft}$. All these points will be covered in the next section of this study to look at the effect of this integrated approached of logging and interpretation for detecting minor downhole leak.

\subsubsection{Rigless Model Development Results}

The developed model confirms the previous integrated analysis. Still there is a minor difference between this model and the integrated model. This difference appeared due to that what is predicted numerically is usually more accurate compare to the manual or normal analyses. However, still whatever product is produced by that machine required human intelligence to confirm the validity of that product. The maximum noticed frequency in this well was $18 \mathrm{KHZ}$ and the minimum was zero which is indication of good downhole condition. So, with this classification $18 \mathrm{KHZ}$ divided by 2 is $9 \mathrm{KHZ}$. In this case, if the frequency in a specific depth is greater than or equal to $9 \mathrm{KHZ}$, this will confirm the presence of leak only if it is supported by the presence of both corrosion and temperature irregularity. For example;

- At depth of $5290 \mathrm{ft}$ which is slightly above the packer, it was noticed a packer leak due to the measure casing thickness was 0.234 inch while the actual casing thickness is 0.634 inch. This was indication of corrosion and supported by irregularity in both noise and temperature surveys. The noticed noise was due to packer not sealing well in that depth while the noticed cooling trend in the temperature was due to many years of 
injection in same formation.

- At depth of $2763 \mathrm{ft}$, corrosion was noticed due to the measure tubing thickness was 0.27 inch while the actual thickness of that tubing is 0.542 inch. After checking temperature anomalies, it was noticed that temperature trend was not changed with depth which was indication of tubing leakage. The noticed frequency at that depth was $9 \mathrm{KHZ}$ which support the presence of tubing leakage.

These depths were confirmed by integrated approach and rig approach in addition to this developed model. Finally, these are the highlighted depths by the developed model:

$>$ For tubing: from $2763 \mathrm{ft}-2775 \mathrm{ft}$ with presences of leak and from $4190 \mathrm{ft}-$ $4195 \mathrm{ft}$ with presences of corrosion only. In addition, a small leak interval was noticed in 1352, 1382, 1684, and $1905 \mathrm{ft}$.

For casing, above the packer from $5290 \mathrm{ft}-5298 \mathrm{ft}$ which is due to 7' ' packer is not sealing. Also, in the interval of $5369 \mathrm{ft}$ directly above the perforation only corrosion was noticed. 


\subsection{Rig Approach for Detection and Fixing Downhole Leak}

This part is divided into two visible inspection areas which are surface inspection for tubing and pressure test for casing. The purposed of these two items are to check mechanically the integrity of downhole completion.

\section{- Tuning inspection:}

The utilized rig was used only to fix the mechanical leakage problems. After pulling tubing out of hole, several leak areas were identified through surface inspection for tubing. These major leakage tubing depths were at the following depths as follow; 1350, 1380, 1680, 1900, 1920, 2240, 2280, and $2770 \mathrm{ft}$. Below are some pictures of tubing after being inspected at surface.

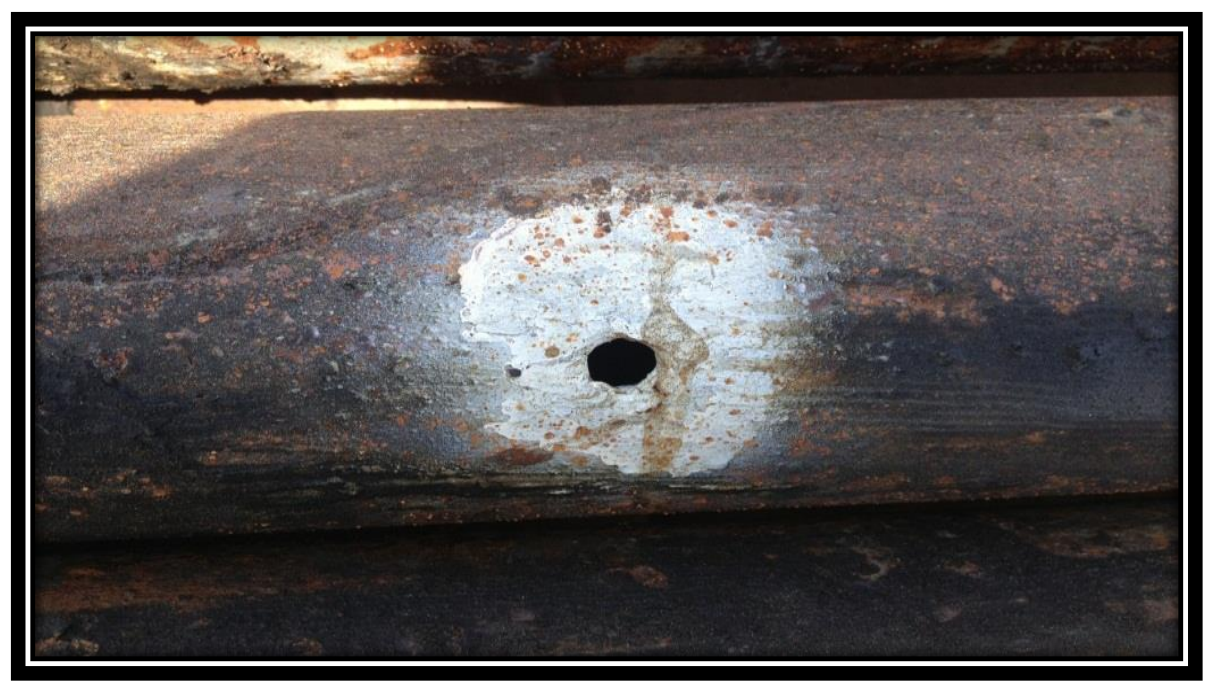

Figure 4.12: Tubing at Depth of $1350 \mathrm{ft}$ 


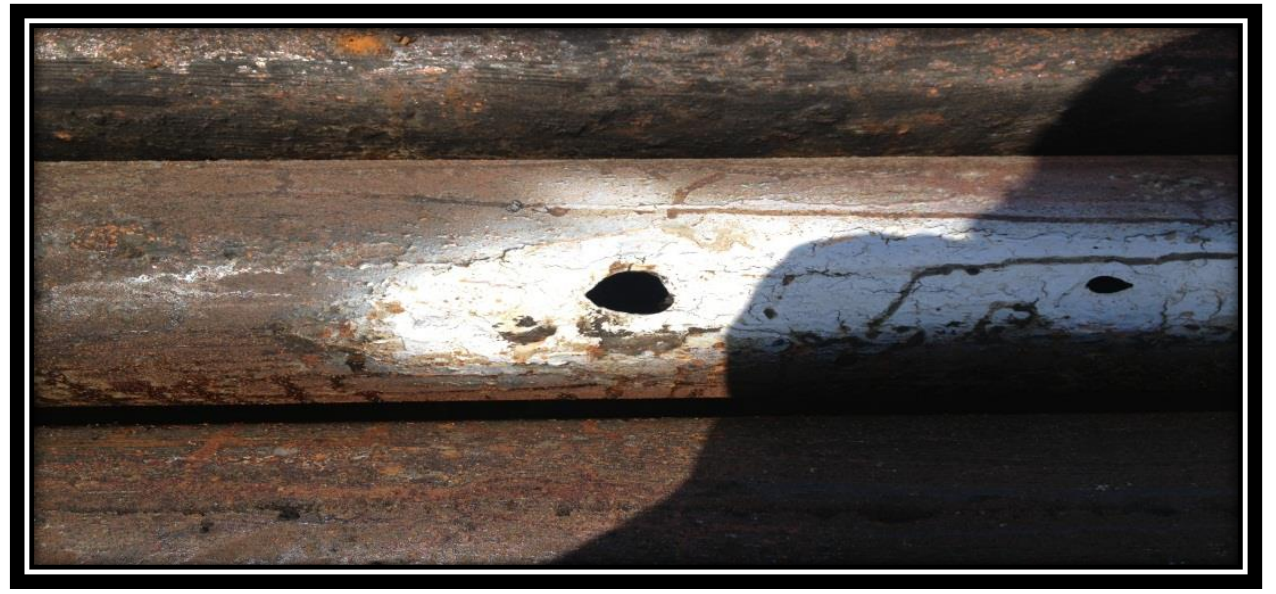

Figure 4.13: Tubing at Depth of $1380 \mathrm{ft}$

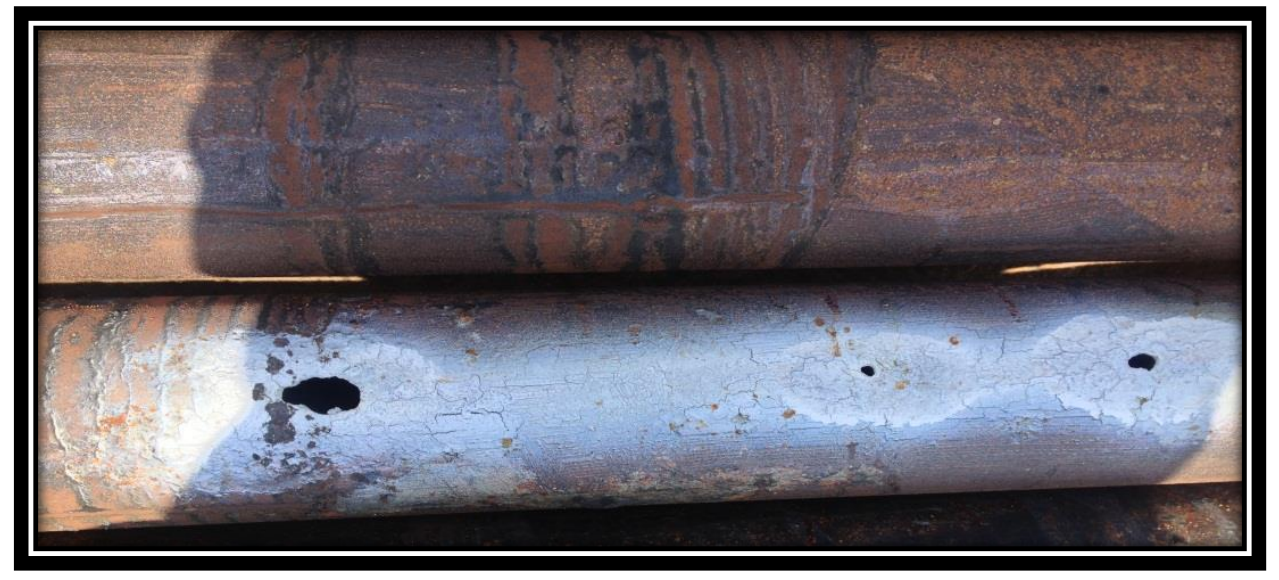

Figure 4.14: Tubing at Depth of $1900 \mathrm{ft}$

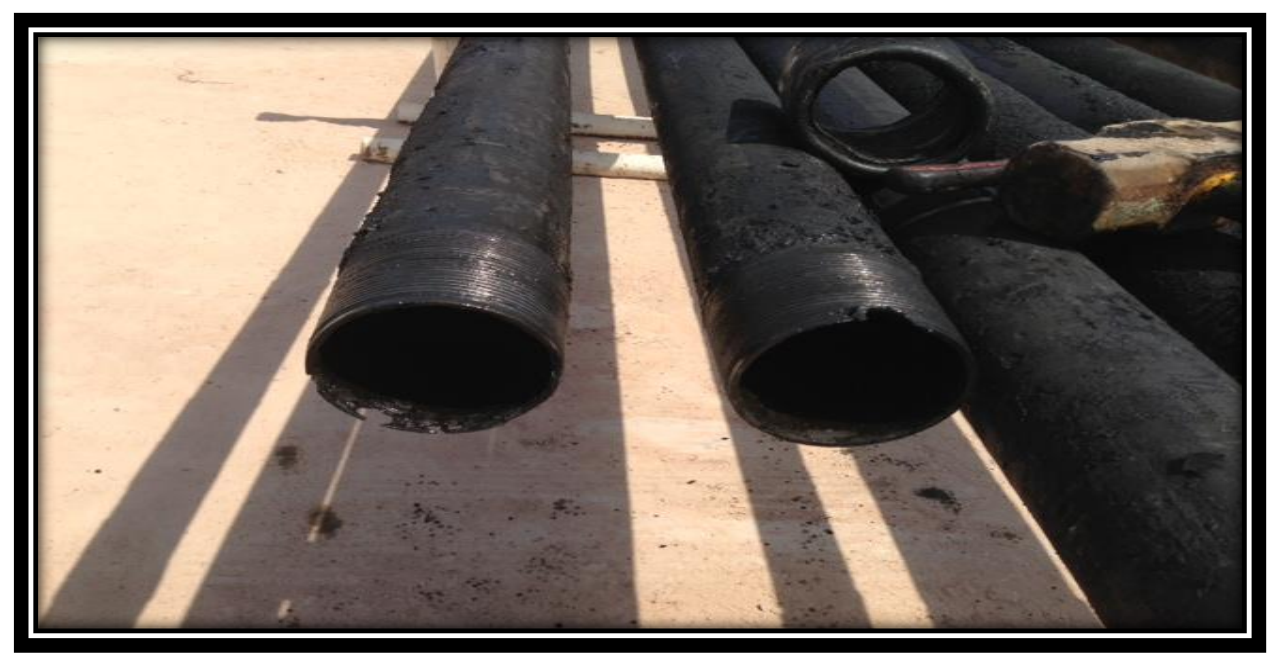

Figure 4.15: Tubing Eroded at Connection Joint 


\section{- Pressure Test for Casing}

Pressure test for casing is needed to evaluate the mechanical integrity of casing. The well has a downhole mechanical integrity if there is no significant leak in its casing. The mechanical integrity of the well casing is evaluated by conducting a hydraulic pressure test and monitoring pressure loss during that test. Casing pressure tests is run in accordance with the following procedure:

1. Calculate casing test pressures. The minimum wellhead casing test pressure shall be the maximum allowable operating injection pressure at the wellhead.

2. Depressurize the well.

3. Remove any tubing strings from the well and isolate perforation.

4. Set a retrievable bridge plug or packer immediately above the cavern for the purpose of pressure testing the casing. The packer or plug must be capable of making a tight seal to allow the casing to be hydraulically pressure tested.

5. Start the casing pressure test by pumping fresh water

Note: well should be isolate before introducing pressure to the casing.

6. Functioning pressure gauges that will be used to monitor the tested pressure in the beginning of the test.

7. Conduct the test of each stage of interval for a minimum half hour.

8. Record the data and if pressure is reduced more than $5 \%$ of the initial test pressure is not acceptable and may indicate the well is leaking.

9. If a satisfactory test is not obtained, remove the well from service until corrective action has been taken. Determine the location of the casing leak and evaluate any impact to the environment. The rig man is required to submit an environmental remediation plan, including corrective action when it is needed. Below is example of the mechanical integrity test table. 
Table 4.1: Example of Mechanical Integrity Test Table

\begin{tabular}{|l|l|}
\hline \multicolumn{2}{|c|}{ Mechanical Integrity Test Results } \\
\hline Test results were: & Not Satisfactory: \\
\hline Satisfactory: & \\
\hline \hline Type of liquid Pressurized: & \\
\hline Method Used to Pressurized: & End Time: \\
\hline Surface testing Pressure: & \\
\hline Time (24 HR) Start: & \% of Pressure loss/gain \\
\hline Pressure (psig) & \\
\hline amount of Pressure loss/gain (Psig) & \\
\hline Tested Casing & \multicolumn{1}{|c|}{ Testing Gauge Data } \\
\hline The Bottom of the tested Interval set at & \\
\hline Depth of tested interval & \multicolumn{2}{|c|}{} \\
\hline Total bottom to Top interval & \\
\hline \multicolumn{2}{|c|}{ Mechanical Integrity Test Results } \\
\hline & Not Satisfactory: \\
\hline Demonstration test gauge functioning: & \\
\hline Calibration of gauge provided & \\
\hline Demonstration total hydraulic test & \\
\hline Serial Number of Test Gauge & \\
\hline \multicolumn{2}{|c|}{} \\
\hline Test results were: \\
\hline Satisfactory: & \\
\hline
\end{tabular}

For the study case, the casing was tested with 600 psig pressure through using 7" RTTS packer up to down every $1000 \mathrm{ft}$. This step was done after isolating the perforations. The result of this pressure showed the casing only corroded without a leak. Through further evaluation of corrosion, noise, temperature $\operatorname{logs}$ and the original $\mathrm{CBL} \log$ which was conducted during the drilling time of this well, decision made to spot cement plug in a weak casing interval from depth of 1260 to $2700 \mathrm{ft}$. After spot G-cement plug, expendable liner was set from 1200 to $2800 \mathrm{ft}$. Moreover, the liner was tested to the design pressure which shows that it is holding pressure. This liner was put to avoid any future leak development in that weak area. Moreover, a new 4-1/2"' tubing was run to replace the old corroded tubing. 


\subsection{Artificial Intelligence Results for Leak Detection}

The results of decision tree classification algorithm for the four selected candidates are shown as follow:

\section{- Decision Tree results for Well No.1:}

Table 4.2 shows the similarity between actual and predicted data. From that correlation or fitting, we can say that the best correlation was found between GTEM actual and predicted with about $20 \%$ fitting and the worst correlation was between CID predicted and actual.

Table 4.2: Regression Result for Well No.1

\begin{tabular}{lrrrrrrrr}
\hline \multicolumn{1}{c}{ Well } & \multicolumn{1}{c}{ CID } & \multicolumn{1}{c}{$\boldsymbol{S P}$} & FREQ & \multicolumn{1}{c}{ ETHK } & GR & GTEM & RGR & output \\
\hline CID & 1 & & & & & & & \\
SP & 0.220663 & 1 & & & & & & \\
FREQ & 0.214129 & 0.998862 & 1 & & & & & \\
ETHK & 0.228474 & 0.94569 & 0.945065 & 1 & & & & \\
GR & -0.08731 & -0.06265 & -0.06158 & -0.05392 & 1 & & \\
GTEM & -0.03886 & 0.058644 & 0.067305 & 0.06948 & 0.181734 & 1 & \\
RGR & -0.08085 & -0.05819 & -0.05715 & -0.04892 & 0.962485 & 0.168025 & 1 & \\
output & $\mathbf{0 . 0 3 9 4 8 4}$ & $\mathbf{- 0 . 1 3 1 1}$ & $\mathbf{- 0 . 1 4 3 5 3}$ & $\mathbf{- 0 . 1 4 7 1}$ & $\mathbf{- 0 . 0 6 9 1}$ & $\mathbf{- 0 . 1 9 8 5 8}$ & $\mathbf{- 0 . 0 6 3 9 8}$ & $\mathbf{1}$ \\
\hline
\end{tabular}

Since there is no strong relation between input and target which is either leak or no leak through regression, decision tree is used and the result is shown below for Well No.1:

The outcomes AI for this model were grouped as " 0 " and " 1 ":

Group number "0" indicates no leak which represents a total of 4,126 samples used in the developed model. However, group number "1" which represents leak has a total of 973 samples which is part of model development. 
Case 1: Using all input variables

Table 4.3: Data Classification for well No.1 case 1

\begin{tabular}{|l|c|}
\hline \multicolumn{1}{|c|}{ Input data summary } & No. \\
\hline No. of Sample & 5099 \\
\hline No. of features & 8 \\
\hline No. of Outcome Classes & 2 \\
\hline No. of Samples in Training set & 3570 \\
\hline No. of Samples in Testing set & 1529 \\
\hline
\end{tabular}

In case-1, a study was conducted to check the efficiency of the developed program for the entire well. The entire data shown in table 4.3 were considered for training and testing. The well was trained random selection with $70 \%$ of the data available followed by testing the remaining $30 \%$ data on the same well.

\section{$\underline{\text { ROC Curves, Training and Testing Results: }}$}

A Receiver Operating Characteristic (ROC) curve Sensitivity was plotted in a function of the Specificity for different cut-off points. Each point on the ROC curve represents a sensitivity-specificity pair which corresponding to a particular decision which are either leak or no leak. Figure-4.16 shows that the model was able to detect the area that is leaking and not leaking with $\mathrm{AUC}=1$ for both leaking and not leaking. Moreover, figure 4.17 shows model structure and development during the training and testing of case-1. The percentage of correct classification in this case in training is $100 \%$. Similarly, the percentage of correct classification for testing is $99.9 \%$. The obtained results for both testing and training are excellent which led to have a strong developed AI model. 

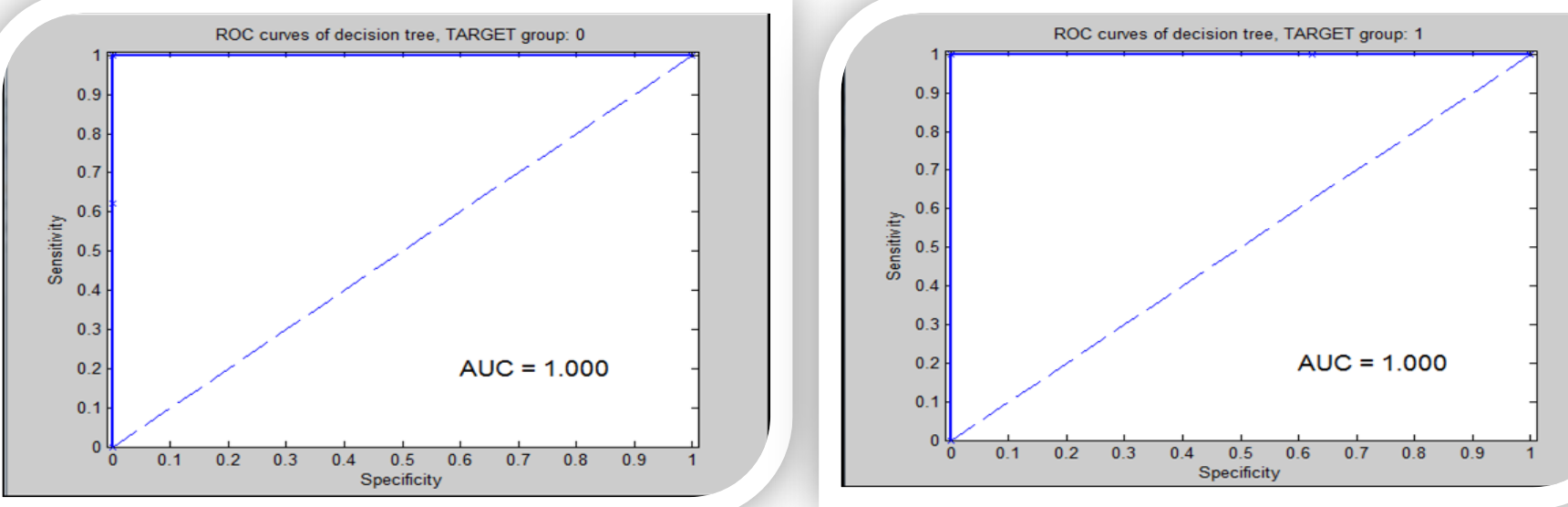

Figure 4.16: Area under Curve for Group $0 \& 1$ of case- 1 of Well No.1

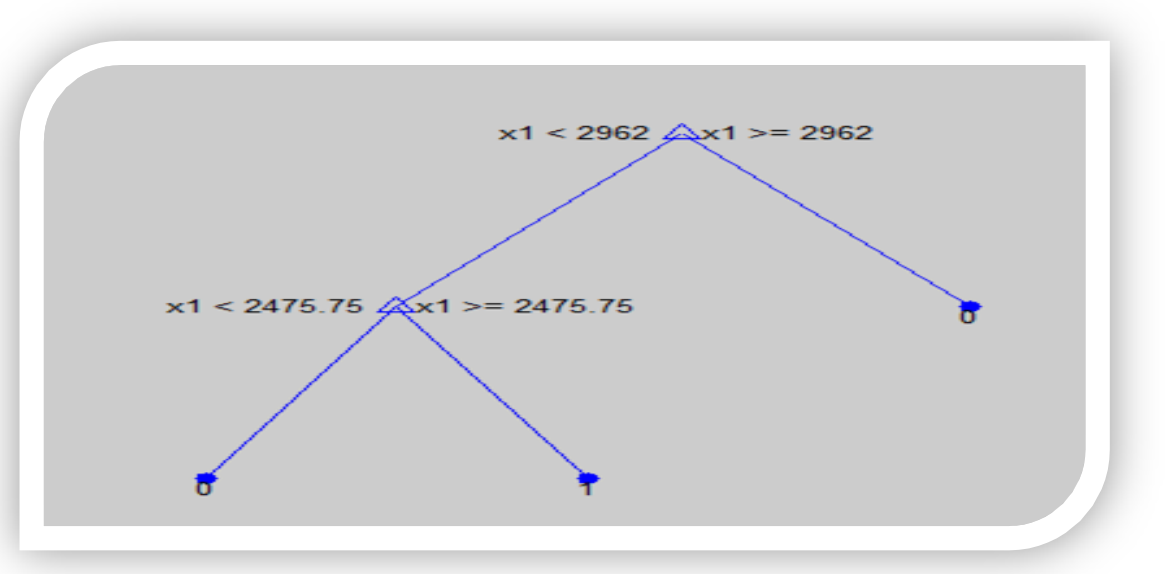

Figure 4.17: Decision Tree Model of case-1 of Well No.1

Case 2: using the most reliable data through random selection as per program intelligence

Table 4.4: Data Classification for well No.1 case 2

\begin{tabular}{|l|c|}
\hline \multicolumn{1}{|c|}{ Input data summary } & No. \\
\hline No. of Sample & 5099 \\
\hline No. of features & 5 \\
\hline No. of Outcome Classes & 2 \\
\hline No. of Samples in Training set & 3570 \\
\hline No. of Samples in Testing set & 1529 \\
\hline
\end{tabular}


In case-2, a study was conducted to check the efficiency of the developed program for the entire well. Out of the 8 sets of data and as per program intelligence, the number of features in this case was selected by program to be 5 as fallow: CID, SP, FREQ, ETHK, and GTEM. Table 4.4 shows that the well was trained using random selection with $70 \%$ of the data available followed by testing the remaining $30 \%$ of data on the same well.

\section{$\underline{\text { ROC Curves, Training and Testing Results: }}$}

Figure-4.18 showed that the model was able to detect AUC for both group 0 and 1with $\mathrm{AUC}=1$. Moreover, figure 4.19 shows model structure and development during the training and testing of case-2. The percentage of correct classification for case 2 in training was $100 \%$ and $99.9 \%$ for testing.
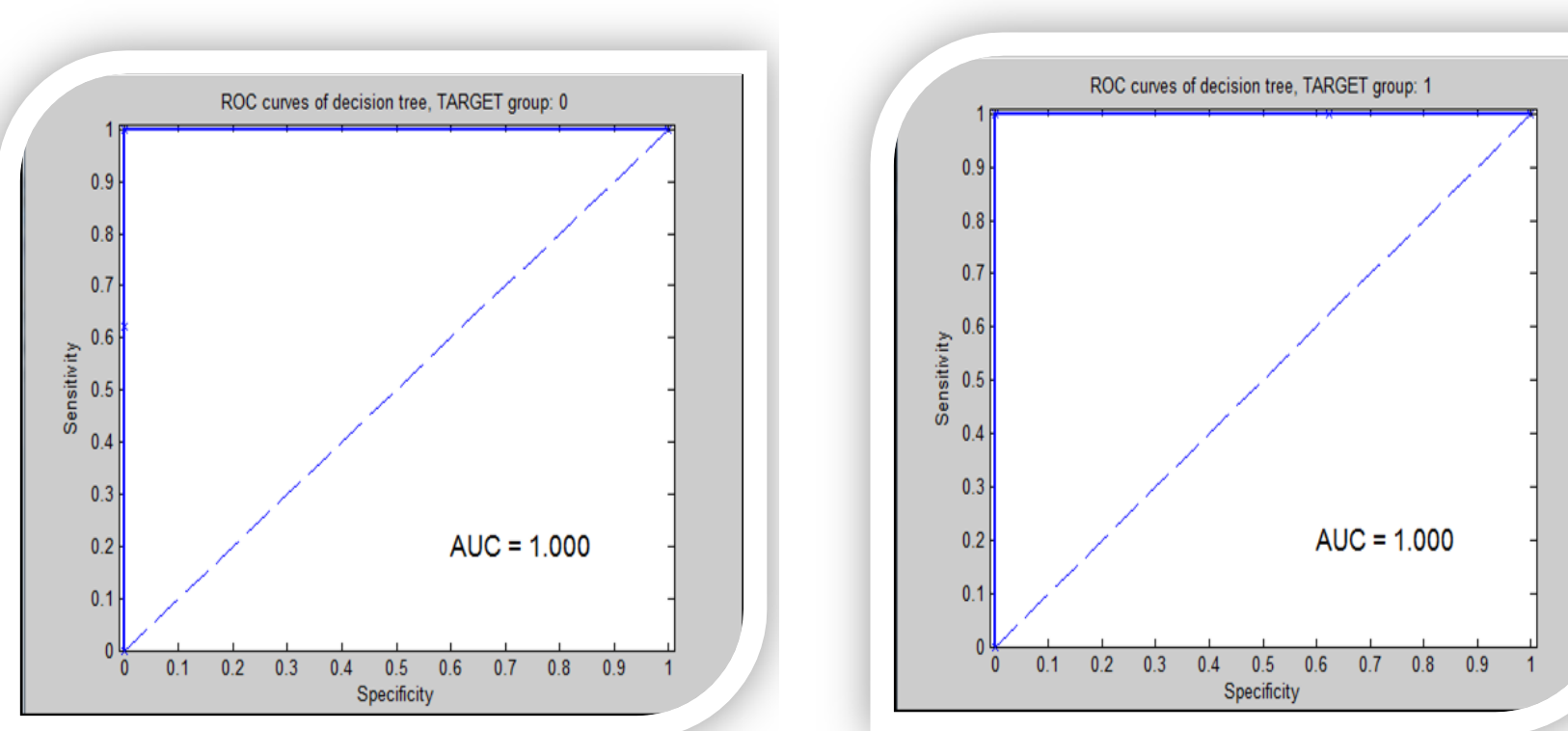

Figure 4.18: Area under Curve for Group 0 \& 1 of case- 2 of Well No.1 


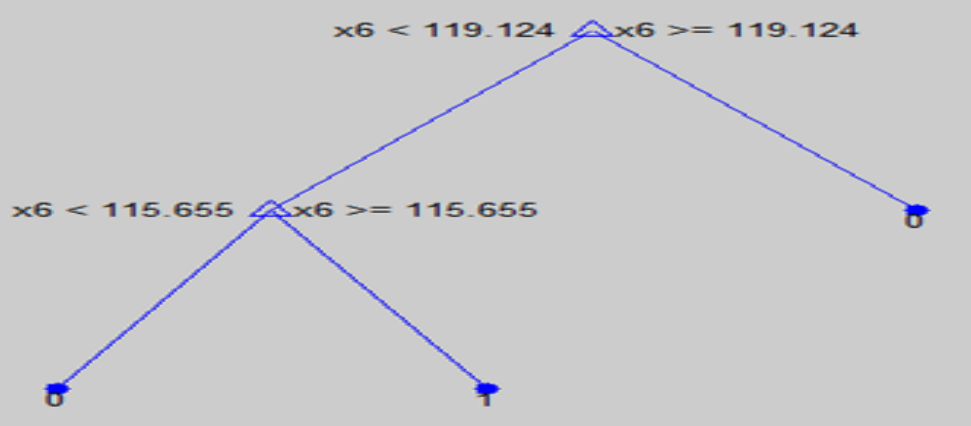

Figure 4.19: Decision Tree Model of case-2 of Well No.1

Case 3: Using the most reliable data (Frequency, Pipe Thickness, and Temperature)

Table 4.5: Data Classification for Well No.1 Case 3

\begin{tabular}{|l|c|}
\hline \multicolumn{1}{|c|}{ Input data summary } & No. \\
\hline No. of Sample & 5099 \\
\hline No. of features & 3 \\
\hline No. of Outcome Classes & 2 \\
\hline No. of Samples in Training set & 3570 \\
\hline No. of Samples in Testing set & 1529 \\
\hline
\end{tabular}

In case-3, a study was conducted to check the efficiency of the developed program for the entire well. Out of the 8 sets of data and as per integrated approach study, the number of features in this case was selected to be 3 as fallow: FREQ, ETHK, and GTEM. Table 4.5 shows that the well was trained random selection with $70 \%$ of the data available followed by testing the remaining $30 \%$ data on the same well. 


\section{$\underline{\text { ROC Curves, Training and Testing Results: }}$}

Figure-4.20 shows that the model was able to detect AUC for both group 0 and 1with AUC $=0.9952$. Moreover, figure 4.21 showed model structure and development during the training and testing of case-3. The percentage of correct classification for case 3 in training was $100 \%$ and $93.3 \%$ for testing.
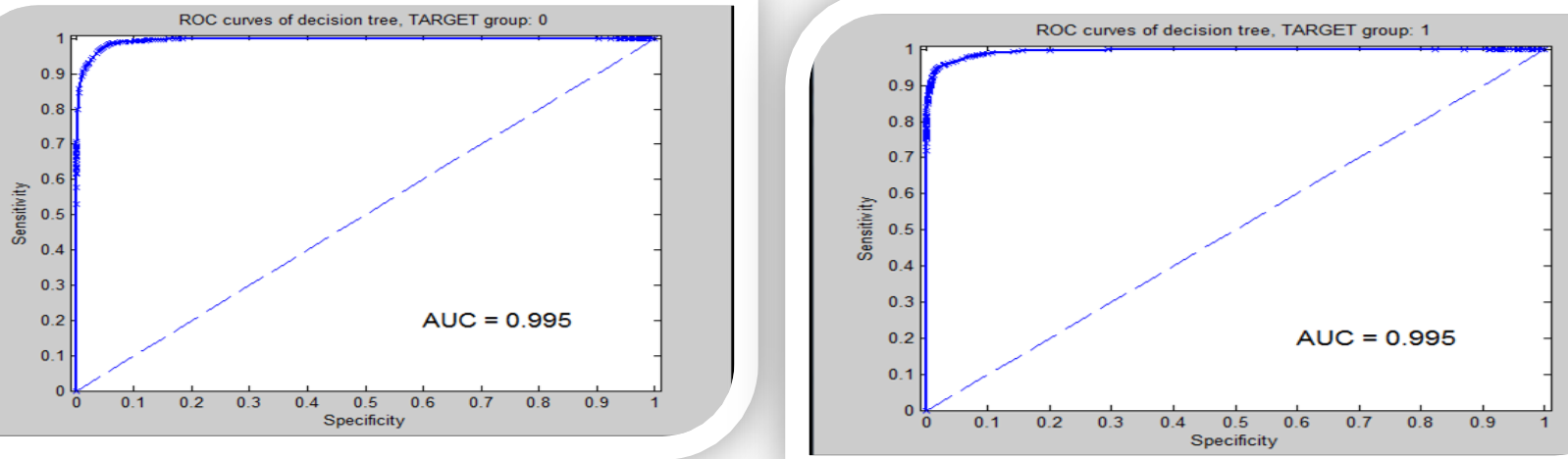

Figure 4.20: Area under Curve for Group 0 \& 1 of case-3 of Well No.1

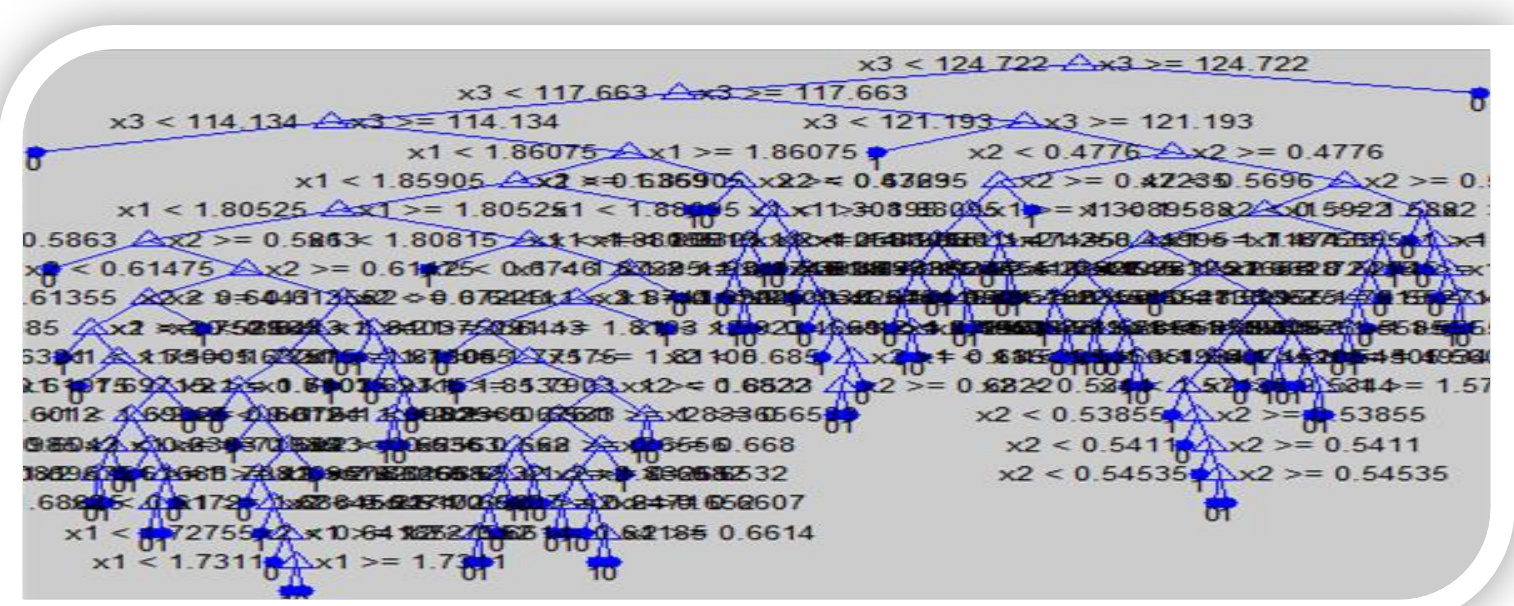

Figure 4.21: Decision Tree Model of case-3 of Well No.1 


\section{- Decision Tree results for Well No.2:}

Table 4.6 shows the similarity between actual and predicted data. From that, we can say that the best fitting was found between ETHK actual and predicted with about $35.5 \%$ similarity and the worst correlation was between RGR predicted and actual.

Table 4.6 Regression Result for Well No.2

\begin{tabular}{lrrrrrrrr}
\hline Well\#2 & \multicolumn{1}{c}{ CID } & \multicolumn{1}{c}{$\boldsymbol{S P}$} & FREQ & ETHK & GR & GTEM & RGR & output \\
\hline CID & 1 & & & & & & & \\
SP & 0.030516 & 1 & & & & & & \\
FREQ & 0.030285 & 0.998985 & 1 & & & & & \\
ETHK & 0.029334 & 0.909797 & 0.912135 & 1 & & & \\
GR & -0.00535 & 0.163048 & 0.169171 & 0.176864 & 1 & & \\
GTEM & -0.00796 & 0.411722 & 0.427331 & 0.423487 & 0.438631 & 1 & \\
RGR & -0.00446 & 0.1444 & 0.149863 & 0.1584 & 0.939518 & 0.399139 & 1 & \\
output & $\mathbf{- 0 . 0 1 0 3 4}$ & $\mathbf{- 0 . 3 5 0 2 9}$ & $\mathbf{- 0 . 3 4 8 1 7}$ & $\mathbf{- 0 . 3 5 4 7 6}$ & $\mathbf{0 . 0 0 3 3 0 1}$ & $\mathbf{0 . 1 6 7 6 7 5}$ & $\mathbf{0 . 0 0 3 0 1 5}$ & $\mathbf{1}$ \\
\hline
\end{tabular}

Since, there is no strong relation was found between input and target which is either leak or no leak through regression, decision tree was used and the result is shown as follow:

For model development, 4,926 samples used in group number- 0 which represents no leak, whereas, a total of 173 samples used in group number-1 and represents leak.

Case 1: Using all input variables

Table 4.7: Data Classification for Well No.2 Case 1

\begin{tabular}{|l|c|}
\hline \multicolumn{1}{|c|}{ Input data summary } & No. \\
\hline No. of Sample & 5099 \\
\hline No. of features & 8 \\
\hline No. of Outcome Classes & 2 \\
\hline No. of Samples in Training set & 3570 \\
\hline No. of Samples in Testing set & 1529 \\
\hline
\end{tabular}

In case-1, a study was conducted to check the efficiency of the developed program for the entire well. The entire data shown in table 4.7 were considered for training and testing. The 
well was trained using random selection with $70 \%$ of the data available followed by testing the remaining $30 \%$ of data on the same well.

\section{$\underline{\text { ROC Curves, Training and Testing Results: }}$}

Figure-4.22 shows that the model is able to detect AUC for both group 0 and 1 with AUC=1. Moreover, figure 4.23 shows model structure and development during the training and testing of case-2. The percentage of correct classification for case 1 in training is $100 \%$ and $99.7 \%$ for testing.
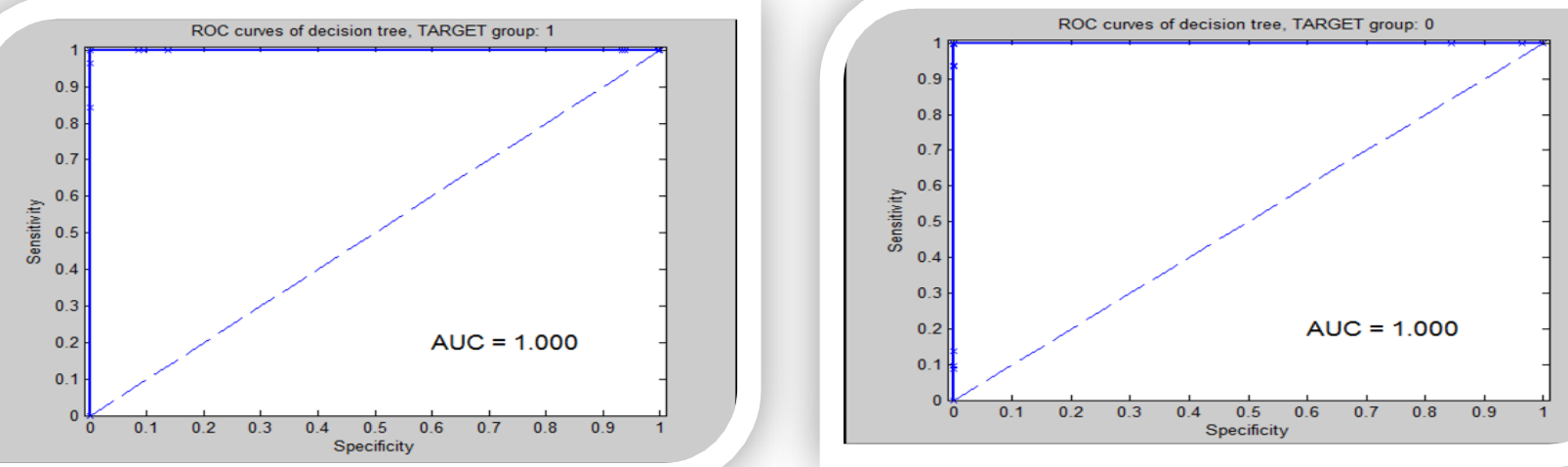

Figure 4.22: Area under Curve for Group $0 \& 1$ of case- 1 of Well No. 2

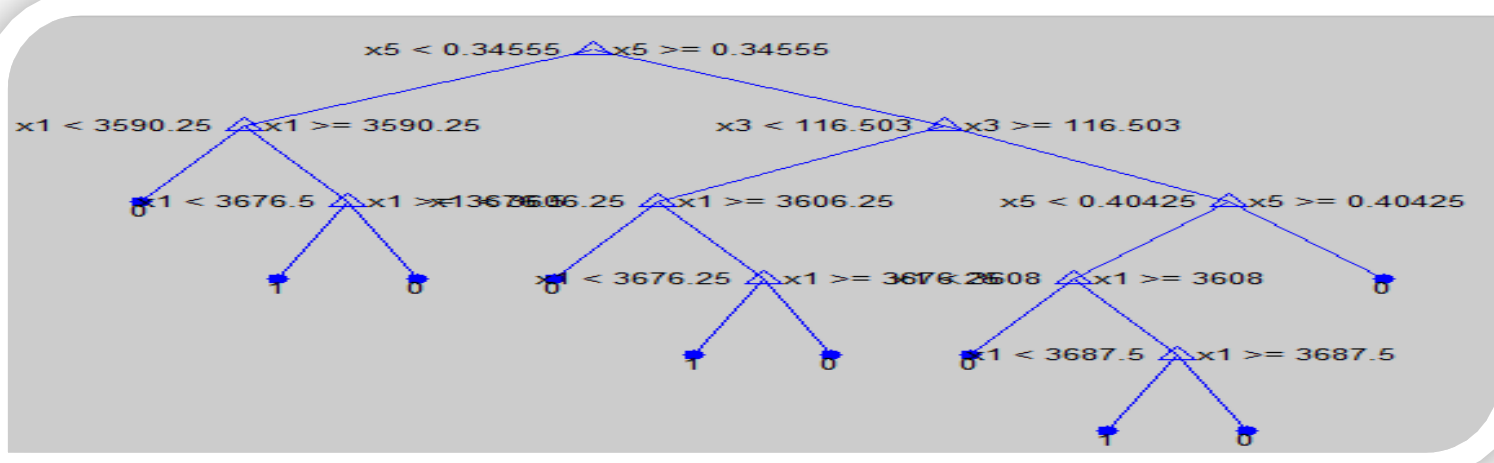

Figure 4.23: Decision Tree Model of case-1 of Well No. 2 
Case 2: using the most reliable data random selection as per program intelligence

Table 4.8: Data Classification for Well No.2 Case 2

\begin{tabular}{|l|c|}
\hline \multicolumn{1}{|c|}{ Input data summary } & No. \\
\hline No. of Sample & 5099 \\
\hline No. of features & 5 \\
\hline No. of Outcome Classes & 2 \\
\hline No. of Samples in Training set & 3570 \\
\hline No. of Samples in Testing set & 1529 \\
\hline
\end{tabular}

In case-2, a study was conducted to check the efficiency of the developed program for the entire well. Out of the 8 sets of data and as per program intelligence, the number of features in this case was selected by program to be five variables as fallow: SP, FREQ, ETHK, GR, and GTEM. Table 4.4 shows that the well was trained using random selection with $70 \%$ of the data available followed by testing the remaining $30 \%$ data on the same well.

\section{$\underline{\text { ROC Curves, Training and Testing Results: }}$}

Figure-4.24 shows that the model is able to detect AUC for both group 0 and 1 with AUC=1. Moreover, figure 4.25 shows model structure and development during the training and testing of case-2. The percentage of correct classification for case 2 in training is $100 \%$ and $99.7 \%$ for testing.
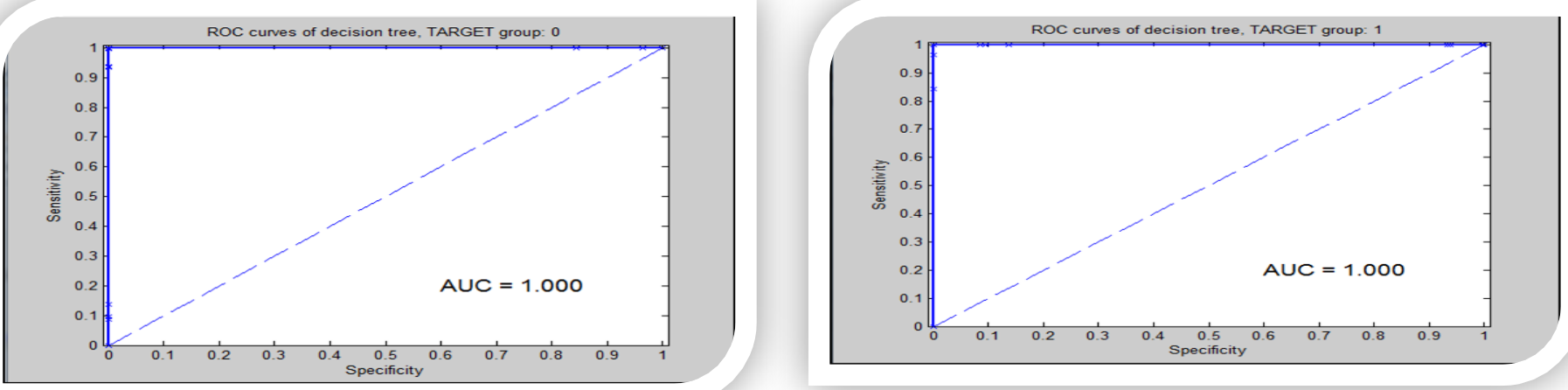

Figure 4.24: Area under Curve for Group $0 \& 1$ of case- 2 of Well No. 2 


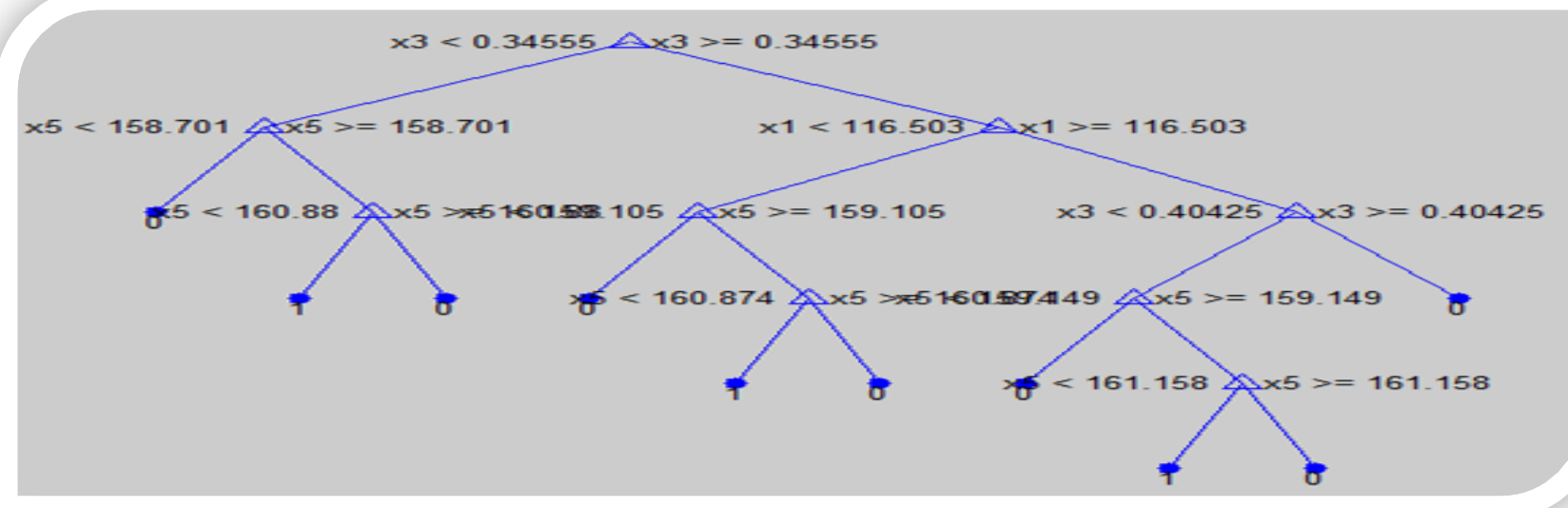

Figure 4.25: Decision Tree Model of case-2 of Well No. 2

Case 3: Using the most reliable data (Frequency, Pipe Thickness, and Temperature)

Table 4.9: Data Classification for Well No.2 Case 3

\begin{tabular}{|l|c|}
\hline \multicolumn{1}{|c|}{ Input data summary } & No. \\
\hline No. of Sample & 5099 \\
\hline No. of features & 3 \\
\hline No. of Outcome Classes & 2 \\
\hline No. of Samples in Training set & 3570 \\
\hline No. of Samples in Testing set & 1529 \\
\hline
\end{tabular}

In case-3, a study was conducted to check the efficiency of the developed program for the entire well. Out of the 8 sets of data and as per rigless approach study, the number of features in this case was selected to be 3 as fallow: FREQ, ETHK, and GTEM. Table 4.8 shows that the well was trained random selection with $70 \%$ of the data available followed by testing the remaining $30 \%$ of data on the same well. 


\section{$\underline{\text { ROC Curves, Training and Testing Results: }}$}

Figure-4.26 shows that the model is able to detect AUC for both group 0 and 1with AUC $=0.9920$ for both group. Moreover, figure 4.27 shows model structure and development during the training and testing of case-3. The percentage of correct classification for this case in training is $100 \%$ and $95.4 \%$ for testing.
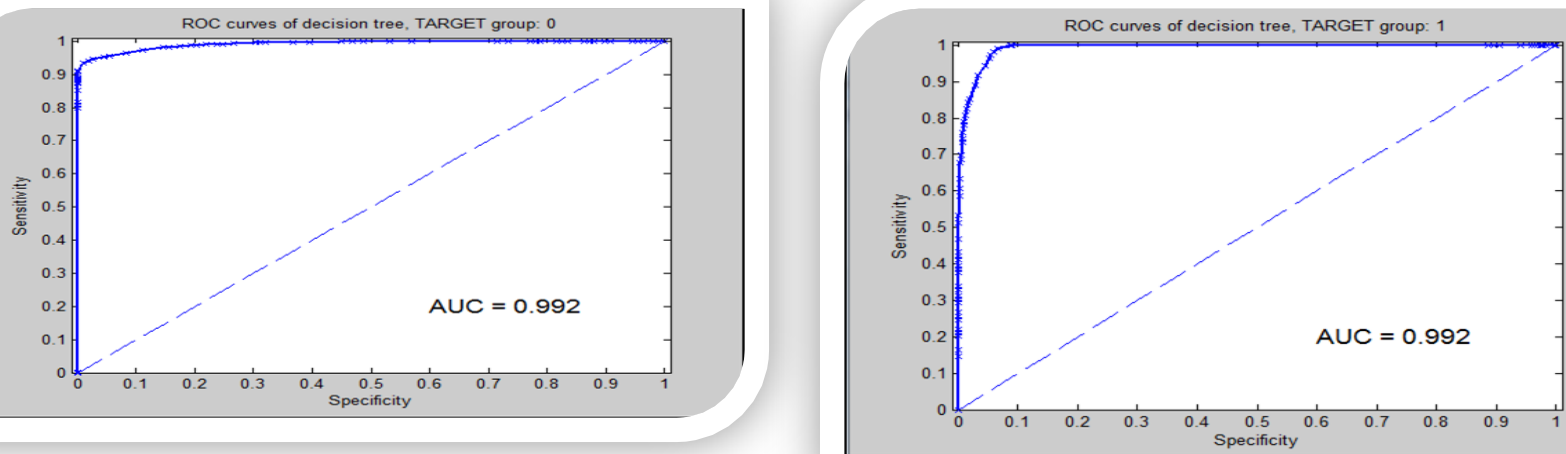

Figure 4.26: Area under Curve for Group 0 \& 1 of case- 3 of Well No. 2

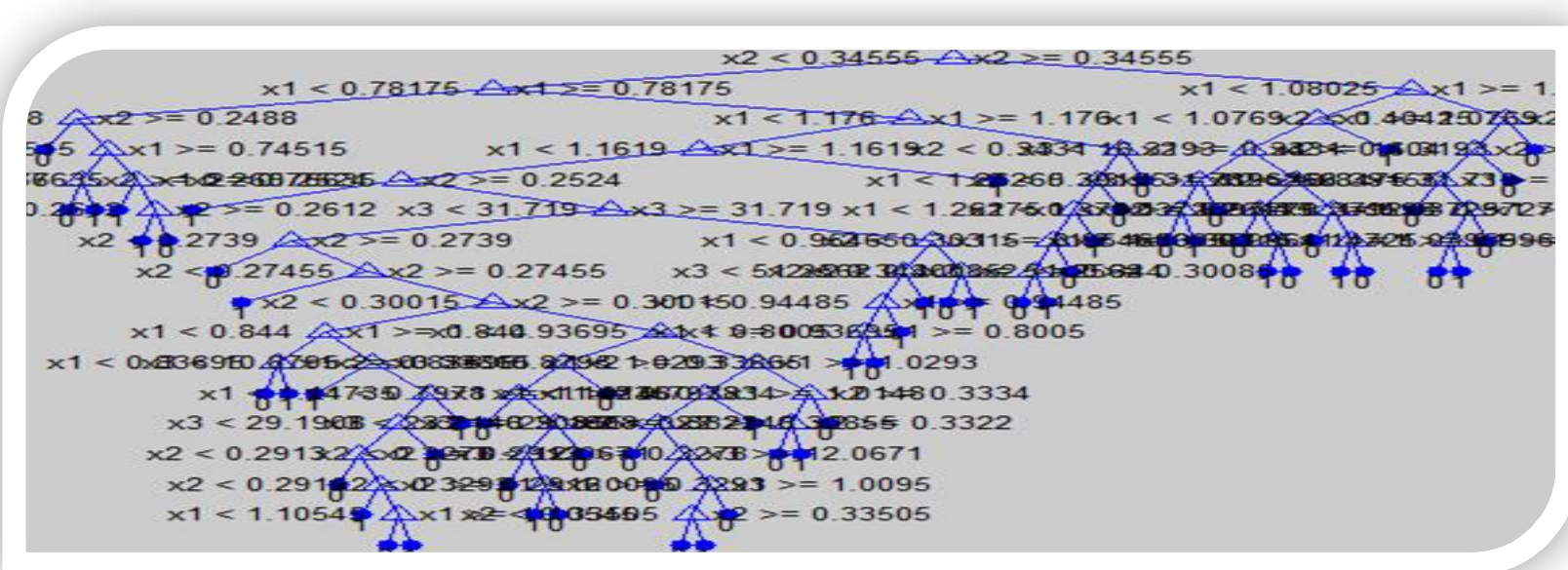

Figure 4.27: Decision Tree Model of case-3 of Well No.2 


\section{- Decision Tree results for Well NO.3:}

Table 4.9 shows the similarity between actual and predicted data through regression. From that, we can say that the best fitting was found between FREQ actual and predicted with about $45 \%$ similarity and the worst correlation was between CID predicted and actual.

Table 4.10: Regression Result for Well No. 3

\begin{tabular}{lrrrrrrrr}
\hline Well\#3 & \multicolumn{1}{c}{ CID } & \multicolumn{1}{c}{$\boldsymbol{S P}$} & FREQ & ETHK & GR & GTEM & RGR & output \\
\hline CID & 1 & & & & & & & \\
SP & 0.056239 & 1 & & & & & & \\
FREQ & 0.056977 & 0.998484 & 1 & & & & & \\
ETHK & 0.049689 & 0.899481 & 0.89849 & 1 & & & & \\
GR & 0.207014 & -0.00451 & 0.003764 & -0.01656 & 1 & & \\
GTEM & 0.724725 & 0.211358 & 0.220517 & 0.221437 & 0.216053 & 1 & \\
RGR & 0.188875 & -0.01225 & -0.005 & -0.02191 & 0.944741 & 0.196848 & 1 & \\
output & $\mathbf{0 . 0 0 4 9 5 9}$ & $\mathbf{- 0 . 3 3 0 7 2}$ & $\mathbf{- 0 . 4 5 8 6 7}$ & $\mathbf{- 0 . 4 2 8 7 8}$ & $\mathbf{0 . 1 4 8 6 2 9}$ & $\mathbf{- 0 . 0 1 1 3 8}$ & $\mathbf{0 . 1 3 4 8 6 3}$ & $\mathbf{1}$ \\
\hline
\end{tabular}

Since, there is no strong relation was found between input and target which is either leak or no leak through regression, decision tree was used and the result is shown as follow:

For model development, 5067 samples used in group number- 0 which represents no leak, whereas, a total of 32 samples used in group number-1 and represents leak.

Case 1: Using all input variables

Table 4.11: Data Classification for Well No. 3 Case 1

\begin{tabular}{|l|c|}
\hline \multicolumn{1}{|c|}{ Input data summary } & No. \\
\hline No. of Sample & 5099 \\
\hline No. of features & 8 \\
\hline No. of Outcome Classes & 2 \\
\hline No. of Samples in Training set & 3570 \\
\hline No. of Samples in Testing set & 1529 \\
\hline
\end{tabular}

In case-1, a study was conducted to check the efficiency of the developed program for the entire well. The data of the entire used well as of table 4.10 were considered for training and 
testing. The well was trained random selection with $70 \%$ of the data available followed by testing the remaining $30 \%$ of data on the same well.

\section{$\underline{\text { ROC Curves, Training and Testing Results: }}$}

Figure-4.28 shows that the model is able to detect AUC for both group 0 and 1with AUC $=0.9773$ for both group. Moreover, figure 4.29 shows model structure and development during the training and testing. The percentage of correct classification for this
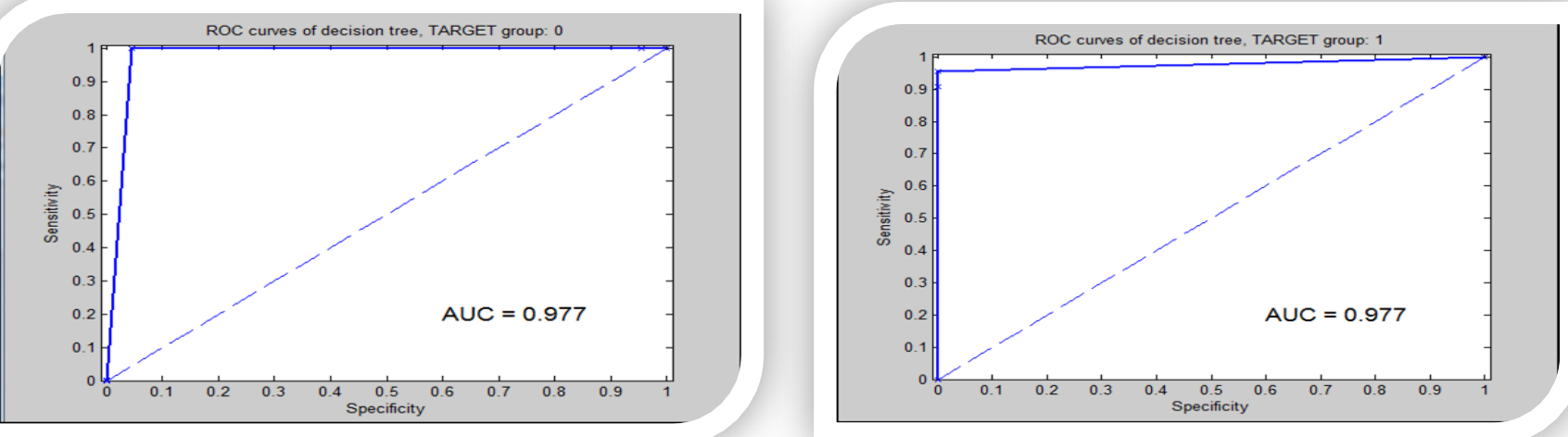

case

in training is $100 \%$ and $99.5 \%$ for testing.

Figure 4.28: Area under Curve for Group $0 \& 1$ of case- 1 of Well No. 3

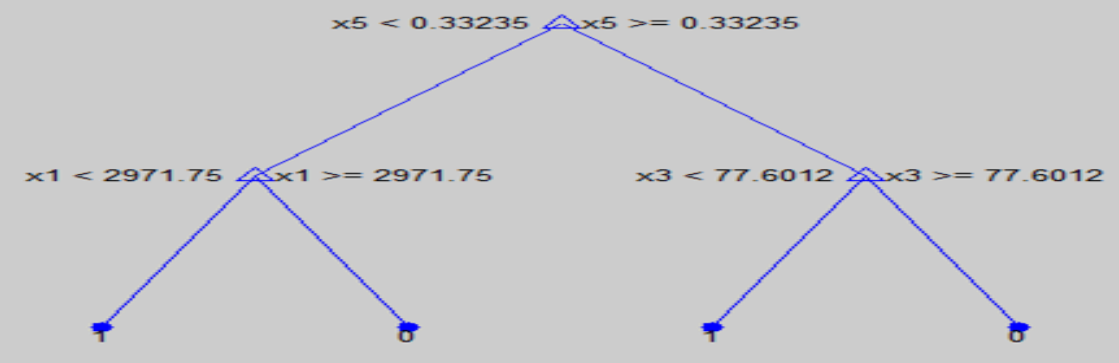

Figure 4.29: Decision Tree Model of case-1 of Well No.3 
Case 2: using the most reliable data random selection as per program intelligence

Table 4.12: Data Classification for Well No. 3 Case 2

\begin{tabular}{|l|c|}
\hline \multicolumn{1}{|c|}{ Input data summary } & No. \\
\hline No. of Sample & 5099 \\
\hline No. of features & 5 \\
\hline No. of Outcome Classes & 2 \\
\hline No. of Samples in Training set & 3570 \\
\hline No. of Samples in Testing set & 1529 \\
\hline
\end{tabular}

In case-2, a study was conducted to check the efficiency of the developed program for an entire well. Out of the 8 set of data and as per program intelligence, the number of features in this case was selected by program to be 5 set of data as fallow: SP, FREQ, ETHK, GR, and GTEM. Table 4.11 showed that the well was trained random selection with $70 \%$ of the data available followed by testing the remaining $30 \%$ of data on the same well.

\section{$\underline{\text { ROC Curves, Training and Testing Results: }}$}

Figure-4.30 shows that the model is able to detect AUC for both group 0 and 1with AUC $=09773$ for both group. Moreover, figure 4.31 shows model structure and development during the training and testing. The percentage of correct classification for this case in training is $100 \%$ and $99.7 \%$ for testing.
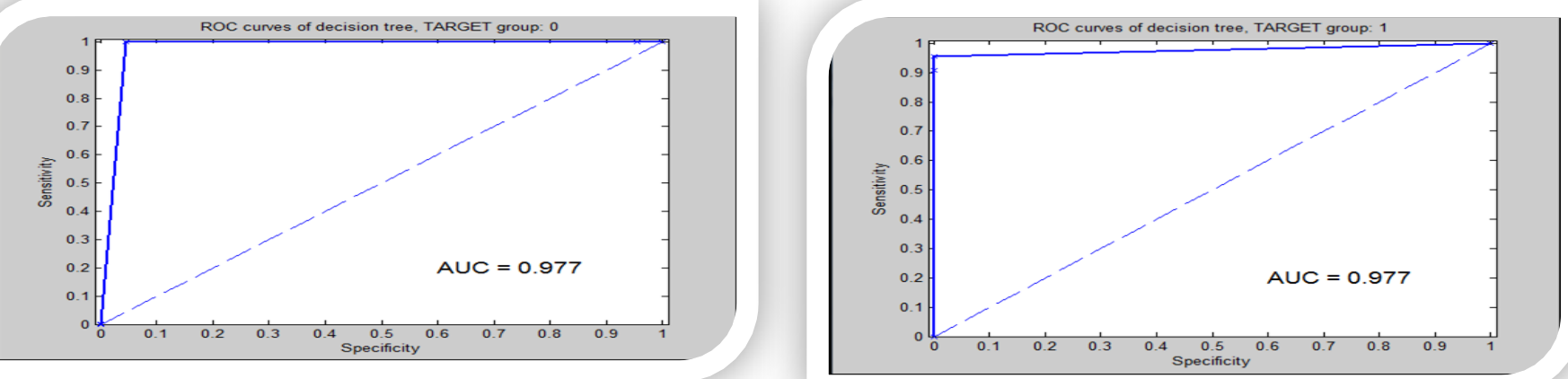

Figure 4.30: Area under Curve for Group $0 \& 1$ of case- 2 of Well No. 3 


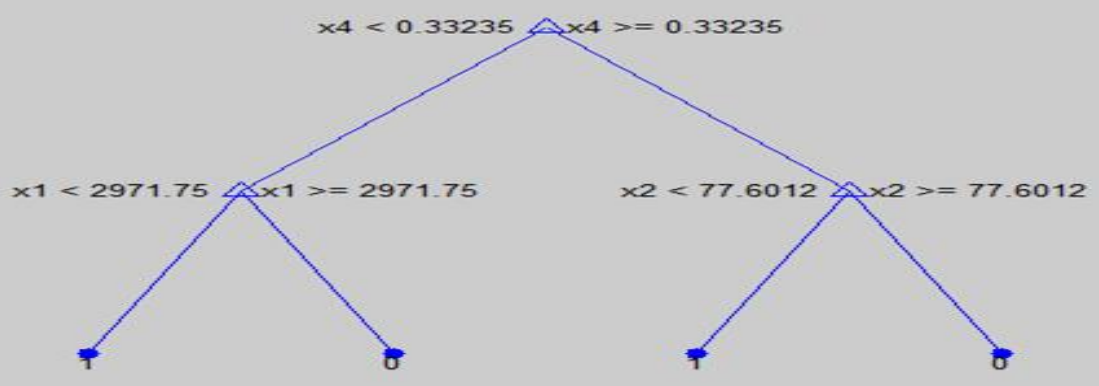

Figure 4.31: Decision Tree Model of case-2 of Well No. 3

Case 3: Using the most reliable data (Frequency, Pipe Thickness, and Temperature)

Table 4.13: Data Classification for Well No. 3 Case 3

\begin{tabular}{|l|c|}
\hline \multicolumn{1}{|c|}{ Input data summary } & No. \\
\hline No. of Sample & 5099 \\
\hline No. of features & 3 \\
\hline No. of Outcome Classes & 2 \\
\hline No. of Samples in Training set & 3570 \\
\hline No. of Samples in Testing set & 1529 \\
\hline
\end{tabular}

In case-3, a study was conducted to check the efficiency of the developed program for the entire well. Out of the 8 sets of data and as per integrated approach study, the number of features in this case was selected to be three as fallow: FREQ, ETHK, and GTEM. Table 4.12 shows that the well was trained using random selection with $70 \%$ of the data available followed by testing the remaining $30 \%$ of data on the same well. 


\section{$\underline{\text { ROC Curves, Training and Testing Results: }}$}

Figure-4.32 show that the model is able to detect AUC for both group 0 and 1with $\mathrm{AUC}=0.9772$ for group 0 and $\mathrm{AUC}=0.9545$ for group 1 . Moreover, figure 4.33 shows model structure and development during the training and testing of this case. The percentage of correct classification for case 3 in training is $100 \%$ and $97.7 \%$ for testing.
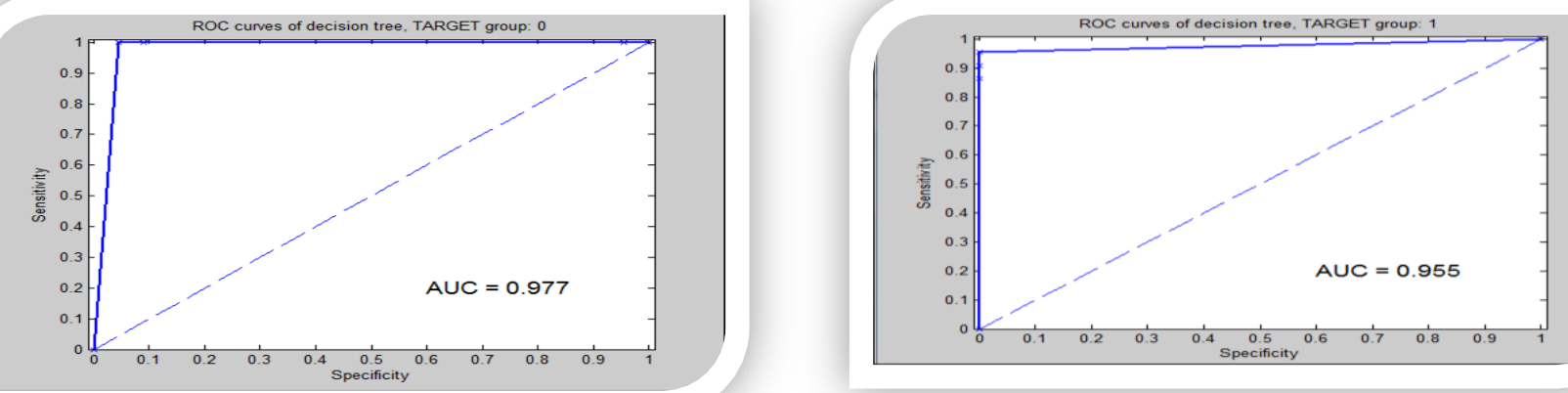

Figure 4.32: Area under Curve for Group 0 \& 1 of case-3 of Well No.3

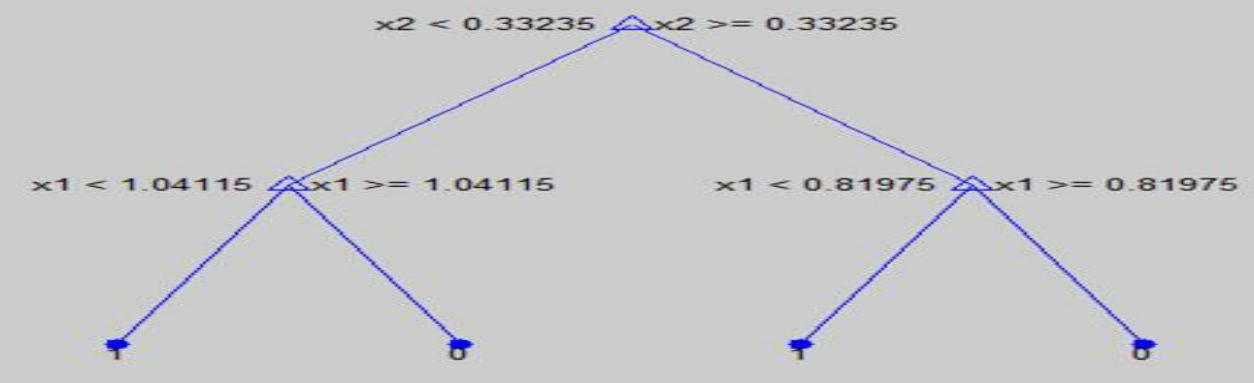

Figure 4.33: Decision Tree Model of case-3 of Well No.3 


\section{Decision Tree results for Well No.4:}

Table 4.13 shows the similarity between actual and predicted data through regression. From that, we noticed that the best fitting was found between FREQ actual and predicted with about $25.5 \%$ similarity and the worst correlation was between RGR predicted and actual.

Table 4.14: Regression Result for Well No. 4

\begin{tabular}{lrrrrrrrr}
\hline Well\#4 & \multicolumn{1}{c}{ CID } & \multicolumn{1}{c}{$\boldsymbol{S P}$} & FREQ & ETHK & GR & GTEM & RGR & output \\
\hline CID & 1 & & & & & & & \\
SP & -0.05289 & 1 & & & & & & \\
FREQ & -0.05702 & 0.998588 & 1 & & & & & \\
ETHK & -0.06569 & 0.916242 & 0.919189 & 1 & & & \\
GR & -0.05308 & 0.094192 & 0.096132 & 0.093273 & 1 & & \\
GTEM & -0.33503 & 0.384127 & 0.393336 & 0.388707 & 0.279662 & 1 & \\
RGR & -0.04803 & 0.079618 & 0.081207 & 0.080155 & 0.955666 & 0.254404 & 1 & \\
output & $\mathbf{- 0 . 1 4 5 0 2}$ & $\mathbf{- 0 . 2 5 2 8 1}$ & $\mathbf{- 0 . 2 5 5 4 8}$ & $\mathbf{- 0 . 2 4 4 3 1}$ & $\mathbf{- 0 . 0 2 6 3 6}$ & $\mathbf{0 . 0 6 1 1 6 2}$ & $\mathbf{- 0 . 0 2 3 8 8}$ & \\
\hline
\end{tabular}

Since, there is no strong relation was found between input and target which is either leak or no leak through regression, decision tree was used and the result us shown below:

For model development, 4956 samples used in group number- 0 which represents no leak, whereas, a total of 143 samples used in group number-1 and represents leak.

Case 1: Using all input variables

Table 4.15: Data Classification for Well No. 4 Case 1

\begin{tabular}{|l|c|}
\hline \multicolumn{1}{|c|}{ Input data summary } & No. \\
\hline No. of Sample & 5099 \\
\hline No. of features & 8 \\
\hline No. of Outcome Classes & 2 \\
\hline No. of Samples in Training set & 3570 \\
\hline No. of Samples in Testing set & 1529 \\
\hline
\end{tabular}


In case-1, a study was conducted to check the efficiency of the developed program for the entire well. The data of the entire used well as of table 4.14 were considered for training and testing. The well was trained random selection with $70 \%$ of the data available followed by testing the remaining $30 \%$ data on the same well.

\section{$\underline{\text { ROC Curves, Training and Testing Results: }}$}

Figure-4.34 shows that the model is able to detect AUC for both group 0 and 1with AUC $=0.9958$ for both group. Moreover, figure 4.35 shows model structure and development during the training and testing of case-1. The percentage of correct classification for this case in training is $100 \%$ and $99.8 \%$ for testing.
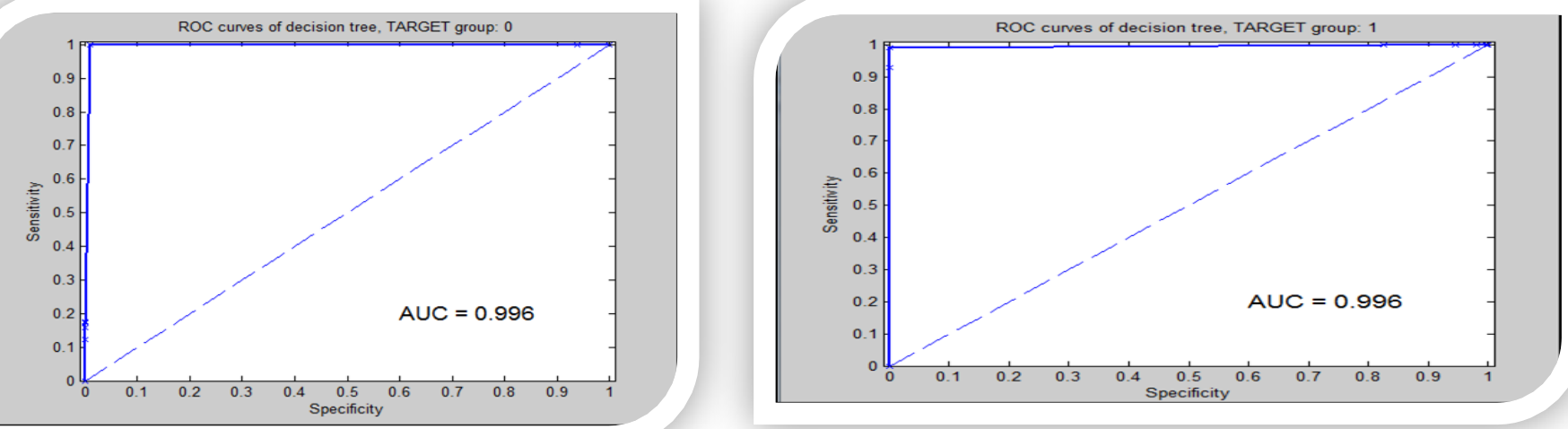

Figure 4.34: Area under Curve for Group 0 \& 1 of case-1 of Well No.4

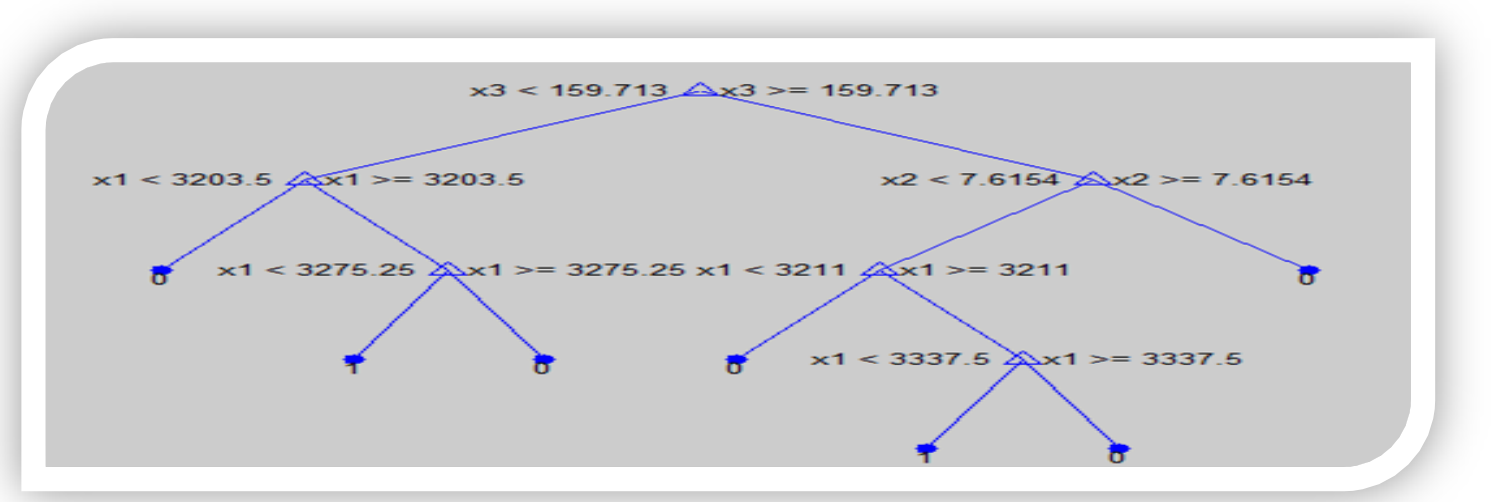

Figure 4.35: Decision Tree Model of case-1 of Well\#4 
Case 2: using the most reliable data random selection as per program intelligence

Table 4.16: Data Classification for Well No. 4 Case 2

\begin{tabular}{|l|c|}
\hline \multicolumn{1}{|c|}{ Input data summary } & No. \\
\hline No. of Sample & 5099 \\
\hline No. of features & 5 \\
\hline No. of Outcome Classes & 2 \\
\hline No. of Samples in Training set & 3570 \\
\hline No. of Samples in Testing set & 1529 \\
\hline
\end{tabular}

In case-2, a study was conducted to check the efficiency of the developed program for the entire well. Out of the 8 sets of data and as per program intelligence, the number of features in this case was selected by program to be five as fallow: CID, FREQ, ETHK, GR, and GTEM. Table 4.15 shows that the well was trained using random selection with $70 \%$ of the data available followed by testing the remaining $30 \%$ of data on the same well.

\section{$\underline{\text { ROC Curves, Training and Testing Results: }}$}

Figure-4.36 shows that the model was able to detect AUC for both group 0 and 1with $\mathrm{AUC}=1$. Moreover, figure 4.37 shows model structure and development during the training and testing of case-2. The percentage of correct classification for case 2 in training is $100 \%$ and $99.7 \%$ for testing.
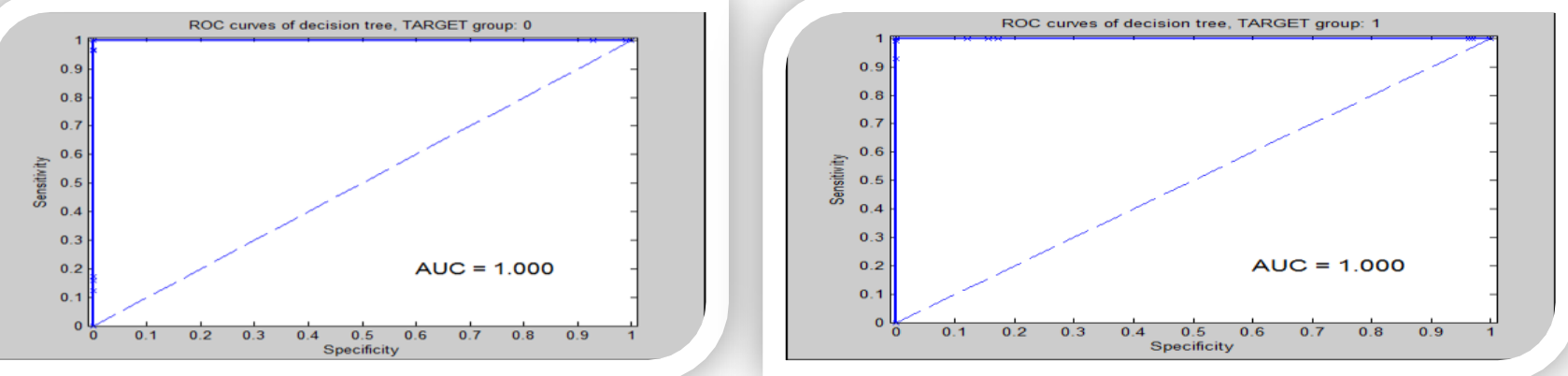

Figure 4.36: Area under Curve for Group 0 \& 1 of case-2 of Well No.4 


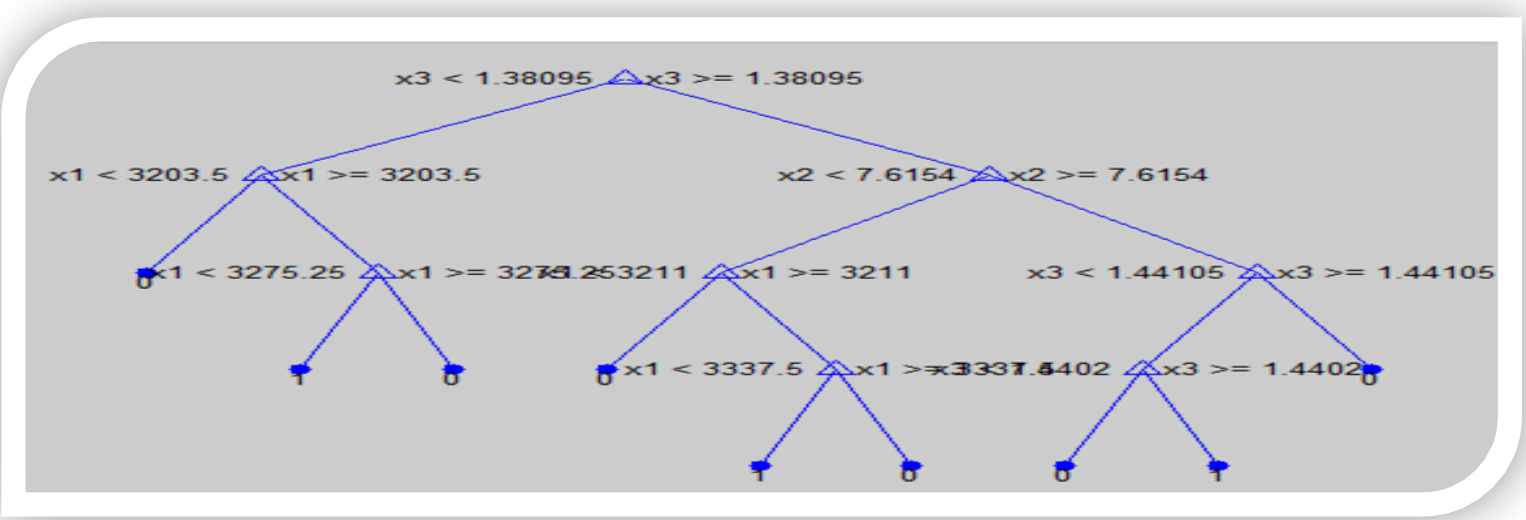

Figure 4.37: Decision Tree Model of case-2 of Well\#4

Case 3: Using the most reliable data (Frequency, Pipe Thickness, and Temperature)

\section{Original Data after Reduction}

Table 4.17: Data Classification for Well No. 4 Case 3

\begin{tabular}{|l|c|}
\hline \multicolumn{1}{|c|}{ Input data summary } & No. \\
\hline No. of Sample & 5099 \\
\hline No. of features & 3 \\
\hline No. of Outcome Classes & 2 \\
\hline No. of Samples in Training set & 3570 \\
\hline No. of Samples in Testing set & 1529 \\
\hline
\end{tabular}

In case-3, a study was conducted to check the efficiency of the developed program for the entire well. Out of the 8 sets of data and as per integrated approach study, the number of features in this case was selected to be three as fallow: FREQ, ETHK, and GTEM. Table 4.16 shows that the well was trained using random selection with $70 \%$ of the data available followed by testing the remaining $30 \%$ of data on the same well. 


\section{ROC Curves, Training and Testing Results:}

Figure-4.38 shows that the model is able to detect AUC for both group 0 and 1with AUC $=0.9949$ for both group. Moreover, figure 4.39 shows model structure and development during the training and testing of case-3. The percentage of correct classification for this case in training is $100 \%$ and $95.7 \%$ for testing.
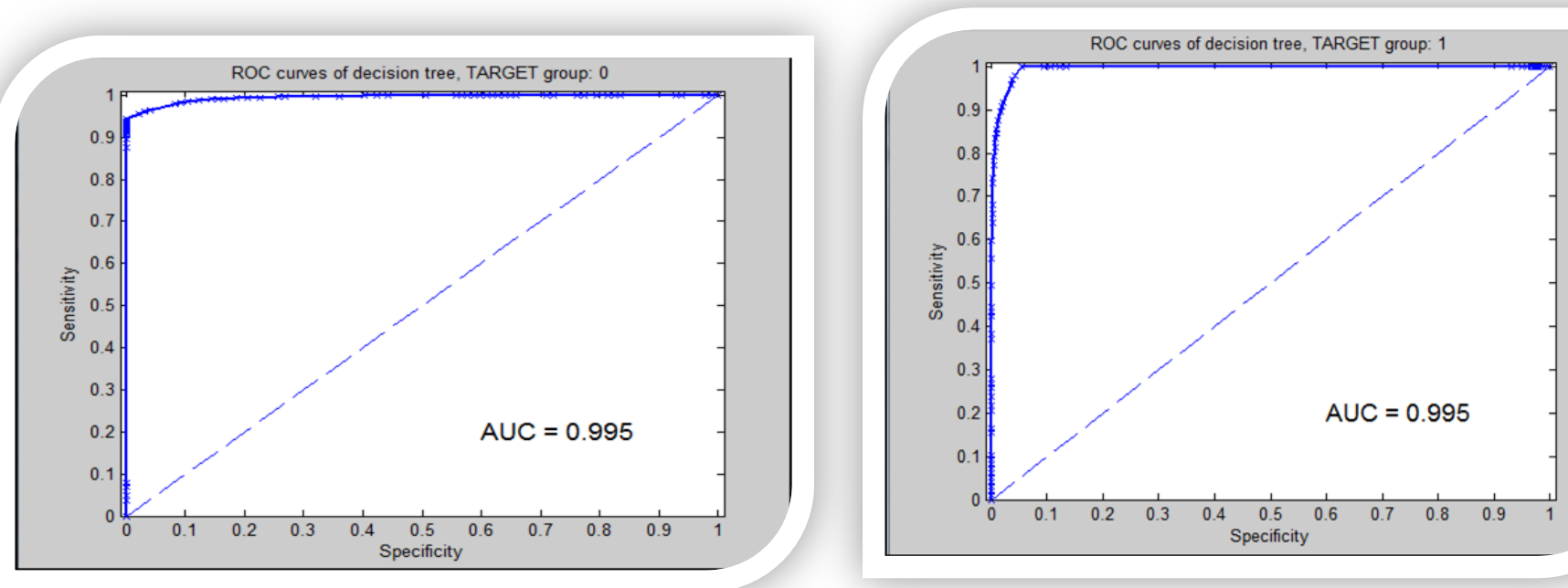

Figure 4.38: Area under Curve for Group 0 \& 1 of case-3 of Well No.4

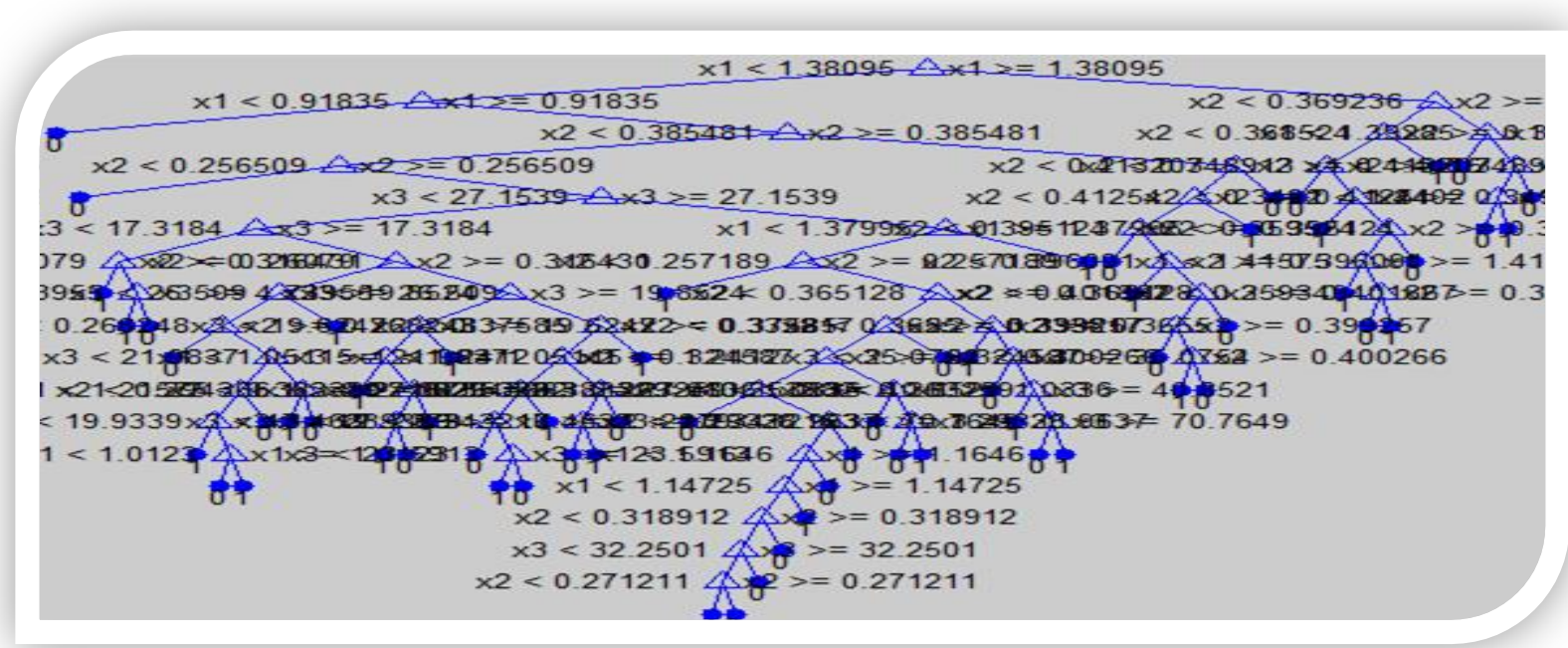

Figure 4.39: Decision Tree Model of case-3 of Well No.4 
- In Summary:

Through utilizing regression, it was noticed that there is no strong relation between input parameters and target, so non-liner model was needed to be build. An artificial intelligence was introduced to look at the tested data since it can deal with complex models. Therefore, Artificial Intelligence was implemented due to simplicity, optimal model and better prediction performance as excellent prediction was obtained.

The following points conclud the classification results:

1. Classification accuracy of using random selection by program intelligence is a little higher than those selected inputs as most reliable input data.

2. There is a match between the results of random selection by program intelligence and all input parameters. However, for well No.4 data set, the random selection by program intelligence produced a little bit litter classification accuracy than all parameters class.

3. As per Occam's Razor Principle: if two different models perform equally, we should use the simpler one that has les number of parameters. So in our case, the model with less number of inputs is lighter, simpler and less complicated than the model that has more parameters. In other word, it is recommended to use the main $\log$ data for leak detection as in case-3 "Temperature, Pipe Thickness and Frequency" since it is less complicated in term of data set number and similar result will be obtained.

Finally, AI approach has been used to develop a model that is able to predict any leak for any well. From the trained and tested data, the model was developed and the obtained result show excellent prediction. 
Table 4.18: Summary of Decision Tree Model within A Well

\begin{tabular}{|c|c|c|c|c|c|c|}
\hline \multirow{2}{*}{ Data sets } & \multirow{2}{*}{ Classification Option } & \multirow{2}{*}{$\begin{array}{l}\text { NO. of } \\
\text { Raw } \\
\text { Inputs }\end{array}$} & \multicolumn{2}{|c|}{$\begin{array}{c}\text { Classification Rate } \\
(\%) \\
\end{array}$} & \multicolumn{2}{|c|}{$\mathbf{A U C}$} \\
\hline & & & $\begin{array}{c}\text { Trainin } \\
\text { g }\end{array}$ & Testing & Group 0 & Group 1 \\
\hline \multirow{3}{*}{$\begin{array}{l}\text { Well } \\
\text { No.1 }\end{array}$} & $\begin{array}{l}\text { Case-A: All Input } \\
\text { Parameters }\end{array}$ & 8 & 100 & 99.9 & 1 & 1 \\
\hline & $\begin{array}{l}\text { Case-B: Random Selection } \\
\text { by program intelligence }\end{array}$ & 5 & 100 & 99.9 & 1 & 1 \\
\hline & $\begin{array}{l}\text { Case-C: Selected Inputs as } \\
\text { most reliable data } \\
\text { (FREQ, ETHK, GTEM) }\end{array}$ & 3 & 100 & 93.3 & 0.995 & 0.995 \\
\hline \multirow{3}{*}{$\begin{array}{l}\text { Well } \\
\text { No.2 }\end{array}$} & $\begin{array}{l}\text { Case-A: All Input } \\
\text { Parameters }\end{array}$ & 8 & 100 & 99.7 & 1 & 1 \\
\hline & $\begin{array}{l}\text { Case-B: Random Selection } \\
\text { by program intelligence }\end{array}$ & 5 & 100 & 99.7 & 1 & 1 \\
\hline & $\begin{array}{l}\text { Case-C: Selected Inputs as } \\
\text { most reliable data } \\
\text { (FREQ, ETHK, GTEM) }\end{array}$ & 3 & 100 & 95.4 & 0.992 & 0.992 \\
\hline \multirow{3}{*}{$\begin{array}{l}\text { Well } \\
\text { No.3 }\end{array}$} & $\begin{array}{l}\text { Case-A: All Input } \\
\text { Parameters }\end{array}$ & 8 & 100 & 99.9 & 0.977 & 0.977 \\
\hline & $\begin{array}{l}\text { Case-B: Random Selection } \\
\text { by program intelligence }\end{array}$ & 5 & 100 & 99.9 & 0.977 & 0.977 \\
\hline & $\begin{array}{l}\text { Case-C: Selected Inputs as } \\
\text { most reliable data } \\
\text { (FREQ, ETHK, GTEM) }\end{array}$ & 3 & 100 & 97.7 & 0.977 & 0.955 \\
\hline \multirow{3}{*}{$\begin{array}{l}\text { Well } \\
\text { No.4 }\end{array}$} & $\begin{array}{l}\text { Case-A: All Input } \\
\text { Parameters }\end{array}$ & 8 & 100 & 99.8 & 0.996 & 0.996 \\
\hline & $\begin{array}{l}\text { Case-B: Random Selection } \\
\text { by program intelligence }\end{array}$ & 5 & 100 & 99.7 & 1 & 1 \\
\hline & $\begin{array}{l}\text { Case-C: Selected Inputs as } \\
\text { most reliable data } \\
\text { (FREQ, ETHK, GTEM) }\end{array}$ & 3 & 100 & 95.7 & 0.995 & 0.995 \\
\hline
\end{tabular}


To further verify the develop model results, decision tree model across wells were successfully completed in the below wells as follow:

Scenario-1: Run all data of Well No.1 to predict the leak in Well No.2

Scenario-2: Run all data of Well No.1 to predict the leak in Well No.3

Scenario-3: Run all data of Well No.1 to predict the leak in Well No.4

Scenario-4: Run all data of Well No.2 to predict the leak in Well No.3

Scenario-5: Run all data of Well No.2 to predict the leak in Well No.4

Scenario-6: Run all data of Well No.3 to predict the leak in Well No.4

The summary of these runs was as fallow:

A. There is a similarity between the obtained results of random selection by program intelligence and all input parameters.

B. Classification accuracy of case-3 is closed to other cases in scenario- 4,5 , and 6 which indicate that the parameters of case- 3 are dependable for leak detection.

C. Case-3 is lighter and less complicated than case-1 and 2. Therefore, it is recommended to use this case for leak detection since it is less complicated in term of data set number and similar or better results could be obtained.

These runs were conducted to confirm the validity of the developed model and the obtained results were shown in table-4.18 in details. 
Table 4.19: Summary of Decision Tree Model across Wells

\begin{tabular}{|c|c|c|c|c|c|c|}
\hline \multirow{2}{*}{$\begin{array}{l}\text { Data sets } \\
\text { Scenario }\end{array}$} & \multirow{2}{*}{ Classification Option } & \multirow{2}{*}{$\begin{array}{l}\text { NO. of } \\
\text { Raw } \\
\text { Inputs }\end{array}$} & \multicolumn{2}{|c|}{$\begin{array}{c}\text { Classification Rate } \\
(\%)\end{array}$} & \multicolumn{2}{|c|}{ AUC } \\
\hline & & & Training & Testing & $\begin{array}{c}\text { Group } \\
\mathbf{0}\end{array}$ & $\begin{array}{c}\text { Group } \\
1\end{array}$ \\
\hline \multirow{3}{*}{$\begin{array}{c}\text { Run all } \\
\text { data of } \\
\text { Well No.1 } \\
\text { to predict } \\
\text { the leak in } \\
\text { Well No.2 }\end{array}$} & $\begin{array}{l}\text { Case-A: All Input } \\
\text { Parameters }\end{array}$ & 8 & 100 & 88.8 & 1 & 1 \\
\hline & $\begin{array}{l}\text { Case-B: Random } \\
\text { Selection by program } \\
\text { intelligence }\end{array}$ & 5 & 100 & 88.8 & 1 & 1 \\
\hline & $\begin{array}{l}\text { Case-C: Selected Inputs } \\
\text { as most reliable data } \\
\text { (FREQ, ETHK, GTEM) }\end{array}$ & 3 & 100 & 84.8 & 0.9738 & 0.9738 \\
\hline \multirow{3}{*}{$\begin{array}{c}\text { Run all } \\
\text { data of } \\
\text { Well No.1 } \\
\text { to predict } \\
\text { the leak in } \\
\text { Well No.3 }\end{array}$} & $\begin{array}{l}\text { Case-A: All Input } \\
\text { Parameters }\end{array}$ & 8 & 100 & 88.6 & 1 & 1 \\
\hline & $\begin{array}{l}\text { Case-B: Random } \\
\text { Selection by program } \\
\text { intelligence }\end{array}$ & 5 & 100 & 88.6 & 1 & 1 \\
\hline & $\begin{array}{l}\text { Case-C: Selected Inputs } \\
\text { as most reliable data } \\
\text { (FREQ, ETHK, GTEM) }\end{array}$ & 3 & 100 & 77.2 & 0.9738 & 0.9738 \\
\hline \multirow{3}{*}{$\begin{array}{c}\text { Run all } \\
\text { data of } \\
\text { Well No.1 } \\
\text { to predict } \\
\text { the leak in } \\
\text { Well No.4 }\end{array}$} & $\begin{array}{l}\text { Case-A: All Input } \\
\text { Parameters }\end{array}$ & 8 & 100 & 96.4 & 1 & 1 \\
\hline & $\begin{array}{l}\text { Case-B: Random } \\
\text { Selection by program } \\
\text { intelligence }\end{array}$ & 5 & 100 & 96.4 & 1 & 1 \\
\hline & $\begin{array}{l}\text { Case-C: Selected Inputs } \\
\text { as most reliable data } \\
\text { (FREQ, ETHK, GTEM) }\end{array}$ & 3 & 100 & 89.5 & 0.9738 & 0.9738 \\
\hline \multirow{3}{*}{$\begin{array}{c}\text { Run all } \\
\text { data of } \\
\text { Well No.2 } \\
\text { to predict } \\
\text { the leak in } \\
\text { Well No.3 }\end{array}$} & $\begin{array}{l}\text { Case-A: All Input } \\
\text { Parameters }\end{array}$ & 8 & 100 & 99.2 & 1 & 1 \\
\hline & $\begin{array}{l}\text { Case-B: Random } \\
\text { Selection by program } \\
\text { intelligence }\end{array}$ & 5 & 100 & 99.2 & 1 & 1 \\
\hline & $\begin{array}{l}\text { Case-C: Selected Inputs } \\
\text { as most reliable data } \\
\text { (FREQ, ETHK, GTEM) }\end{array}$ & 3 & 100 & 99 & 0.9917 & 0.9917 \\
\hline $\begin{array}{l}\text { Run all } \\
\text { data of }\end{array}$ & $\begin{array}{l}\text { Case-A: All Input } \\
\text { Parameters }\end{array}$ & 8 & 100 & 96.4 & 1 & 1 \\
\hline
\end{tabular}




\begin{tabular}{|c|c|c|c|c|c|c|}
\hline \multirow{2}{*}{$\begin{array}{l}\text { Well No.2 } \\
\text { to predict } \\
\text { the leak in } \\
\text { Well No.4 }\end{array}$} & $\begin{array}{l}\text { Case-B: Random } \\
\text { Selection by program } \\
\text { intelligence }\end{array}$ & 5 & 100 & 96.4 & 1 & 1 \\
\hline & $\begin{array}{l}\text { Case-C: Selected Inputs } \\
\text { as most reliable data } \\
\text { (FREQ, ETHK, GTEM) }\end{array}$ & 3 & 100 & 96.2 & 0.9897 & 0.9897 \\
\hline \multirow{3}{*}{$\begin{array}{c}\text { Run all } \\
\text { data of } \\
\text { Well No.3 } \\
\text { to predict } \\
\text { the leak in } \\
\text { Well No.4 }\end{array}$} & $\begin{array}{l}\text { Case-A: All Input } \\
\text { Parameters }\end{array}$ & 8 & 100 & 84.2 & 0.9844 & 0.9844 \\
\hline & $\begin{array}{l}\text { Case-B: Random } \\
\text { Selection by program } \\
\text { intelligence }\end{array}$ & 5 & 100 & 84.2 & 0.9844 & 0.9844 \\
\hline & $\begin{array}{l}\text { Case-C: Selected Inputs } \\
\text { as most reliable data } \\
\text { (FREQ, ETHK, GTEM) }\end{array}$ & 3 & 100 & 91 & 0.9843 & 0.9843 \\
\hline
\end{tabular}

In conclusion, the developed model confirms that temperature, pipe thickness, and frequency are the most reliable parameters for leak detection. Also, this model simplifies the process of identifying any downhole leakage in any well. Therefore, this integrated technique will shorten the existing gap in this subject of downhole leak detection. 


\section{CHAPTER 5}

\section{CONCLUSION AND RECOMMENDATION}

This chapter summarizes the successfully completed work in this report. This was achieved through evaluating the downhole integrity of Well-A by analyzing and evaluating different types of log in both flowing and shut-in conditions. Also, a comparison between rigless and rig approaches were accomplished to evaluate the obtained both results. Finally, artificial intelligence was successfully implemented and a model for the purpose of identifying any downhole completion leak was developed. The developed model can be used to simplify the process of identifying downhole leakage source during the life cycle of any well in future. The results of this work will enhance the current practice of identifying any minor downhole leak since the developed model is able to resolve many downhole integrity issues.

\subsection{Conclusion}

Based on the conducted temperature, noise, and corrosion surveys, the integrated approach identified the leakage zones through the developed model in this report. The obtained results from the rigless approach were identical to the rig approach. The only difference between both approaches is that the developed model is more accuracy compared to rig approach since it can identify any corrosion or leak areas while the rig approach will identify only leak zones. The results of both approaches confirmed packer and tubing problems. Moreover, an expandable liner was set from 1200 to $2800 \mathrm{ft}$ across weak zones to avoid any future leakage in this interval. Also, artificial intelligence was implemented and a model was developed by running twelve sensitivity cases for around 5000 set of data. The results of the developed model were excellent which shows $93 \%$ accuracy. This work 
would add a value to the current well integrity standard which is of high value to oil companies in term of security and safety to the environment.

\subsection{Recommendation}

The following recommendations were made for future researches toward further applications in this area of well integrity:

- Based on the conducted $\operatorname{logs}$ at shut-in and two flowing scenarios which are after bleeding off TCA and CCA, it is recommended to conduct temperature, noise, and corrosion survey to identify any future downhole leak. Also, more research in this area of petroleum engineering would be recommended in order to enhance the current existing techniques and tools for leak detection.

- The developed model is capable to identify any downhole leakage. This model simplifies the complication of this process. However, further research in well integrity subject is recommended which could lead to produce more effective applications that can detect any downhole leakage in a real time. 


\section{References}

1. W Renpu, “Advanced Well Completion Engineering” Third Edition, July 2011.

2. Youngest Chandra, Konark Ogra. "Evaluation of Production Technologies \& Capabilities," paper SPE 153396 presented at Oil \& Gas Conference \&Exhibition, India. March 2012.

3. Backer, A. C., and Price, M. "Modeling the Performance of High-Pressure HighTemperature Wells," paper SPE 20903 presented at Europec 90, The Hague, Netherlands. October 1990.

4. Dale, C. R.; "Bottom Hole Flow Surveys for Determination of Fluid and Gas Movements in Wells," Trans. AIME 186 (1949), 205-210.

5. Kuchuk, F.J., Zhan, L., Ma, S.M., Al-Shahri, A.M., Ramakrishnan, T.S., Altundas, B., et al.: "Determination of In-Situ Two-Phase Flow Properties through Downhole Fluid Movement Monitoring," SPE paper 116068,presented at the SPE Annual Technical Conference and Exhibition, Denver, Colorado, September 21-24, 2008.

6. Carnahan, B.D., al.: "Fiber Optic Temperature Monitoring Technology," paper SPE54599 presented at 1999 Western Regional Meeting," Alaska, 26-27 May.

7. Julian, King, Cismoski, Younger, Brown, Richards, Meyer, Sierra. "Downhole Leak Determination Using Fiber Optic Distributed Temperature Surveys at Prudhoe Bay, Alaska" SPE107070, California Nov 2007.

8. Zhan, L., Kuchuk, F.J., Al-Shahri, A.S., Ma, S.M., Ramakrishna, T.S., Altundas, B., et al.: "Characterization of Reservoir Heterogeneity through Fluid Movement Monitoring with Deep Electromagnetic and Pressure Measurements," SPE Reservoir Evaluation \& Engineering, Vol. 13, No. 3, June 2010, pp. 509-522.

9. Novak, T. J.: "The Estimation of Water Injection Profiles from Temperature Surveys," J. Pet. Tech. (August, 1953) 203-212.

10. Barrett, Abbasy, Santos, Bedrikovetsky. "Determining Gas Flow Rate \& Formation Thermal Conductivity from Pressure \& Temperature Profile in Vertical Well” SPE paper 152034 presented at EAGE Annual Conference \& Exhibition, Denmark, June 2012.

11. Skinner N.G., Maida, J.L., Jr.: "Downhole Fiber Optic Sensing: The Oilfield services Provider's Perspective," Proceedings of SPE, 2004.

12. Cooke, C. E., Jr.: "Radial Differential Temperature (RDT) Logging - A New Tool for Detecting and Treating Flow Behind Casing," J. Pet. Tech (June 1979), 676-682.

13. Maslennikova, Bochkarev, Savinkov. "Spectral Noise Log Data Processing Technologies." paper SPE 162081 presented at Russian Oil \& Gas Exploration \& Production Conference \& Exhibition. October 2012. 
14. Yoshioka, "Detection of Water or Gas Entry into Horizontal wells by using PDHMS", Texas A\&M University, 2007.

15. Ochi I. Achinivu, Zhuoyi LI, D. Zhu and A.D. Hill, "An Interpolation Method of Downhole Temperature and Pressure Data for Profiles in Gas Wells" Russian Oil \& Gas Technical Conference and Exhibition, SPE 116292, 2008.

16. Yogesh Chandra, Konark Ogra, Vibhor Verma, Arun Pandey, "Evaluation of Production Logging Technologies and Capabilities: In Quest to Know the Unknown, A Brown Field Case Study, Mumbai High, ONGC Western Offshore" Indian Oil \& Gas Conference and Exhibition, SPE 153396, 2012.

17. Julian, King, Johns, Sack, Robertson; "Detection Ultra-small Leaks with Ultrasonic Leak Detection-Case Histories from the North Slope, Alaska" paper SPE108906 presented at 2007 International Oil Conference and Exhibition, 27-30 Jun 2007. Mexico.

18. S.A Syed Mohd Sharil, M. Ariff Shazwan, O. Mohd Zulkifi, C. Nussbaum, "Strategic Rigless Approach in Identifying and Curing Complex and Multiple Completion Leaks In Malaysia" CT \& Well Intervention Conference, SPE 163938, February 2013.

19. McKinely R. "Temperature Radioactively Tracer, and Noise Logging for well Integrity”, Robert S. Environmental Research Laboratory, Oklahoma.

20. Baker Hughes, "Introduction to Wireline Log Analysis" Advancing reservoir Performance Textbook.

21. Salim Ghalem, Elyes Draoui, Aymen Mohamed, Osama Keshta, Amr Mohamed Serry, "Innovation Noise and High-Precision Temperature Logging Tool for Diagnosing Complex Well Problems" Abu Dhabi International Petroleum Exhibition and Conference, SPE $161712,2012$.

22. Zaki Bassiouni, "Theory, Measurement, and Interpretation of Well Log” SPE Textbook Series vol.4.

23. AlGhasham, Catte, AlHaji, "Integrated Analysis of Downhole Corrosion Logs to investigate Casing Leaks" Middle East Oil \& Gas Show and Conference in Bahrain, SPE 93184, 2005

24. Sanjay K Singh, Herry Subekti, Mona AlAsmakh, Layth AlSamarrale "An Integrated Approach to well Integrity Evaluation Via Reliability Assessment of Well Integrity Tools and Methods: Results from Dukhan Field, Qatar" International Production and Operation Conference and Exhibition in Qatar, SPE 156052, 2012.

25. Evinger, H. H. and Muskat, M.: "Calculation of Theoretical Productivity Factor", Trans., AIME, 1942, 146, 126-139. 
26. S. D. Joshi: "Horizontal Well technology", Tulsa, Oklahoma; pennWell Publishing Company 1991.

27. McKinley, R. M., Bower, F. M., and Rumble, R. C.: "The Structure and Interpretation of Noise from Flow Behind Cemented Casing," J. Pet. Tech. (March, 1973), 329-338.

28. Bourgoyne, Jr., A.T., Chenevert, M.E., Millhelm, K.K., and Young, Jr., F.S.: “Applied Drilling Engineering," SPE Textbook Series, Vol. 2, Society of Petroleum Engineers, pp. 85-112, Richardson, Texas, 1986.

29. Howard B. Bradley, "Petroleum Engineering Handbook" SPE Third Edition, Richardson, TX, U.S.A.

30. Talabani, S., Chukwu, G.A., and Hatzignatiou, D.G.: "Gas Channeling and MicroFractures in Cemented Annulus," SPE 26068 presented at 1993 Western Regional Meeting, Anchorage,

Alaska, 26-28 May.

31. Lockyear, C.F., Ryan, D.F., and Gunningham, M.M.: "Cement Channeling: How to Predict and Prevent,” SPE Drilling Engineering, SPE 19865, presented in September 1990.

32. Carpenter, R.B., Brady, J.L., and Blount, C.G.: "The Effects of Temperature and Cement

Admixes on Bond Strength," SPE 22063 presented at the 1991 International Arctic

Technology Conference, Alaska.

33. Sutton, D.L., and Ravi, K.M.: "New Method for Determining Downhole Properties that Affect Gas Migration and Annular Sealing," paper 19520 presented at 1989 SPE Annual Technical Conference and Exhibition, San Antonio, Texas, 8-11 October.

34. Bourgoyne, Jr., A.T., Chenevert, M.E., Millhelm, K.K., and Young, Jr., F.S.: “Applied Drilling Engineering," SPE Textbook Series, Vol. 2, Society of Petroleum Engineers, pp. 85-112, Richardson, Texas, 1986.

35. Russel, S. and Norvig, P., Artificial Intelligence: A Modern Approach. 1995: Prenticehall.

36. Onur, M. and Kuchuk, F.J.: "Nonlinear Regression Analysis of Well Test Pressure Data with Uncertain Variance," SPE paper 62918, presented at the SPE Annual Technical Conference and Exhibition, Dallas, Texas, October 1-4, 2000.

37. Salzberg, S., Chandar, R., Ford, H., Murthy, S. K., and White, R. "Decision trees for automated identification of cosmic-ray hits in Hubble Space Telescope images". Publ. Astron. Soc. Pacific107:279-288, 1995.

38. Kearns, M. and Mansour, Y. "On the boosting ability of top-down decision tree learning algorithms", 28 ACM Symposium, Theory of Computing, 1996. 
39. Fatai, and Safiriyu Eludiora, "Application of Artificial Intelligence in Network Intrusion Detection: A Succinct Review" World Applied Programming Journal, Vol. 2, Issue 3, pp. 9, March 2012.

40. Almuallim, H. "Efficient Algorithm for Optimal Pruning of Decision Trees". Artificial Intelligence: 83:347 362, 1996.

41. S.K. Murthy, "Automatic Construction of Decision Tree from Data: A Multidisciplinary Survey”, data Mining and Knowledge Discovery, 1998. 


\section{VITAE}

Name: Al-Hussain, Ali Musa T.

Nationality: Saudi Arabia

Email: alimusa0o@hotmail.com

Address: Dhahran, Eastern Province, Saudi Arabia

P.O. Box 9876, Dhahran, 31311, Saudi Arabia

\section{Education:}

- King Fahd University of Petroleum and Minerals, Master Degree in Petroleum Engineering, December 2014.

- King Fahd University of Petroleum and Minerals, Bachelor Degree in Petroleum Engineering, February 2009.

\section{Professional Certification:}

- $\quad$ SPE Certification of Petroleum Engineering, Feb 2014.

\section{Work Experiences:}

- Have worked in oil industry since March 2009 as Petroleum Engineer in different oil areas:

- Production Engineering \& Well Services from March 2009 to Jan 2011 and from Feb 2013 up to now as a production engineer.

- $\quad$ Offshore Drilling from Feb.2012 up to Jan 2013 as a drilling engineer.

- $\quad$ Reservoir Management from Feb. 2011 to Jan 2012 as a reservoir management engineer. 